Prepared in cooperation with the Operational Science Advisory Team (OSAT3) Steering Committee chartered by the Deepwater Horizon Federal On-Scene Coordinator (FOSC)

\title{
Application of a Hydrodynamic and Sediment Transport Model for Guidance of Response Efforts Related to the Deepwater Horizon Oil Spill in the Northern Gulf of Mexico Along the Coast of Alabama and Florida
}

Open-File Report 2012-1234 



\section{Application of a Hydrodynamic and Sediment Transport Model for Guidance of Response Efforts Related to the Deepwater Horizon Oil Spill in the Northern Gulf of Mexico Along the Coast of Alabama and Florida}

By Nathaniel G. Plant, Joseph W. Long, P. Soupy Dalyander, David M. Thompson, and Ellen A. Raabe

Open-File Report 2012-1234 


\title{
U.S. Department of the Interior SALLY JEWELL, Secretary
}

\section{U.S. Geological Survey Suzette M. Kimball, Acting Director}

\author{
U.S. Geological Survey, Reston, Virginia: 2013
}

For more information on the USGS - the Federal source for science about the Earth, its natural and living resources, natural hazards, and the environment, visit http://www.usgs.gov or call 1-888-ASK-USGS.

For an overview of USGS information products, including maps, imagery, and publications, visit http://www.usgs.gov/pubprod

To order this and other USGS information products, visit http://store.usgs.gov

Any use of trade, firm, or product names is for descriptive purposes only and does not imply endorsement by the U.S. Government.

Although this information product, for the most part, is in the public domain, it also may contain copyrighted materials as noted in the text. Permission to reproduce copyrighted items must be secured from the copyright owner.

Suggested citation:

Plant, N.G, Long, J.W., Dalyander, P.S., Thompson, D.M., and Raabe, E.A., 2013, Application of a hydrodynamic and sediment transport model for guidance of response efforts related to the Deepwater Horizon oil spill in the northern Gulf of Mexico along the coast of Alabama and Florida: U.S. Geological Survey Open-File Report 2012-1234, 48 p., http://pubs.usgs.gov/of/2012/1234/. 


\section{Contents}

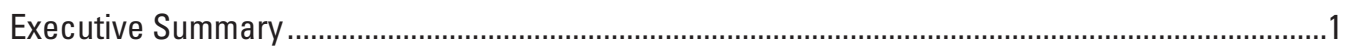

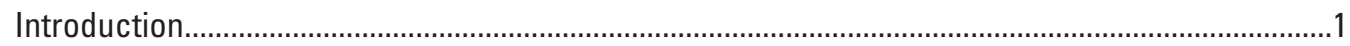

Overall OSAT3 objectives .......................................................................................................

Objectives of USGS Hydrodynamic and Sediment Transport Modeling..................................2

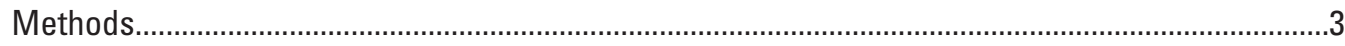

Modeling Approach ...........................................................................................................

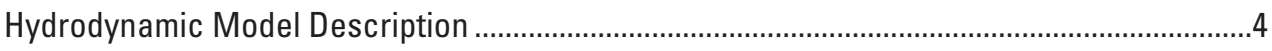

Hydrodynamic Model Input Data ...................................................................................

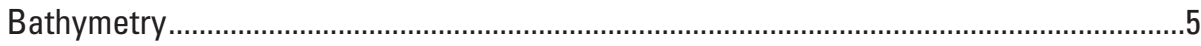

Waves 6

Winds 6

Tides and Surge

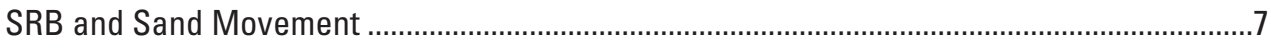

Physical Properties of Sand and SRBs ...................................................................

Physical Processes of Sand and SRB Mobility ..............................................................

Sand and SRB Representative Class Definition ...........................................................8

Inlet Dynamics and Sediment Mobility .........................................................................

Metrics for Evaluating Sand and SRB Mobility and Redistribution Patterns .........................10

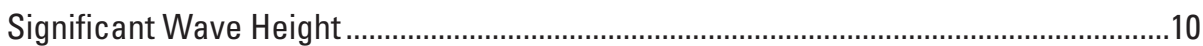

Maximum and Median Alongshore Current.................................................................10

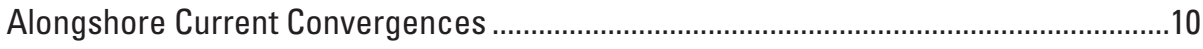

Alongshore Current Decelerations ...........................................................................11

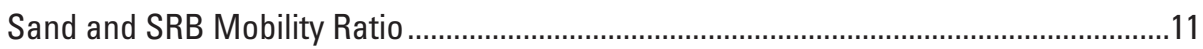

SRB Surf-Zone Integrated Alongshore Potential Flux...................................................12

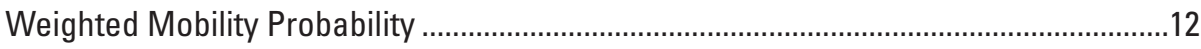

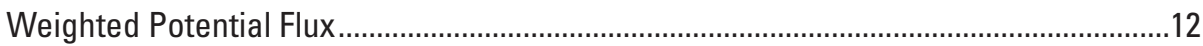

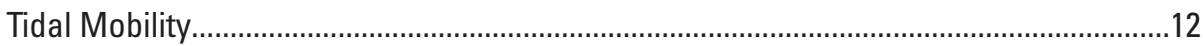

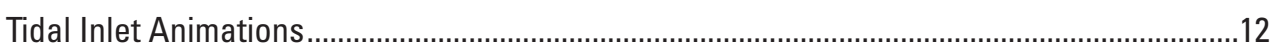

Results 13

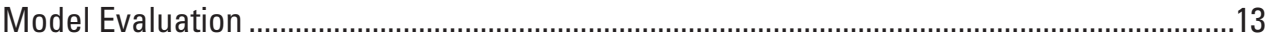

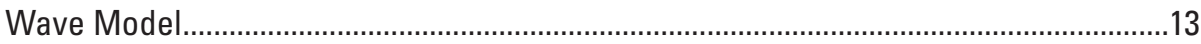

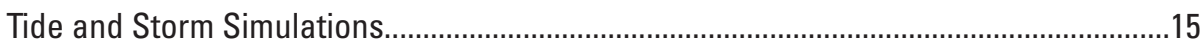

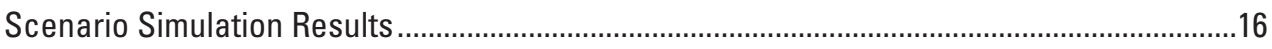

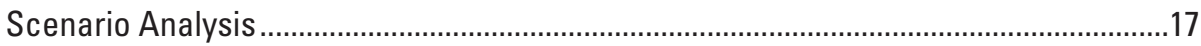

SRB and Sand Weighted Mobility Probability and Potential Flux...................................21

Tidal-Inlet Time-Series Results.....................................................................................

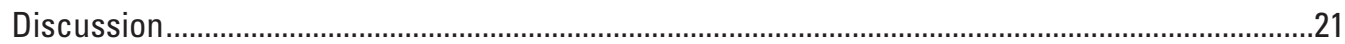

Implications of Results for Understanding SRB Formation, Burial, Exhumation, and

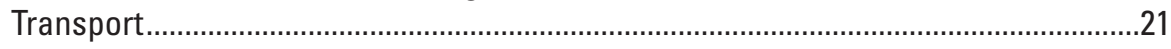

Alongshore-Currents and Gradients in Transport.......................................................24

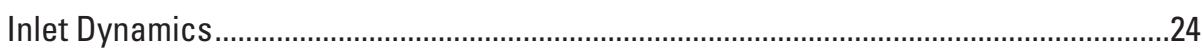

Complexity of Coupled SRB and Sand Dynamics .......................................................25 


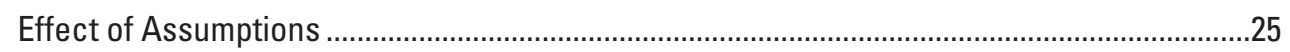

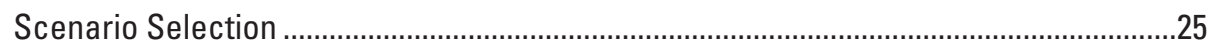

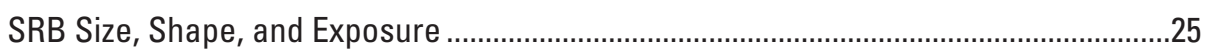

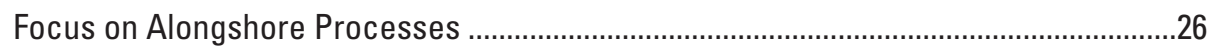

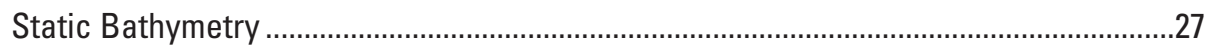

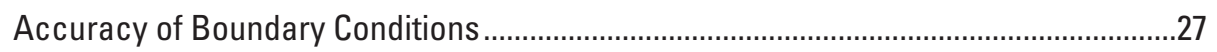

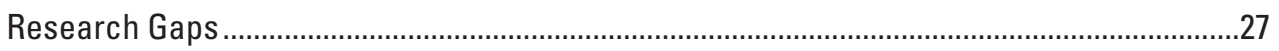

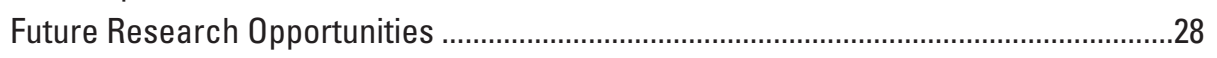

Operational Applications of Results and Methods ......................................................28

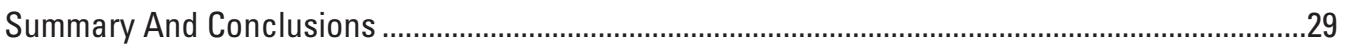

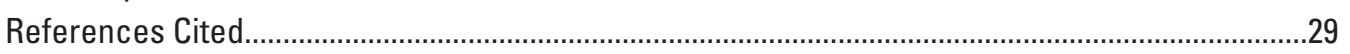

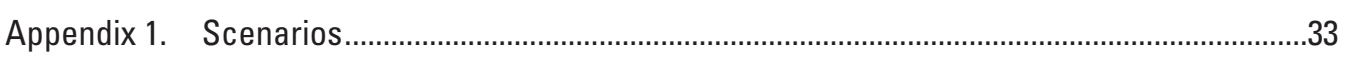

Appendix 2. Examples of Input Files for the Model ................................................................37

Appendix 3. Calculations of Mobility and Potential Flux............................................................4

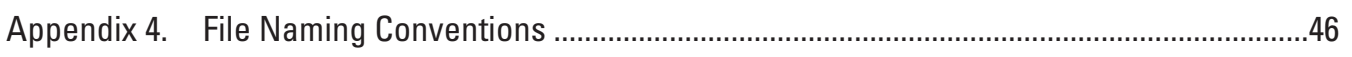

Appendix 5. Time Step of Maximum Ebb and Flood for Inlets in the Model Domain .....................47

\section{Figures}

1. OSAT3 model domain within the northern Gulf of Mexico and showing bathymetry

2. Schematization of wave height and direction observations from NDBC buoy 42040 for April 1, 2010, to May 1, 2012 .............................................................................

3. Generation of alongshore currents due to wave breaking at an angle to the Gulf coast of Alabama and Florida .5

4. Modeled wave height from the H5_D7 scenario simulation and associated wavedriven current vectors showing resolution of the cross-shore variable alongshore current profile. .5

5. Elevations (NAVD88) at three levels of detail for Little Lagoon Inlet, Ala .6

6. Distribution of surface residual ball density $(\rho)$ calculated from chemical composition along the Alabama and Florida Gulf coast.....

7. Processes driving surface residual ball and sediment mobility and transport along the Alabama and Florida Gulf coast....

8. Critical shear stress (in $\mathrm{Pa}$ ) of surface residual balls along the Alabama and Florida Gulf coast as a function of diameter.

9. Critical stress of sand and surface residual balls along the Alabama and Florida Gulf coast, after Shields (1936) shown as a function of density and grain size for six particle sizes.

10. Two mechanisms of increased probability for surface residual ball accumulation ........11

11. NDBC directional wave buoys $(42012,42039$, and 42040$)$ and a Naval Research Laboratory acoustic doppler current profiler used for model evaluation along the Alabama and Florida Gulf coast

12. Comparison of Wavewatch III and SWAN model output to significant wave height and wave period observations at NDBC buoy 42012 between May 1, 2010, and May 1, 2011 
13. Model predictions of wave height and wave direction from the 80 scenarios compared with observations at NDBC buoy 42012 in the northern Gulf of Mexico alongshore Alabama and Florida

14. Model predictions of wave height, peak wave direction and peak wave period in the northern Gulf of Mexico alongshore Alabama and Florida for January 15-25, 2007

15. Evaluation of accuracy of simulated water levels against NOAA tidal measurements

16. Simulated and measured wave characteristics at buoy 42012 in the northern Gulf of Mexico alongshore Alabama and Florida during Hurricane Isaac in August 2012.

17. Simulation of water levels in the northern Gulf of Mexico alongshore Alabama and Florida during Hurricane Isaac in August 2012 compared with measured water level at the NOAA tide stations.

18. Significant wave height for scenarios H3_D6 and H3_D8 in the northern Gulf of Mexico alongshore Alabama and Florida...

19. Maximum alongshore velocity smoothed over a 2-kilometer length scale for scenarios H3_D6 and H3_D8 in the northern Gulf of Mexico alongshore Alabama and Florida

20. Flow convergence for scenarios H3_D6 and H3_D8 in the northern Gulf of Mexico alongshore Alabama and Florida

21. Flow deceleration for scenarios H3_D6 and H3_D8 in the northern Gulf of Mexico alongshore Alabama and Florida.

22. Mobility ratio in the northern Gulf of Mexico alongshore Alabama and Florida for a midlevel threshold of 2.5-centimeter surface residual balls for scenarios H3_D6 and H4_D6

23. Mobility ratio in the northern Gulf of Mexico alongshore Alabama and Florida for sand for scenarios H3_D6 and H4_D6.

24. Mobility ratio in the northern Gulf of Mexico alongshore Alabama and Florida for a midlevel threshold of 2.5-centimeter surface residual balls along the Gulf Islands National Seashore

25. Surf-zone integrated alongshore potential flux smoothed over 2 kilometers for 2.5-centimeter surface residual balls in the northern Gulf of Mexico alongshore Alabama and Florida

26. Weighted mobility probability from April 2010 to May 2012 along the Gulf Islands National Seashore for 2.5-centimeter surface residual balls

27. Weighted surf-zone integrated alongshore potential flux, indicating the average potential flux in the northern Gulf of Mexico alongshore Alabama and Florida from April 2010 to May 2012

28. Tidal inlet surface residual ball mobility at maximum flood and maximum ebb for 2.5-centimeter SRBs using a low critical threshold at Little Lagoon Inlet, Ala.....

29. Maximum alongshore flow speed smoothed over a 2-kilometer length scale and mobility ratio using the lowest critical stress threshold, appropriate for surface residual balls

30. Morphologic features at the Pensacola Inlet, Fla., that interact with the tidal flow.......25

31. Mobility ratios of $0.03-$ centimeter quartz sand (sediment); and $2.5-\mathrm{cm}$ and $10-\mathrm{cm}$ surface residual balls under large wave conditions in the northern Gulf of Mexico......26

32. Observed wave height at the Naval Research Labortory acoustic dopler current 
profiler in the northern Gulf of Mexico alongshore Alabama and Florida for

September 15, 2006, through December 23, 2007.

1-1. Example of a scenario H3_D8 with wave height of 1.25 meters and wave direction of 169 degrees. .35

1-2. Comparison of the best-match condition to the target values for the scenario against all observations for scenario H3_D8.

\section{Tables}

1. Classes of surface residual ball size and density considered in mobility, potential flux analysis, and critical stress in the northern Gulf of Mexico alongshore Alabama and Florida

2. Nine metrics for hydrodynamic and surface residual ball and sediment mobility and alongshore redistribution in the northern Gulf of Mexico along the Alabama and Florida coast.

3. Comparison of high resolution SWAN model output to Wavewatch III model output, evaluated against observed buoy data from May 1, 2010, to May 1, 2011

4. Comparison of Wavewatch III model output to data from three northern Gulf of Mexico offshore NDBC buoys for the 2-year time period of from May 1, 2010, to May 1, 2012

1-1. Wave height and direction scenarios

5-1. Time step index corresponding to maximum flood and ebb for inlets within the model domain 


\section{Conversion Factors, Datum, and Abbreviations}

SI to Inch/Pound

\begin{tabular}{|c|c|c|}
\hline Multiply & By & To obtain \\
\hline \multicolumn{3}{|c|}{ Length } \\
\hline centimeter $(\mathrm{cm})$ & 0.3937 & inch (in.) \\
\hline millimeter (mm) & 0.03937 & inch (in.) \\
\hline meter $(\mathrm{m})$ & 3.281 & foot $(\mathrm{ft})$ \\
\hline kilometer $(\mathrm{km})$ & 0.6214 & mile (mi) \\
\hline \multicolumn{3}{|c|}{ Area } \\
\hline square kilometer $\left(\mathrm{km}^{2}\right)$ & 247.1 & acre \\
\hline square meter $\left(\mathrm{m}^{2}\right)$ & 10.76 & square foot $\left(\mathrm{ft}^{2}\right)$ \\
\hline \multicolumn{3}{|c|}{ Volume } \\
\hline cubic meter $\left(\mathrm{m}^{3}\right)$ & 264.2 & gallon (gal) \\
\hline cubic meter $\left(\mathrm{m}^{3}\right)$ & 35.31 & cubic foot $\left(\mathrm{ft}^{3}\right)$ \\
\hline \multicolumn{3}{|c|}{ Flow rate } \\
\hline meter per second $(\mathrm{m} / \mathrm{s})$ & 3.281 & foot per second $(\mathrm{ft} / \mathrm{s})$ \\
\hline cubic meter per second $\left(\mathrm{m}^{3} / \mathrm{s}\right)$ & 35.31 & cubic foot per second $\left(\mathrm{ft}^{3} / \mathrm{s}\right)$ \\
\hline \multicolumn{3}{|c|}{ Mass } \\
\hline kilogram (kg) & 2.205 & pound avoirdupois (lb) \\
\hline \multicolumn{3}{|c|}{ Pressure } \\
\hline kilopascal $(\mathrm{kPa})$ & 0.1450 & pound-force per inch (lbf/in) \\
\hline \multicolumn{3}{|c|}{ Density } \\
\hline kilogram per cubic meter $\left(\mathrm{kg} / \mathrm{m}^{3}\right)$ & 0.06242 & pound per cubic foot $\left(\mathrm{lb} / \mathrm{ft}^{3}\right)$ \\
\hline \multicolumn{3}{|c|}{ Hydraulic conductivity } \\
\hline meter per day $(\mathrm{m} / \mathrm{d})$ & 3.281 & foot per day $(\mathrm{ft} / \mathrm{d})$ \\
\hline \multicolumn{3}{|c|}{ Hydraulic gradient } \\
\hline $\begin{array}{l}\text { meter per kilometer }(\mathrm{m} / \mathrm{km}) \\
\text { Vertical coordinate information } \\
\text { (NAVD 88). }\end{array}$ & $\frac{5.27983}{\text { eferenced to }}$ & $\begin{array}{l}\text { foot per mile (ft/mi) } \\
\text { American Vertical Datum of } 1988\end{array}$ \\
\hline Horizontal coordinate informati & referenced & rld Geodetic System of 1983 (WGS 83). \\
\hline Elevation, as used in this repor & rs to distal & he vertical datum. \\
\hline
\end{tabular}




\section{Abbreviations}

\begin{tabular}{ll}
\hline \multicolumn{1}{c}{ Term } & \\
\hline ADCP & acoustic doppler current profiler \\
BP & British Petroleum \\
CO-OPS & Center for Operational Oceanographic Products and Services \\
DOI & U.S. Department of the Interior \\
EMC & Environmental Modeling Center \\
FOSC & Deepwater Horizon Federal On-Scene Coordinator \\
GCRO & Gulf Coast Restoration Organization \\
HYCOM & Hybrid Coordinate Ocean Model \\
JONSWAP & Joint North Sea Wave Project \\
NCEP & National Center for Environmental Prediction \\
NDBC & National Data Buoy Center \\
NGDC & National Geophysical Data Center \\
NOAA & National Oceanic and Atmospheric Administration \\
NRDA & Natural Resource Resource Assessment \\
NRL & Naval Research Laboratory \\
NWS & National Weather Service \\
OSAT3 & Operational Science Advisory Team \\
R & coefficient of determination \\
RMSE & root mean square error \\
SRB & surface residual balls \\
SWAN & Simulating Waves Nearshore \\
USACE & U.S. Army Corps of Engineers \\
USCG & U.S. Coast Guard \\
USGS & U.S. Geological Survey \\
\hline & \\
\hline
\end{tabular}




\title{
Application of a Hydrodynamic and Sediment Transport Model for Guidance of Response Efforts Related to the Deepwater Horizon Oil Spill in the Northern Gulf of Mexico Along the Coast of Alabama and Florida
}

\author{
By Nathaniel G. Plant, Joseph W. Long, P. Soupy Dalyander, David M. Thompson, and Ellen A. Raabe
}

\section{Executive Summary}

U.S. Geological Survey (USGS) scientists have provided a model-based assessment of transport and deposition of residual Deepwater Horizon oil along the shoreline within the northern Gulf of Mexico in the form of mixtures of sand and weathered oil, known as surface residual balls (SRBs). The results of this USGS research, in combination with results from other components of the overall study, will inform operational decisionmaking. The results will provide guidance for response activities and data collection needs during future oil spills.

In May 2012 the U.S. Coast Guard, acting as the Deepwater Horizon Federal on-scene coordinator, chartered an operational science advisory team to provide a sciencebased review of data collected and to conduct additional directed studies and sampling. The goal was to characterize typical shoreline profiles and morphology in the northern Gulf of Mexico to identify likely sources of residual oil and to evaluate mechanisms whereby reoiling phenomena may be occurring (for example, burial and exhumation and alongshore transport). A steering committee cochaired by British Petroleum Corporation (BP) and the National Oceanic and Atmospheric Administration (NOAA) is overseeing the project and includes State on-scene coordinators from four States (Alabama, Florida, Louisiana, and Mississippi), trustees of the U.S. Department of the Interior (DOI), and representatives from the U.S. Coast Guard.

This report presents the results of hydrodynamic and sediment transport models and developed techniques for analyzing potential SRB movement and burial and exhumation along the coastline of Alabama and Florida. Results from these modeling efforts are being used to explain the complexity of reoiling in the nearshore environment and to broaden consideration of the different scenarios and difficulties that are being faced in identifying and removing residual oil. For instance, modeling results suggest that larger SRBs are not, under the most commonly observed low-energy wave conditions, likely to move very far alongshore. This finding suggests that SRBs from one source location may not (outside of storm conditions) be redistributed to other up or down coast locations. This information can guide operational response decisions. In addition, because SRBs are less mobile compared with sand, they are likely to become buried and unburied under normal sand transport processes thereby lengthening the time SRBs may take to move onshore. The rate of onshore movement was not specifically addressed by this study, yet the results resolve the cross-shore domain and cross-shore variations in alongshore transport that are relevant to achieving the primary objectives. Furthermore, during infrequent events (for example, winter storms and severe meteorological events such as Hurricane Isaac of August 2012), energy is shown to be sufficient to move a greater range of SRB sizes and potentially expose and break up submerged oil mats. When SRBs do move alongshore, the models indicate that there are regions that are more conducive to accumulation of SRB material than others. Accumulation can occur where there are reversals and decelerations in alongshore currents and where forces created by shear stress drops below critical thresholds to maintain or initiate SRB movement. In addition, flow and SRB mobility patterns around inlets indicate patterns in hydrodynamic forces that influence redistribution of SRBs and the surface oil that mixed with sediment to form oil mats in the first place.

\section{Introduction}

Source, transport, and deposition of residual Deepwater Horizon oil that is causing shoreline reoiling along the coastlines of Alabama, Florida, Louisiana, and Mississippi is not well understood, and existing scientific knowledge has proven insufficient to fully support cleanup response and management decisions. Therefore, in May 2012, the U.S. Coast Guard, acting as the Federal On-Scene Coordinator chartered the third Operational Science Advisory Team (OSAT3) to provide science-based review of data collected 
(for example, morphologic elevations and oiling locations) and to conduct additional directed studies and sampling as necessary. A steering committee cochaired by British Petroleum Corporation (BP) and the National Oceanic and Atmospheric Administration (NOAA) is overseeing the project and includes State on-scene coordinators from four States (Alabama, Florida, Louisiana, and Mississippi), trustees of the U.S. Department of the Interior (DOI), and representatives from the U.S. Coast Guard.

Residual oil from the Deepwater Horizon spill is found in the shallow surf-zone in the northern Gulf of Mexico in two primary forms: submerged oil mats and surface residual balls (SRBs). Mats formed when weathered oil at the surface reached a shallow, energetic-enough location for wave-stirred sediment to mix with the oil and create a sand and oil mixture. This mixture can become heavier than water and settle to the the sea floor where more sediment can be incorporated, forming a submerged mat. Mats encountered as part of the Deepwater Horizon response efforts are generally meters in cross-shore width, meters to tens of meters in alongshore length, and a few to tens of centimeters thick. Under sufficiently energetic wave conditions, buried mats can be exhumed and pieces of the mats can break off and form SRBs (Shoreline Cleanup and Assessment Team, oral commun., 2012). The SRBs are observed in the surf zone and may wash up on beaches. SRBs and mats in the surf zone and on the beach are targets of ongoing cleanup response efforts. This report presents the results of an OSAT3 subgroup that developed hydrodynamic and sediment transport models and developed techniques for analyzing potential SRB redistribution and burial and exhumation to provide a better understanding of alongshore processes and movement of SRBs along the coastline of Alabama and Florida.

\section{Overall OSAT3 objectives}

To provide improved understanding and guidance in support of the operational response to shoreline reoiling, OSAT3 undertook five main tasks:

- Evaluate the trends observed in frequency, rate, and potential for remobilization on beach segments in the areas affected by reoiling.

- Determine and record the locations and typical shoreline profiles and morphology for likely sources of residual oil or origin of the SRBs.

- Define or determine the mechanisms whereby reoiling phenomena may be occurring.

- Investigate the potential for mitigation actions that may be taken to reduce these potential occurrences and, to the extent reoiling phenomena are identified, evaluate the feasibility of the mitigation actions and net environmental benefit of employing such actions.
- Recommend a path forward to reach shoreline cleanup completion plan guidelines or appropriately manage identified areas through alternative methods.

To achieve these overall objectives, the OSAT3 subgroup collected and analyzed shoreline cleanup data (for example, SRB and mat recovery records and photographs showing location and size of SRBs) and geomorphic data (beach profiles, aerial imagery, shorelines, topography, and bathymetry) and conducted numerical modeling analysis of waves, water levels, currents, and local surficial sediment, and SRB mobility and transport. This report specifically addresses the numerical modeling aspect of the OSAT3 objectives along the coastline of Alabama and Florida; overall OSAT3 findings are not within the scope of the analysis of this report.

\section{Objectives of USGS Hydrodynamic and Sediment Transport Modeling}

This report documents the approach, results, and conclusions from the USGS OSAT3 subgroup that developed hydrodynamic and sediment (including SRBs) transport models to provide better understanding and prediction of alongshore processes and movement of SRBs. The subgroup was split into two teams tasked with analyzing specific regions of the affected coastline. One team covered the Louisiana and Mississippi coastlines (results not presented in this report), and the other team covered the Alabama and Florida coastlines. The latter region was modeled by researchers from the USGS Coastal and Marine Geology Program. The specific objectives of this subgroup's effort were to:

- identify spatial patterns in alongshore current directions and velocity;

- identify zones of convergence and alongshore current reversal;

- identify potential sediment and SRB sinks;

- estimate SRB movement along the coast; and,

- determine the influence of tidal currents on SRB mobility and transport in the vicinity of tidal inlets.

These objectives were achieved through modeling scenarios covering the range of weather and wave variability since the Deepwater Horizon spill; extracting wave-driven alongshore currents, wave-orbital stirring, and tidal currents; and computing associated sediment and SRB mobility and alongshore transport patterns. The approach to selecting scenarios, hydrodynamic modeling, and SRB mobility and transport modeling is described in the Methods section. In the Results section, the modeled hydrodynamics are evaluated against observations and the alongshore current and SRB transport results from the scenarios are described. The impact of the results on achieving the overall OSAT3 objectives is described in the Discussion section. An analysis of our assumptions along with implications of our methods and 
findings for future operations associated with reoiling response are also discussed. The major findings from this study are summarized in the Conclusions section.

\section{Methods}

The coastline of interest included in our analysis stretches from Dauphin Island, Ala. to Panama City Inlet, Fla. The domain for our entire OSAT3 model encompasses a wider stretch of coast from Horn Island, Miss. to Crooked Island, Fla. (fig. 1) to ensure that the regions of interest in Alabama and Florida were not affected by the lateral boundaries of the domain for the model. The curvilinear model grid resolution was variable with an average alongshore resolution of 250 meters $(\mathrm{m})$ and a cross-shore grid spacing ranging from 150 $\mathrm{m}$ far offshore to $2.5 \mathrm{~m}$ near the shoreline. The size of the model domain allowed the inclusion of large-scale variations in wind and wave patterns, and the increased resolution in the nearshore allowed for computation of finer scale surf zone processes driven by depth-induced wave breaking. Computational efficiency was achieved with the variable grid spacing. This domain was nested within global and basin-scale wave and hydrodynamic model domains encompassing at a minimum the entire Gulf of Mexico in order to derive adequate spatially varying boundary conditions to drive processes in the OSAT3 model domain.

\section{Modeling Approach}

Hydrodynamic simulations included scenarios derived from wave and weather observations at the National Data Buoy Center (NDBC; 2012) buoy 42040 from April 1, 2010, to May 1, 2012. This buoy was just offshore of the eastern side of the OSAT3 model domain. The wave observations were schematized by dividing wave heights into 5 bins bounded by $0.0,0.5,1.0,1.5,2.0$, and $5.0 \mathrm{~m}$ and sampling wave directions in 16 bins each spanning 22.5 degrees $\left(^{\circ}\right)$, from $0^{\circ}$ to $360^{\circ}$. The combination of wave height and direction bins yielded 80 different scenarios. The probability of occurrence of each scenario (fig. 2) indicated that waves were most likely to have heights of 0.5 to $1.0 \mathrm{~m}$ and come from the southeast. However, the set of scenarios that were considered included common and relatively rare wave conditions. The details of selecting scenarios are described in appendix 1.

Due to the large geographic extent and variability of the model domain, application of spatially homogeneous wave conditions along the entire offshore model boundary would provide unrealistic results. Therefore, for each of the scenarios, the observed wave record was searched for a specific time that most closely matched the characteristics of

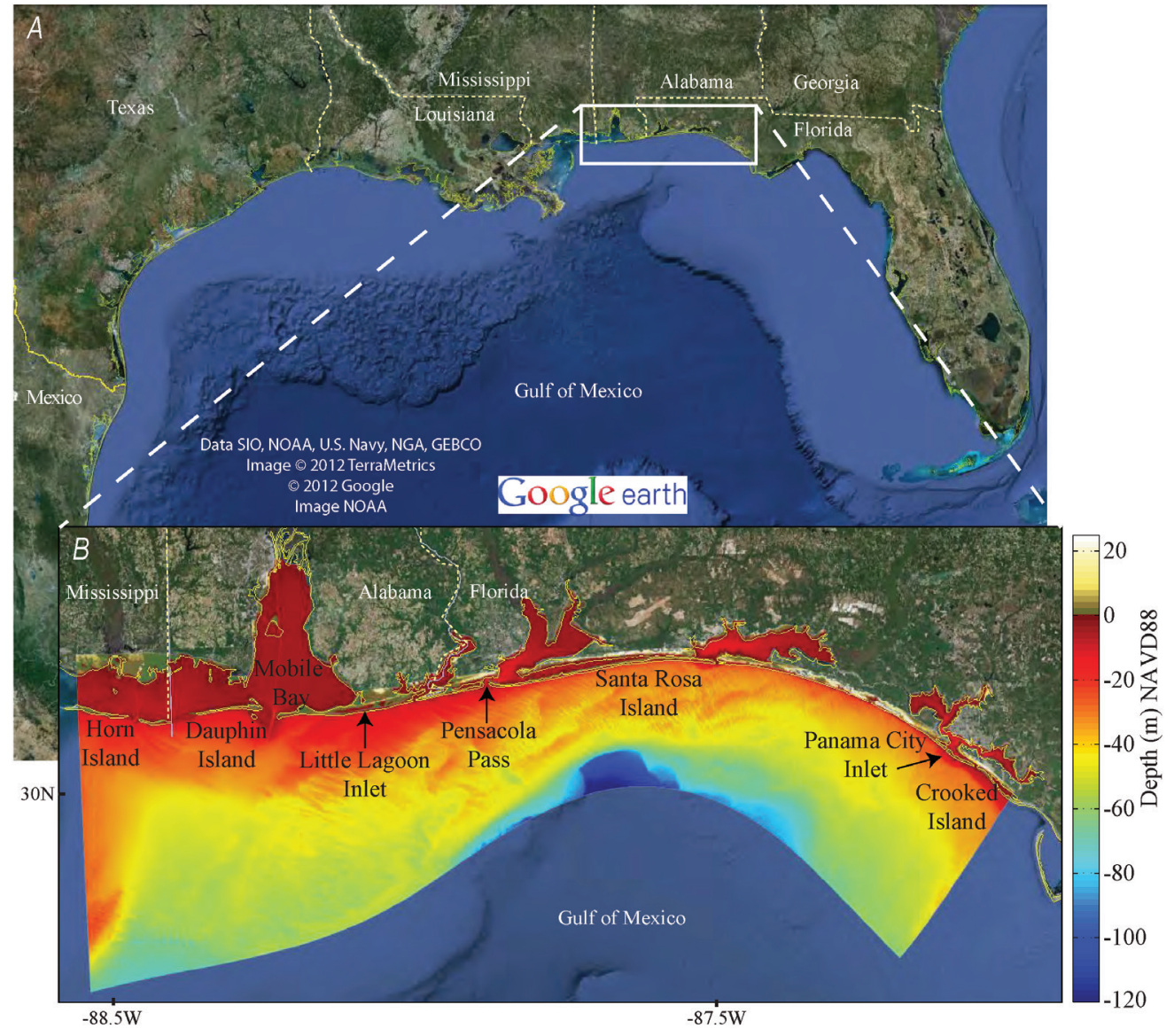

Figure 1. OSAT3 model domain within $A$, the northern Gulf of Mexico and $B$, showing bathymetry. Colors in $B$ represent water depths relative to the North American Vertical Datum of 1988 (NAVD88). Analysis of model results extends from Dauphin Island, Ala., to Panama City Inlet, Fla. 
Figure 2. Schematization of wave height and direction observations from NDBC buoy 42040 for April 1, 2010, to May 1, 2012. Colors indicate the percentage $(\%)$ of the occurrence for each wave height-direction bin. Wave height bins (numbered $\mathrm{H} 1-\mathrm{H} 5$ ) are organized from the center outward with larger waves ( $2 \mathrm{~m}$ and higher) in the outer ring $(\mathrm{H} 5)$. Wave direction bins (numbered D1-D16) each span 22.5 degrees $\left({ }^{\circ}\right)$, from $0^{\circ}$ to $360^{\circ}$, labeled around the circumference of the diagram.

the scenario. Then, archived results from the National Weather Service (NWS) National Center for Environmental Prediction (NCEP) NOAA Wavewatch III regional wave model (Environmental Modeling Center, 2012), corresponding to that specific time, were applied to the OSAT3 model domain boundaries. Archived winds from the same regional model, also corresponding to the same point in time, were applied to the free-surface boundary of the entire OSAT3 model domain. Stationary wave conditions were used and variations in water level were not considered for the scenario simulations.

In addition to the stationary scenarios, two time periods were simulated to evaluate model accuracy over a range of conditions: (1) January 15-25, 2007, which included both quiescent and storm conditions during winter and (2) Hurricane Isaac on August 27-31, 2012, an extreme weather event during summer. For these simulations, timevarying wave conditions were imposed on the boundaries of the OSAT3 model.

\section{Hydrodynamic Model Description}

We used the Delft3D (version 4.00.01) coupled waveflow model to compute stirring associated with wave orbital velocities and steady wave and wind-driven alongshore currents (Lesser and others, 2004; Deltares, 2007). The model computes flow variables using the depth-averaged shallow water equations that are intrinsically relevant to analyzing alongshore currents in the domain, particularly in the surf zone. We used model parameter values that have been demonstrated in Lesser and others (2004) to be appropriate for the sandy coastlines similar to those within our project area. Model parameters are documented in appendix 2 as part of the example input files for the Flow and Wave modules.

Three-dimensional surf zone processes were not simulated due to the focus on the prediction and role of alongshore currents (as opposed to cross-shore processes) in transporting SRBs along the project domain. In the nearshore environment, currents are caused primarily by wave-breaking processes. Reniers and others (2004) showed that vertical profiles of wave-driven alongshore currents are relatively depth-uniform, indicating that the use of depth-averaged models is acceptable. Density stratification was also assumed to be negligible due to intense vertical mixing by breaking waves and stratification was not included in the model equations. Winds are included in the model to generate waves within the domain. Although currents caused by wave breaking processes are dominant in the nearshore environment, the model also simulates currents generated by wind blowing over the ocean surface. Variable water depth and its influence on wave refraction, shoaling, and breaking and alongshore current magnitude and location was included. 
Alongshore current directions and magnitudes (for example, eastward or westward following the curvature of the model grid) were required to understand the movement of sediments and SRBs under various wave conditions. Waves approaching the shoreline at an angle break and transfer their momentum to the water column, creating the primary force that is responsible for driving alongshore currents (fig. 3). Generally, waves approaching from the west drive currents to the east and vice versa. Depending on the local geometry

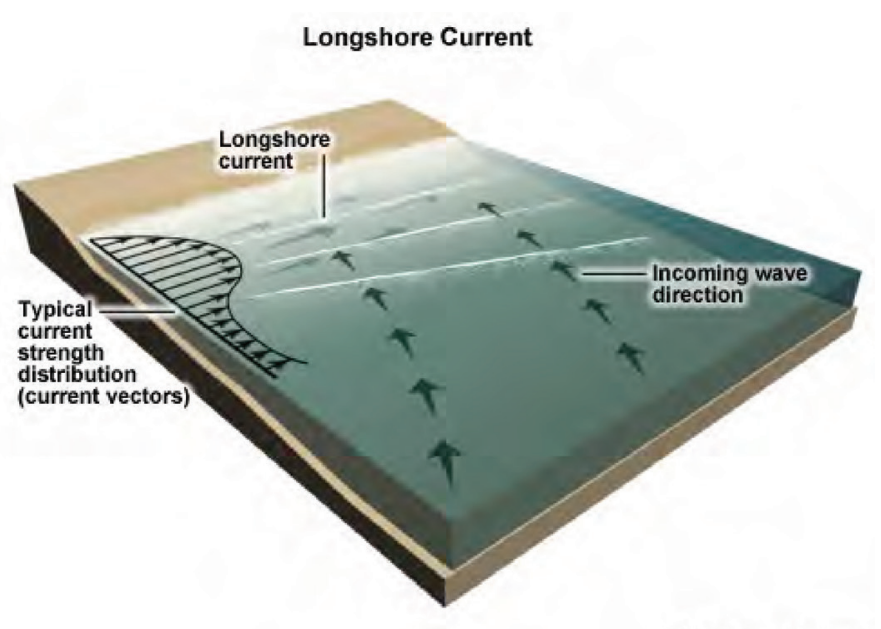

(9The COMET Program

Figure 3. Generation of alongshore currents due to wave breaking at an angle to the Gulf coast of Alabama and Florida. Image used with permission (COMET ${ }^{\circledR}$ Website, 2011). of the coast and nearshore bathymetry, complex spatial patterns in the magnitude and direction of the alongshore current can develop. The cross shore and alongshore variations of the nearshore currents were resolved with the model grid and depict the alongshore current jet that is driven by wave breaking near the shoreline (fig. 4).

\section{Hydrodynamic Model Input Data}

\section{Bathymetry}

Bathymetric data (fig. 1) were obtained from the northern Gulf Coast digital elevation map of the NOAA National Geophysical Data Center (NGDC; Love and others, 2012). These data, with 30-m resolution, satisfied the large-scale needs of the OSAT3 domain. An exception was at Little Lagoon Inlet, Ala., which, at $10 \mathrm{~m}$ wide, required higher grid resolution and more accurate bathymetric data (fig. $5 \mathrm{~A}$ ) to define the inlet for simulations, including tidal variations. Refined inlet resolution was not used in the scenario simulations where temporal water level variations were not considered. At Little Lagoon, we used data from the U.S. Army Corps of Engineers (USACE, 2010) collected in January through March 2010, just before the Deepwater Horizon oil spill (fig. 5B). Additionally, for the Little Lagoon Inlet, we assimilated stereoelevation data collected as part of the spill response (Aero-Metric, Inc., unpub. data, 2012) to improve simulation results, determine the sensitivity of modeled flows

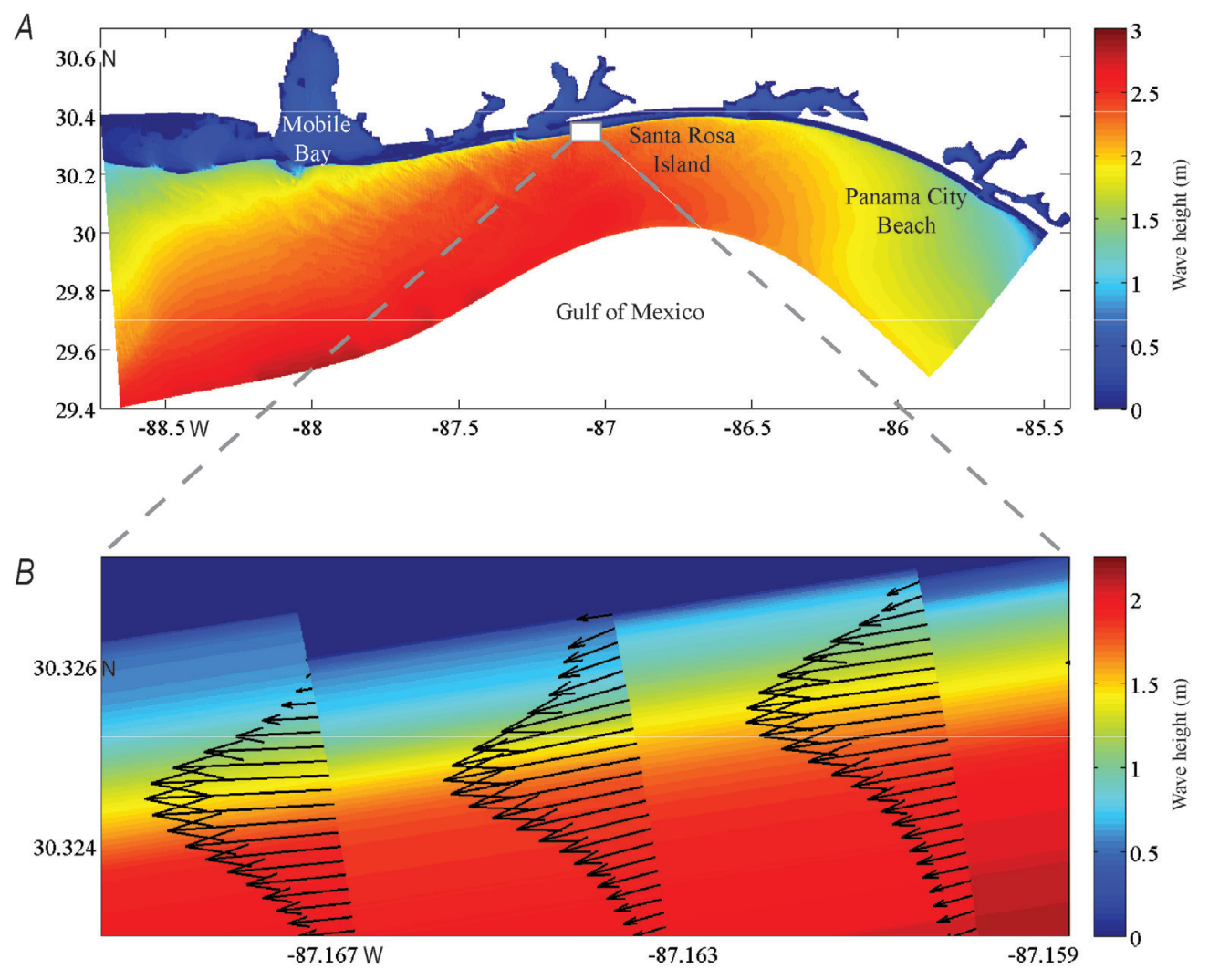

Figure 4. A, Modeled wave height from the H5_D7 scenario simulation (fig. 2; wave height more than $2 \mathrm{~m}$ from the southeast); $B$, associated wave-driven current vectors showing resolution of the cross-shore variable alongshore current profile (arrow length is proportional to current speed). The number of current vectors has been reduced by a factor of six in the cross-shore direction in $B$ for better viewing. Color gradation near the coast in $B$ illustrates depth-induced wave breaking in shallow water depths. 

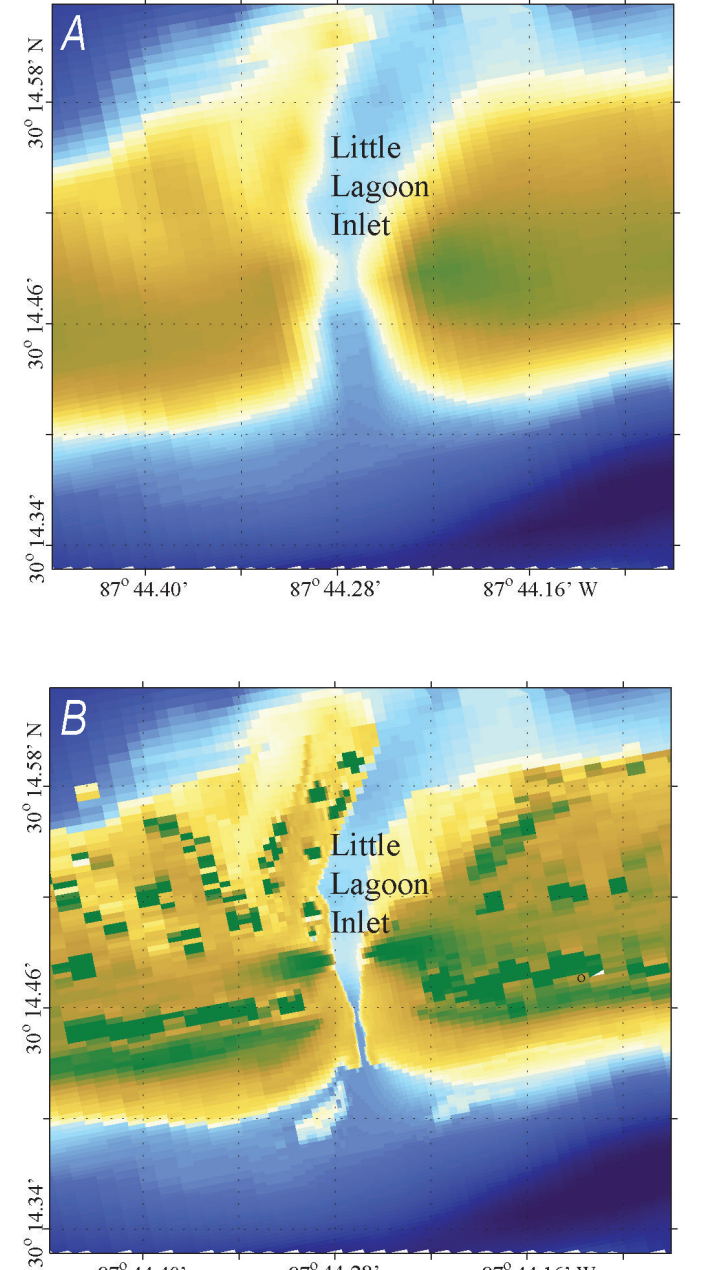

$-2$
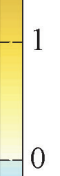

छ్

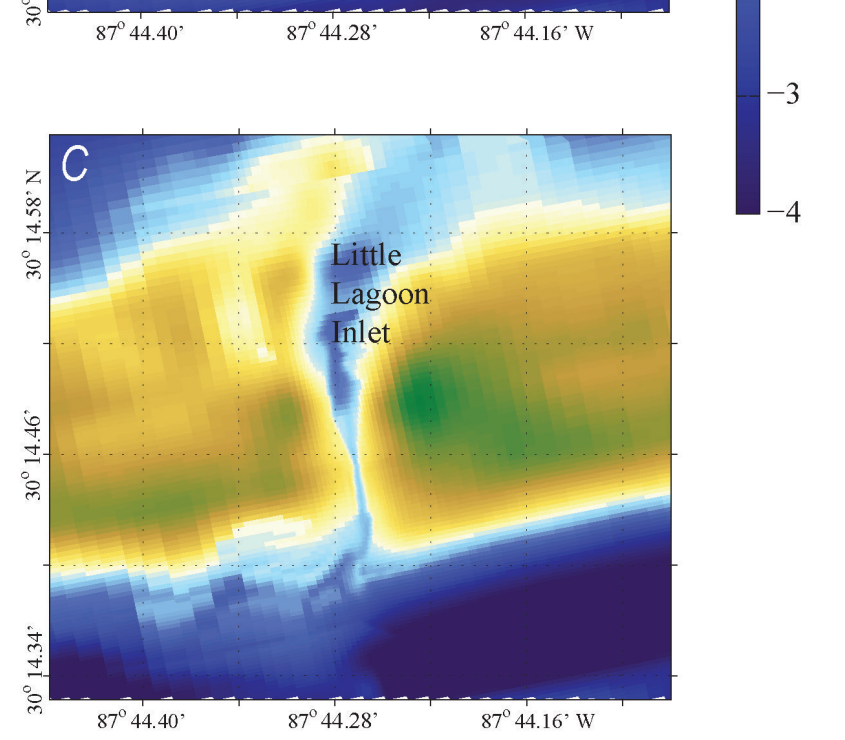

Figure 5. Elevations (NAVD88) at three levels of detail for Little Lagoon Inlet, Ala. A, 30-m resolution digital elevations (Love and others, 2012); B, 1-m resolution lidar elevations (USACE, 2010); and $C$, fall 2012 2-m resolution stereoanalysis elevations (Aero-Metric, Inc., unpub. data, 2012). Elevations are posted on the model grid to illustrate the increased resolution at the inlet. to bathymetric changes, and demonstrate an ability to integrate this relatively novel data source (fig. 5C).

Geomorphic features larger than the smallest grid cells of the model (that is, $250 \mathrm{~m}$ in the alongshore and $10 \mathrm{~m}$ in the cross-shore) were resolved in the model. Thus, nearshore features such as sandbars, mega cusps, and other features relevant to this effort were evaluated. These nearshore features, however, are highly ephemeral, and temporal variations were not resolved over the approximately 2-year time period that the simulations represented. Lidar or stereometric observations (fig. $5 B, C$ ) near Little Lagoon represented more recent and accurate snapshots of bathymetric variation. Large offshore features such as submarine canyons that can affect the wave climate were spatially resolved by the models providing boundary conditions to the domain use in our modeling simulations.

\section{Waves}

Archived results from the NOAA Wavewatch III operational 4-minute ('), or about 7.5-kilometer ( $\mathrm{km}$ ) resolution U.S. East Coast and Gulf of Mexico wave model (Tolman, 2008; Environmental Modeling Center, 2012) were used for the boundary conditions in the Wave module of Delft3D. This wave model is part of a nested series of operational models of varying sizes and resolutions that extend to a global-scale parent grid. The model system has been run, essentially in the stated configuration, since February 2005, and NOAA provides archives of bulk wave parameters at 3-hour intervals from modeled hindcasts. Wave heights, periods, and directions from Wavewatch III were extracted and prescribed along the offshore and lateral boundaries of the OSAT3 domain with an assumed Joint North Sea Wave Project (JONSWAP) spectral shape (Hasselmann and others, 1973). The boundary conditions were prescribed at every thirtieth grid cell, matching the coarse resolution of the Wavewatch III model. Wave conditions for the scenario simulations were held stationary. For the time series simulations, wave conditions were updated every 3 hours. The directional domain for the wave model covered a full circle with a resolution of $5^{\circ}$ (72 bins in total), and the frequency domain was 0.05 to 1 hertz $(\mathrm{Hz})$ with logarithmic spacing. The bottom-friction dissipation parameterization of Hasselmann and others (1973) was used with a uniform bottom roughness coefficient of 0.067 square meters per second cubed $\left(\mathrm{m}^{2} / \mathrm{s}^{3}\right)$. Additionally, so-called third-generation physics were activated, accounting for wind wave generation, triad wave interactions, and white capping by the Komen and others (1984) parameterization. Depth-induced wave breaking dissipation was included using the Battjes and Janssen (1978) parameterization with default values for alpha (1) and gamma (0.73). More details regarding input parameters can be found in the Wave input file in appendix 2. 


\section{Winds}

Wind velocities were also obtained from the archived Wavewatch III 4'-resolution data. NOAA uses winds from their Global Forecast System weather model to generate waves in Wavewatch III and stores this wind data in the Wavewatch III archives (Environmental Modeling Center, 2012). These wind velocities were extracted from the archives and applied over the entire OSAT3 model domain. As done for the waves, the wind velocities for the scenario simulations were held stationary whereas for the time series simulations wind velocities were updated every 3 hours.

\section{Tides and Surge}

Variations in water levels were accounted for in the timeseries simulations. Water levels imposed at the model boundaries were obtained from the TPXO7.2 global tide model which uses a numerical tidal model and satellite-derived observations of tide elevation to produce tidal constituents (Egbert and Erofeeva, 2010). Subtidal water level fluctuations that accounted for regional oceanographic processes were obtained from a large-scale ocean model (Hybrid Coordinate Ocean Model, 2012a) that simulated tides and surge within the Gulf of Mexico with a resolution of approximately $4 \mathrm{~km}$. Hybrid Coordinate Ocean Model (HYCOM; 2012b) data assimilation incorporates observations of water level derived from satellite altimeters, which increases prediction accuracy. Hourly water level variations from the combination of tidal and subtidal water level models were imposed at the two offshore corners of the domain and linearly interpolated along the offshore boundary. Spatially varying tidal flows into and out of the inlets and estuaries along the project site were included and evaluated in time series simulations.

\section{SRB and Sand Movement}

The goal of assessing SRB response to hydrodynamic conditions is split into determining the likelihood of SRBs to move (thresholds for incipient motion, for example, mobility, are exceeded), the likelihood to be buried or exhumed by surrounding sediment, the propensity for alongshore transport, and the tendency to accumulate. SRB burial and exhumation are more likely in areas of more mobile sediment, particularly where sand is mobile and SRBs are immobile. The types of analysis conducted for each scenario and time-series, therefore, were SRB mobility, local surficial sediment mobility, and SRB potential flux, which was used as a proxy to identify probable alongshore patterns in SRB redistribution. The exact velocity and alongshore transport distances of individual SRBs could not be assessed because the locations of SRBs or their sources are unknown. We are also limited by some fundamental uncertainties about SRB transport (see Discussion section).

\section{Physical Properties of Sand and SRBs}

The response of sand and SRBs to hydrodynamic forces is a function of the size and density of the particles. For sediment (without oil), the median grain size in the surf zone in this region was determined to vary between 0.250 and 0.500 millimeters (mm; D.C. Phelps and others, Florida Geological Survey, unpub. data, 2011). Sand in this region was predominantly quartz (Balsam and Beeson, 2003) and therefore of approximately 2,650-kilogram per cubic meter $\left(\mathrm{kg} / \mathrm{m}^{3}\right)$ density. Quantitative information on SRB chemical composition came from an OSAT-supplied dataset (L. Bruce, British Petroleum Corporation, Gulf Coast Restoration Organization (GCRO), Science Natural Resource Damage Assessment Team (NRDA), unpub. data, 2012) and was used to calculate the variability in density (fig. 6; appendix 3). Observational data on the size distribution of SRBs were not available, therefore a range of classes $(0.03$ centimeters $(\mathrm{cm}), 0.5 \mathrm{~cm}, 1 \mathrm{~cm}, 2.5 \mathrm{~cm}$, $5 \mathrm{~cm}$, and $10 \mathrm{~cm}$ ) were chosen to span the estimated range of SRB size variability (W. Bryant, U.S. Geological Survey, oral commun., 2012).

\section{Physical Processes of Sand and SRB Mobility}

The processes that were considered in the SRB and sediment mobility and transport analysis included stirring due to wave orbital motion at the sea floor, alongshore currents, and tidal currents at inlets (fig. 7). SRBs or sand grains will begin to move when the shear stress force associated with the combined action of waves and currents exceeds a size- and density-specific critical threshold value. See appendix 3 for calculation of shear stress from hydrodynamic results and calculation of critical stress thresholds. Localized turbulence and wave-to-wave variation can cause any individual particle to move at calculated stress values below threshold; however, the formulations used here, on average, have been found to be accurate for surf zone calculation (Deigaard and others, 1991; Soulsby and others, 1993).

Critical stress values could also be affected by particle shape and exposure above the sea floor. The empirical mobility relationship originally developed by Shields (1936) and used in this analysis is for a uniform bed of well-packed sediment, and larger particles such as SRBs extruding above the bed would have a lower critical value for mobility than estimated with the standard Shields calculation (Fenton and Abbott, 1977; Andrews, 1983; Wiberg and Smith, 1987; Wilcock, 1998; Bottacin-Busolin and others, 2008). Because individual SRBs may have varying exposure above the surrounding sea floor, three critical stress values were considered to account for departures from the simple assumption in Shields (1936). The high critical stress values recorded during the study would be the ones required to move unexposed SRBs sitting approximately level with the surrounding bed, such as might be expected in a recently fragmented mat. The medium critical stress values correspond to a partially exposed SRB, and the low critical stress values correspond to a single isolated SRB 
Figure 6. Distribution of surface residual ball (SRB) density $(\rho)$ calculated from chemical composition along the Alabama and Florida Gulf coast. Data are from L. Bruce, British Petroleum Corporation, GCRO, Science/NRDA Team (unpub. data, 2012).

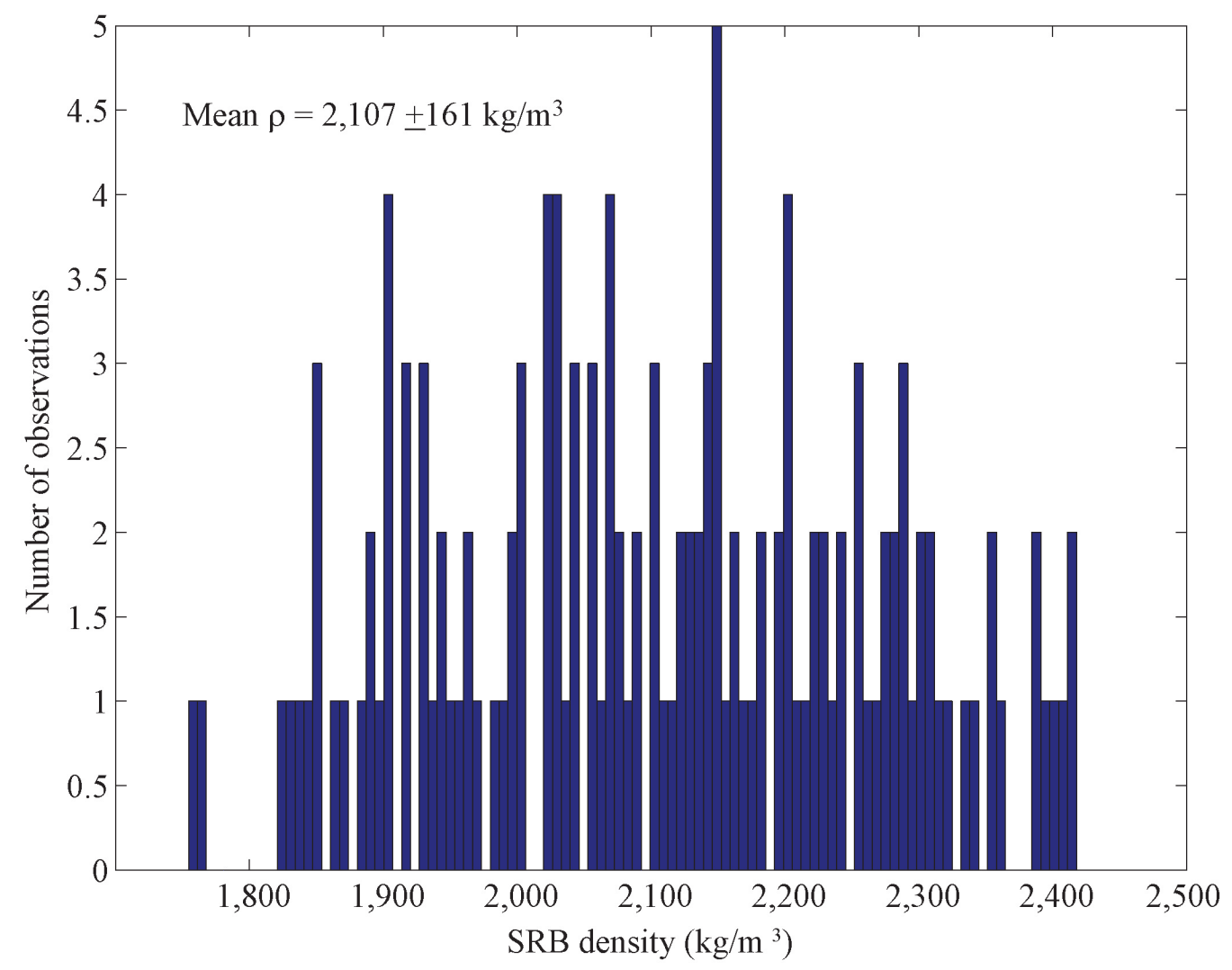

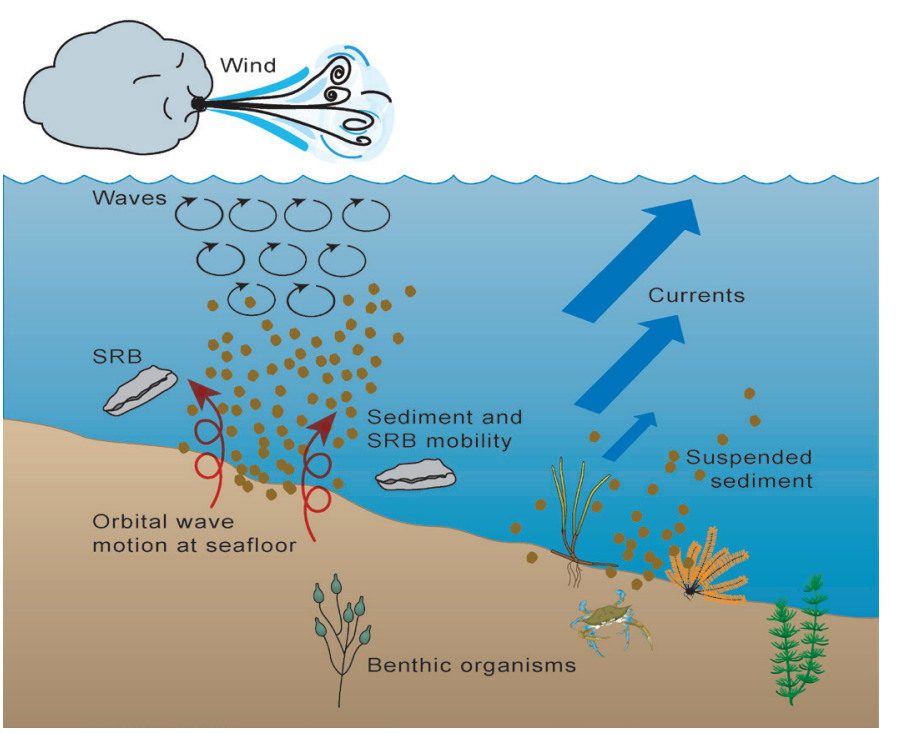

Figure 7. Processes driving surface residual ball (SRB) and sediment mobility and transport along the Alabama and Florida Gulf coast. Wave- and current-induced shear stress can resuspend sand, SRBs, and other material from the sea floor, leading to potential transport by currents. (Symbols used by permission from Integration and Application Network, 2012). fully exposed atop on the sea floor (appendix 3). The medium and low critical stress values for any given particle are roughly a third and a sixth of the high critical stress estimate (fig. 8). Local surficial sediment mobility was assessed using a single critical stress value based on the Shields parameterization or the high estimate for SRBs because the sand in the northern Gulf of Mexico surf zone is of generally uniform size.

\section{Sand and SRB Representative Class Definition}

To estimate the mobility and potential flux associated with the modeled waves and currents, SRB or local sediment diameter and density must be specified. Particle density is well constrained for the predominantly quartz sand in this region but varied somewhat for observed SRBs. The sensitivity of the critical stress required for inducing particle mobility was examined for a range of densities consistent with SRB data. The variations in SRB density caused relatively small critical stress variations compared with the differences due to variations in SRB size and in comparison sand mobility (fig. 9). Thus, particle diameter was the dominant control on mobility (figs. 8 and 9). Therefore, overall SRB variability was characterized by a set of six classes of varying size and fixed density. Local sediment was characterized by a single size and density (table 1). 


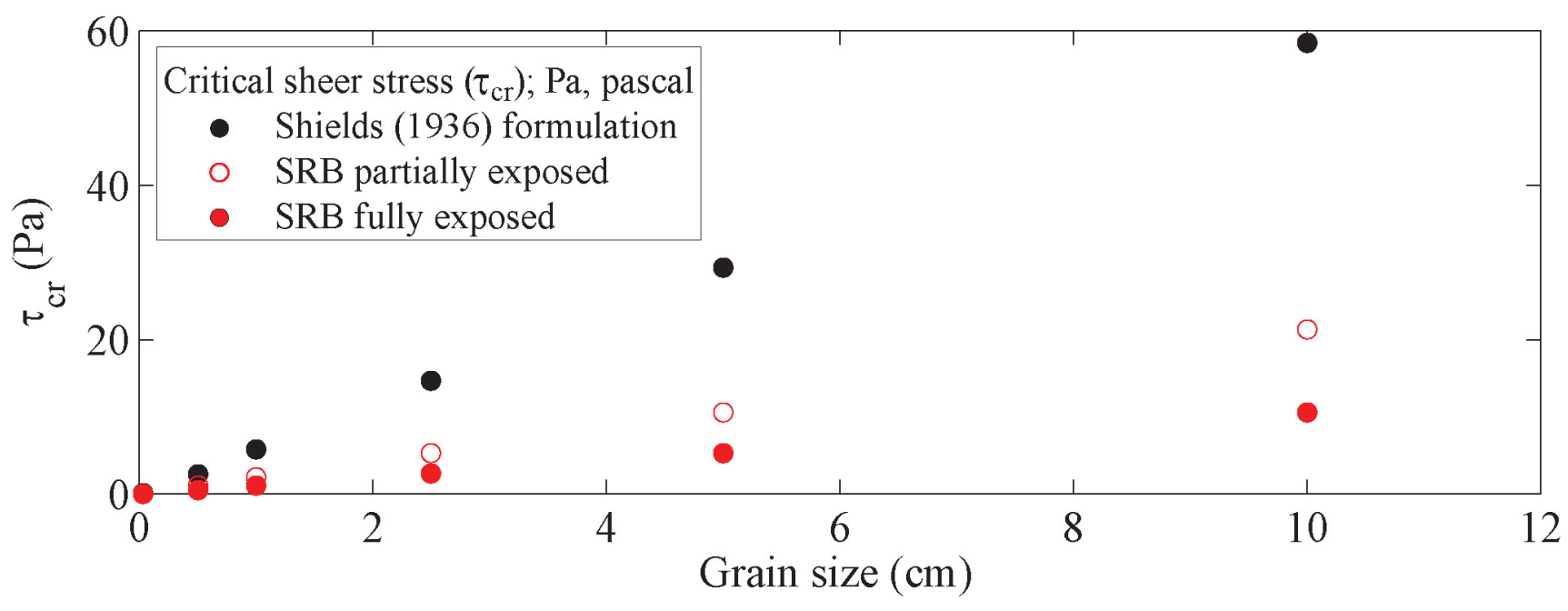

Figure 8. Critical shear stress (in Pa) of surface residual balls (SRBs) along the Alabama and Florida Gulf coast as a function of diameter (in $\mathrm{cm}$ ). Shown are values calculated using the original Shields (1936) formulation, and a modified version accounting for exposure wherein the dimensionless sheer stress approaches a constant value for particles that are partially exposed (0.1) or fully exposed (0.2; see appendix 3).

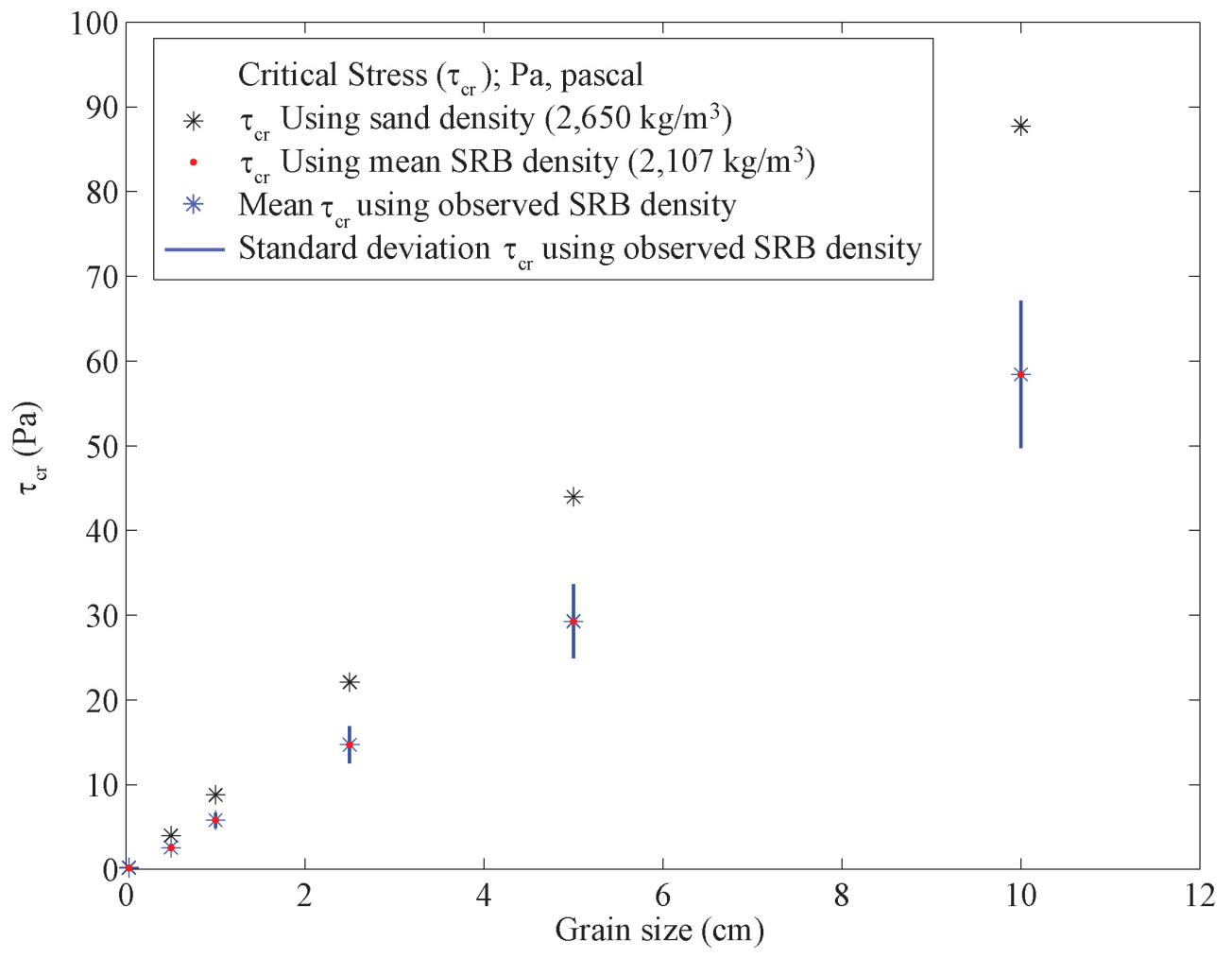

Figure 9. Critical stress of sand and surface residual balls (SRBs) along the Alabama and Florida Gulf coast, after Shields (1936) shown as a function of density and grain size for six particle sizes. For each standardized surface residual ball (SRB) grain size (table 1), we calculate the critical stress for the range of observed SRB densities, with the resultant critical stress mean and one standard deviation shown. The critical stress calculated for each size using the mean SRB density is within the small range of variability but is greater than the critical stress of a particle of the same size with the density of quartz sand.

\section{Inlet Dynamics and Sediment Mobility}

The influence of tidal currents on sediment transport, including sand and SRBs, in the vicinity of tidal inlets and estuaries is more complicated than the open-coast analysis where wave-generated alongshore currents dominate flow patterns. Inlet effects caused by tidal flows and their interaction with the incoming wave field (wave-current interaction) were evaluated across the model domain for 24 hours using wind and wave parameters of scenario H4_D7 (fig. 2).

Identifying inlet convergence and divergence patterns requires detailed shallow bathymetry at the inlet. The model 
Table 1. Classes of surface residual ball size and density considered in mobility, potential flux analysis, and critical stress in the northern Gulf of Mexico alongshore Alabama and Florida

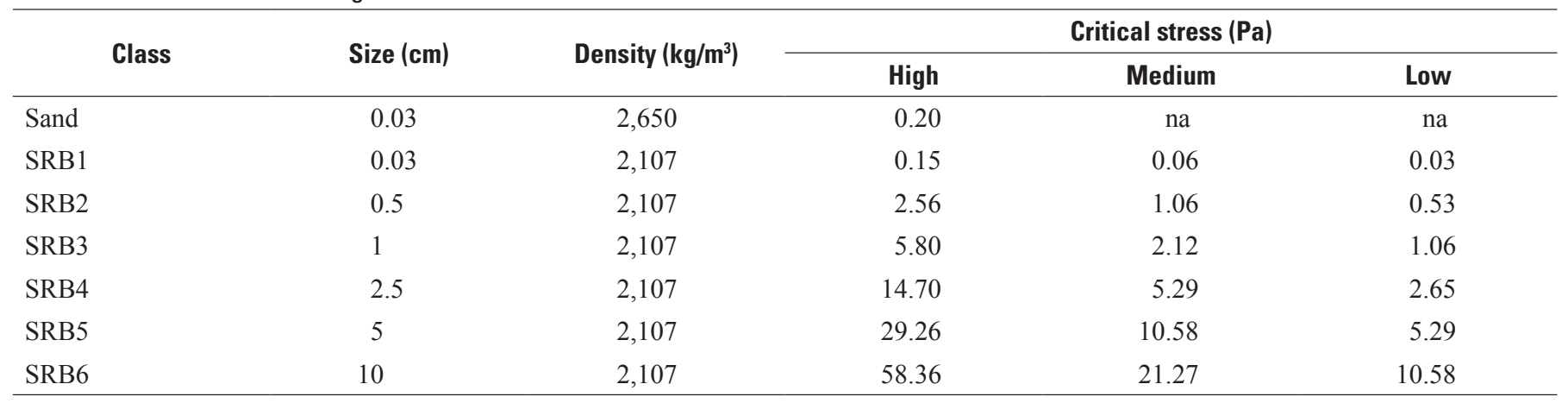

grid used for inlet simulations at Pensacola Pass, Fla., Little Lagoon, and Panama City (fig. 1) therefore included higher (for example, 1- to 50-m) alongshore resolution within the three inlets. The flow field and water levels were coupled with the wave model every 3 hours to include the effects of flow and water level processes on the incoming waves for simulations of sediment mobility at inlets.

\section{Metrics for Evaluating Sand and SRB Mobility and Redistribution Patterns}

Analyses were conducted to determine sediment and SRB movement probability and alongshore redistribution patterns for SRBs of size classes for each individual scenario, illustrating the likely mobility and redistribution patterns under the conditions that scenario represents. In addition, metrics of mobility and alongshore potential flux were calculated as weighted averages of all the scenarios, indicating probable patterns in mobility and redistribution over longer time scales, and mobility over a 24-hour period was calculated for one scenario to assess the variability in mobility over a tidal cycle.

Metrics for hydrodynamic and SRB and sediment movement probability and alongshore redistribution for wave scenarios are:

- significant wave height;

- maximum and median alongshore current;

- alongshore current convergences;

- alongshore current decelerations;

- mobility ratio; and,

- potential flux.

Two additional metrics used to assess the overall probability of mobility and alongshore distribution over the time period of interest are:

- weighted mobility probability; and,

- weighted potential flux.
The range of tidally induced SRB and sand mobility over a 24-hour period for one scenario is evaluated with:

- tidal mobility.

These metrics are listed in table 2 with the naming convention of the associated output shapefiles (appendix 4). Metric calculations are described below.

\section{Signific ant Wave Height}

The significant wave height (metric 1) is calculated by the Wave module of Delft3D for each scenario. This parameter is an output of the model, is converted to Esri ArcGIS polygon shapefile format over the model domain, and is included to illustrate the spatial variability in wave height for each scenario.

\section{Maximum and Median Alongshore Current}

The alongshore component of the flow velocity within the surf zone was extracted from each scenario simulation (for example, see fig. 4). The modeled surf zone for each scenario was defined as stretching from the shoreline out to the crossshore location of maximum wave height found between the shoreline and the most offshore point of modeled, depthinduced wave breaking dissipation. The maximum and median surf zone alongshore current at each alongshore location, for each scenario, was extracted within this surf zone (metric 2). The currents (maximum and median) were smoothed over a 2-km alongshore region to remove short-scale, noisy variations associated with grid-scale variations that were not well resolved.

\section{Alongshore Current Convergences}

The alongshore varying maximum velocity computed above was used to identify flow convergences (metric 3) and decelerations in the magnitude of flow in the direction of flow movement, indicating locations where the alongshore transport of SRBs would be disrupted and deposition would be more likely (fig. 10). Locations of convergences in the maximum 
Table 2. Nine metrics for hydrodynamic and surface residual ball and sediment mobility and alongshore redistribution in the northern Gulf of Mexico along the Alabama and Florida coast.

[In the file naming convention for associated geographic information system shapefiles, Hh_Dd indicates the individual scenario bin number (fig. 2) and xxx indicates file type extension]

\begin{tabular}{|c|c|c|}
\hline Metric \# & Name and description & File naming convention \\
\hline 1 & Significant wave height & Hh_Dd_wave_height.xxx \\
\hline 2 & $\begin{array}{l}\text { Maximum and median alongshore current in the surf zone, spatially smoothed over } 2 \text { kilome- } \\
\text { ters }(\mathrm{km})\end{array}$ & Hh_Dd_current.xxx \\
\hline 3 & $\begin{array}{l}\text { Locations of alongshore current convergences* in the maximum alongshore current smoothed } \\
\text { over } 2 \mathrm{~km}\end{array}$ & Hh_Dd_conv.xxx \\
\hline 4 & $\begin{array}{l}\text { Locations of alongshore current decelerations in the direction of flow (particles moving with } \\
\text { the flow would encounter decreasing magnitude velocities) in the maximum alongshore } \\
\text { current smoothed over } 2 \mathrm{~km}\end{array}$ & Hh_Dd_decel.xxx \\
\hline 5 & $\begin{array}{l}\text { Sand and SRB mobility ratio of the combined wave-current shear stress to the critical stress } \\
\text { value for high, medium, and low critical stress values }\end{array}$ & Hh_Dd_mobility.xxx \\
\hline 6 & $\begin{array}{l}\text { SRB surf-zone integrated alongshore potential flux, smoothed over } 2 \mathrm{~km} \text {, for high, medium, } \\
\text { and low critical stress values }\end{array}$ & Hh_Dd_potential_flux.xxx \\
\hline 9 & $\begin{array}{l}\text { Tidal mobility, for example, mobility ratio at each of } 24 \text { hourly time steps from a time-series } \\
\text { simulation including tidal current and water level variation. }\end{array}$ & Tidal_mobility_TT.xxx \\
\hline
\end{tabular}

"Not all scenarios have flow convergences. No convergence shapefiles exist for scenarios H3_D6, H4_D5, H4_D12, H4_D13, H5_D4, H5_D5, and H5_D12.

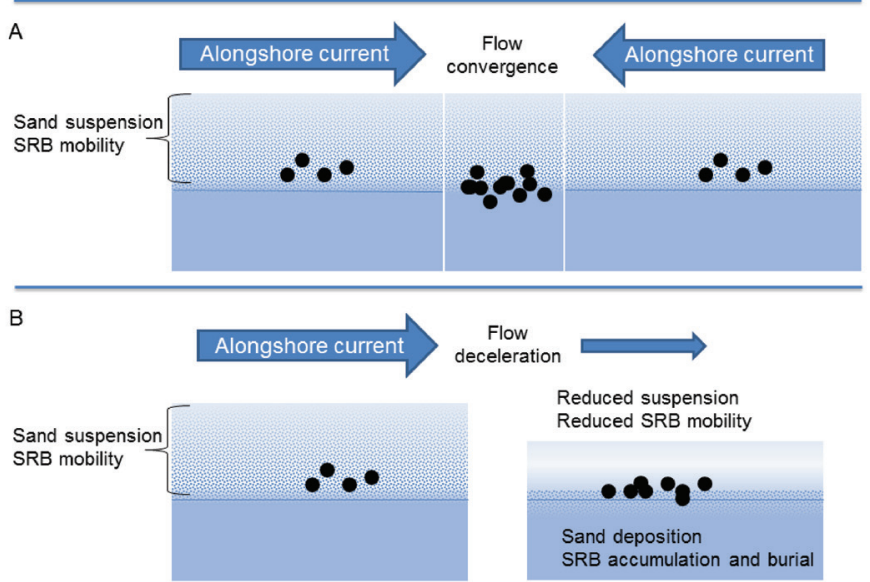

Figure 10. Two mechanisms of increased probability for surface residual ball (SRB) accumulation based on $A$, alongshore flow convergence and $B$, spatially decelerating flows. alongshore current were computed by finding adjacent grid cells where the current velocity transitioned from eastwarddirected (positive alongshore velocity) to westward-directed (negative alongshore velocity). The convergence is always selected as the negative (westward) velocity cell.

\section{Alongshore Current Decelerations}

Spatial decelerations in the direction of flow (metric 4; for example, the flow velocity decreases from one grid cell to the adjacent cell in the direction of flow) were defined using an advective acceleration term, $\frac{\delta u}{\delta y}$, where $u$ is the alongshore current and $y$ is the alongshore grid coordinate. The derivative of $u$ was computed and used to identify locations where the flow decelerated $\left(\frac{\delta u}{\delta y}\right.$ less than $\left.(<) 0\right)$. We identified locations corresponding to peak deceleration (convex points in $\frac{\delta u}{\delta y}$ ) and the magnitude of $u \frac{\delta u}{\delta y}$ at the identified points was also recorded. Note that, for eastward flow ( $u$ greater than $(>) 0$ ), the $u \frac{\delta u}{\delta y}$ deceleration term is negative, whereas for westward flow $(u<0)$, the $u \frac{\delta u}{\delta y}$ deceleration term is positive. 


\section{Sand and SRB Mobility Ratio}

Sand and SRB mobility (metric 5) was assessed by calculating the ratio of the spatially variant maximum combined wave-current bed shear stress $\left(\tau_{\mathrm{wC}}\right)$ for each scenario (appendix 3 ) to the three critical stress values for each representative SRB class. A mobility ratio greater than one indicated critical stress value exceedance and, therefore, particle mobility. Also calculated was the mobility ratio of the local sand-sized sediment. When sand is mobilized, there is the potential for SRB exhumation or burial. The magnitude of the mobility does not indicate distance, direction, or velocity of transport. Movement may consist of rocking back and forth in wave action with no net motion or net cross-shore transport.

\section{SRB Surf-Zone Integrated Alongshore Potential} Flux

To assess alongshore transport patterns, the approach of Soulsby-van Rijn (Soulsby, 1997) was used to develop estimates of SRB combined suspended and bedload potential flux. The Soulsby-van Rijn method accounts for currents, which are the dominant force in alongshore transport, and waves, which contribute a stirring action that keeps particles in motion and allows them to move with current velocities otherwise too weak to support transport. The potential flux was calculated as the mass per second that would be transported across a meter span in the cross-shore. To estimate the total alongshore flux at each alongshore location, the potential flux (in kilograms per meter per second) in each grid cell was multiplied by the cross-shore width of that grid cell to attain the total rate of mass passing through the cell (in kilograms per second). Results from each grid cell in the surf zone at each alongshore location were then added together to attain the total potential rate of mass transfer (in kilograms per second), resulting in an integrated potential flux alongshore the surf-zone (metric 6). The alongshore variant potential flux for each scenario was smoothed with a sliding 2-km Hanning window (Bendat and Piersal, 1971) to remove smaller scale spatial variation not likely to be well resolved by the model.

The Soulsby-van Rijn formulation was developed to estimate flux for a uniform bed of particles of a given size. The actual flux in the case of a mixed bed, such as SRBs mixed in with sand, will be a function of the relative availability of each material. If no SRBs are present, then the flux for the materials in the bed will be 0 . The spatial patterns in the potential flux, however, highlight areas where there are flux convergences and (or) zones of decreasing flux magnitude in the direction of flow, both of which would be more probable areas for SRB deposition. Conversely, flux divergences and (or) zones of increasing flux magnitude in the direction of flow are less likely to accumulate SRBs. The flux sensitivity to the three critical stress values described above (fig. 8) was considered in order to account for potential variability due to exposure above the sea floor.

\section{Weighted Mobility Probability}

In addition to individual scenario results, the results from multiple scenarios were combined to assess persistent patterns in mobility during April 1, 2010, to May 1, 2012. For each scenario, the mobility map was converted to a binary threshold map delineating locations where the critical value for mobility had been exceeded (value $=1$ ) and not exceeded (value $=0$ ). For sand and each SRB class and critical threshold value, an average of this threshold exceedance map was taken, weighted by the scenario probability of occurrence over the 2-year time period considered (appendix 1). The weighted mobility probability (metric 7) varies from 0 to 1 , with values approaching 1 indicating mobility under most wave conditions and values approaching 0 indicating little to no mobility under any wave conditions. The weighted mobility probability is a measure of the probability that SRBs or sand are mobilized and is analogous to the fraction of time at each location that mobility occurred over the time period of interest, whereas the mobility ratio for an individual scenario as previously described, which can be any number greater than or equal to 0 , is the ratio of the stress to the critical threshold value for the single point in time represented by that scenario and must exceed 1 to indicate mobility under the conditions of the scenario.

\section{Weighted Potential Flux}

In addition to the potential flux for each individual scenario, an average surf-zone integrated potential alongshore flux (smoothed over $2 \mathrm{~km}$ in the alongshore direction) was calculated for each SRB class and critical stress threshold from all the scenarios, weighted by scenario probability (metric 8 ). This analysis shows patterns in SRB redistribution over all wave conditions during the 2-year period considered and may thus highlight persistent patterns in SRB alongshore redistribution, assuming that cross-shore processes did not transport SRBs and remove them from the surf zone (either through onshore deposition or loss to the shelf) between individual events.

\section{Tidal Mobility}

The tidal-inlet simulation produces a measure of tidally induced SRB and sand mobility near inlets, referred to as tidal mobility (metric 9). The simulation is based in part on metric 5 (table 2), the mobility ratio, and calculated hourly over a 24-hour tide cycle for scenario H4_D7. The results are output in polygon shapefile format for each of the 24-hour time steps. Appendix 5 includes the time step and shapfile (TT) corresponding to maximum flood and ebb for each inlet in the model domain, and file naming conventions are defined in appendix 4. 


\section{Tidal Inlet Animations}

In addition to tidal mobility metrics (table 2) assessed over the entire model domain for each size class of SRB and sand, animated movies (.avi file format) of the mobility of $2.5-\mathrm{cm} \mathrm{SRBs}$ and sand were created to demonstrate the temporal variation in mobility over the tidal cycle for Pensacola Pass, Fla., Little Lagoon, Ala., and Panama City, Fla. (fig. 1). See appendix 4 for file naming conventions.

\section{Results}

\section{Model Evaluation}

\section{Wave Model}

NDBC directional wave buoy, 42012, (National Data Buoy Center, 2012) off the coast near the Florida-Alabama border, is in 28-m water depth and lies within the OSAT3 model domain (fig. 11). In addition, a wave-resolving acoustic doppler current profiler (ADCP) had been deployed in the project area. We used the observations from the ADCP to evaluate the accuracy of the wave model and to evaluate the suitability of the large-scale wave model to providing boundary conditions for the high-resolution model (K.T. Holland, Naval Research Laboratory, unpub. data, 2012). We evaluated the sensitivity of large-scale model predictions to changes in model resolution at the boundary using the Wavewatch III model results. The output of Wavewatch III 4'-resolution between May 2010 and May 2011 was compared with a validated, high-resolution ( $2^{\prime}$, or about $3.7 \mathrm{~km}$ ) Simulating Waves
Nearshore (SWAN; Booij and others, 1999; Ris and others, 1999) wave hindcast that was run by the USGS Woods Hole Coastal and Marine Science Center and to data from NDBC buoys in the northern Gulf of Mexico (National Data Buoy Center, 2012; fig. 11) over the longer time period of May 2010 to May 2012. Output from the closest grid cell to each buoy was used for model validation. Results from Wavewatch III and SWAN was comparable to data from three NDBC buoys (42012, 42039, and 42040). Specifically, at all three buoys the difference in bias (that is, mean) and root-mean-square (RMS) error in wave height (in meters) and period (in seconds) between the models was less than $0.2 \mathrm{~m}$ (fig. 12; table 3). The overall bias and RMS error, respectively, for the 2-year period were $-0.10 \mathrm{~m}$ and $0.20 \mathrm{~m}$ for significant wave height and $-0.56 \mathrm{~s}$ and $1.28 \mathrm{~s}$ for wave period at buoy 42012 , the closest buoy to the project site. A similar magnitude of error was obtained at two more offshore northern Gulf of Mexico buoys (table 4). This analysis demonstrates that the Wavewatch III model resolves wave conditions sufficiently to provide boundary conditions for the OSAT3 domain, and that accuracy would not be improved by running a higher resolution model to provide boundary conditions.

Timeseries of simulated wave conditions were extracted from the 80 simulation scenarios by comparing the observed wave height and direction at buoy 42040 to the scenario definitions and selecting the best-fit scenario for each hour. Then, simulated wave conditions at each hour were compared to observations from buoy 42012 (fig. 13). This evaluation demonstrates the modeled wave transformation from the offshore boundary to the interior of the OSAT3 model domain. Wave height was predicted well at this location, whereas directions were predicted well for offshore waves propagating at a mean direction from the south, southeast, and southwest,

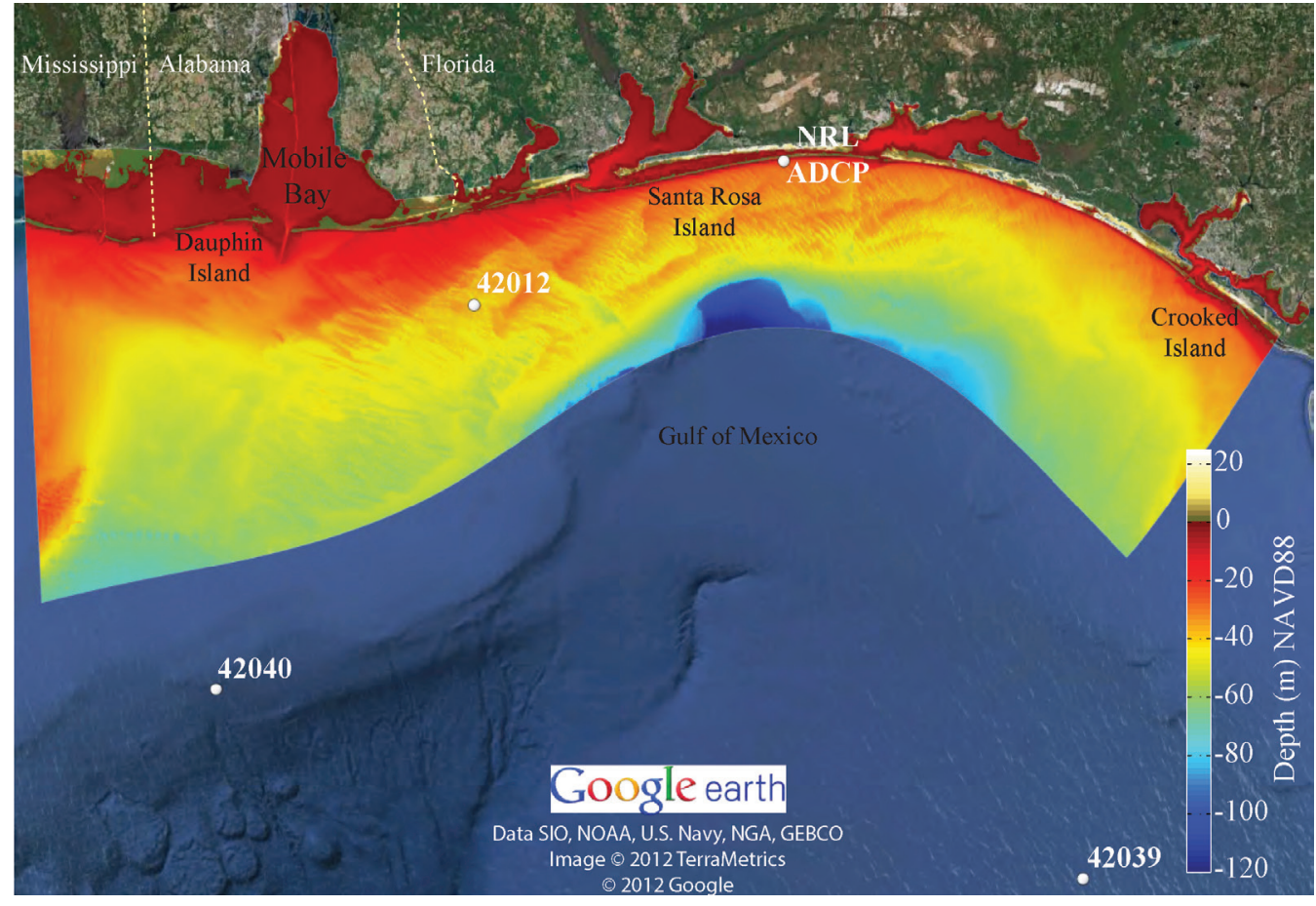

Figure 11. NDBC directional wave buoys $(42012,42039$, and 42040) and a Naval Research Laboratory (NRL) acoustic doppler current profiler (ADCP) used for model evaluation along the Alabama and Florida Gulf coast. 
Figure 12. Comparison of Wavewatch III and SWAN model output to significant wave height and wave period observations at NDBC buoy 42012 between May 1, 2010, and May 1, 2011.
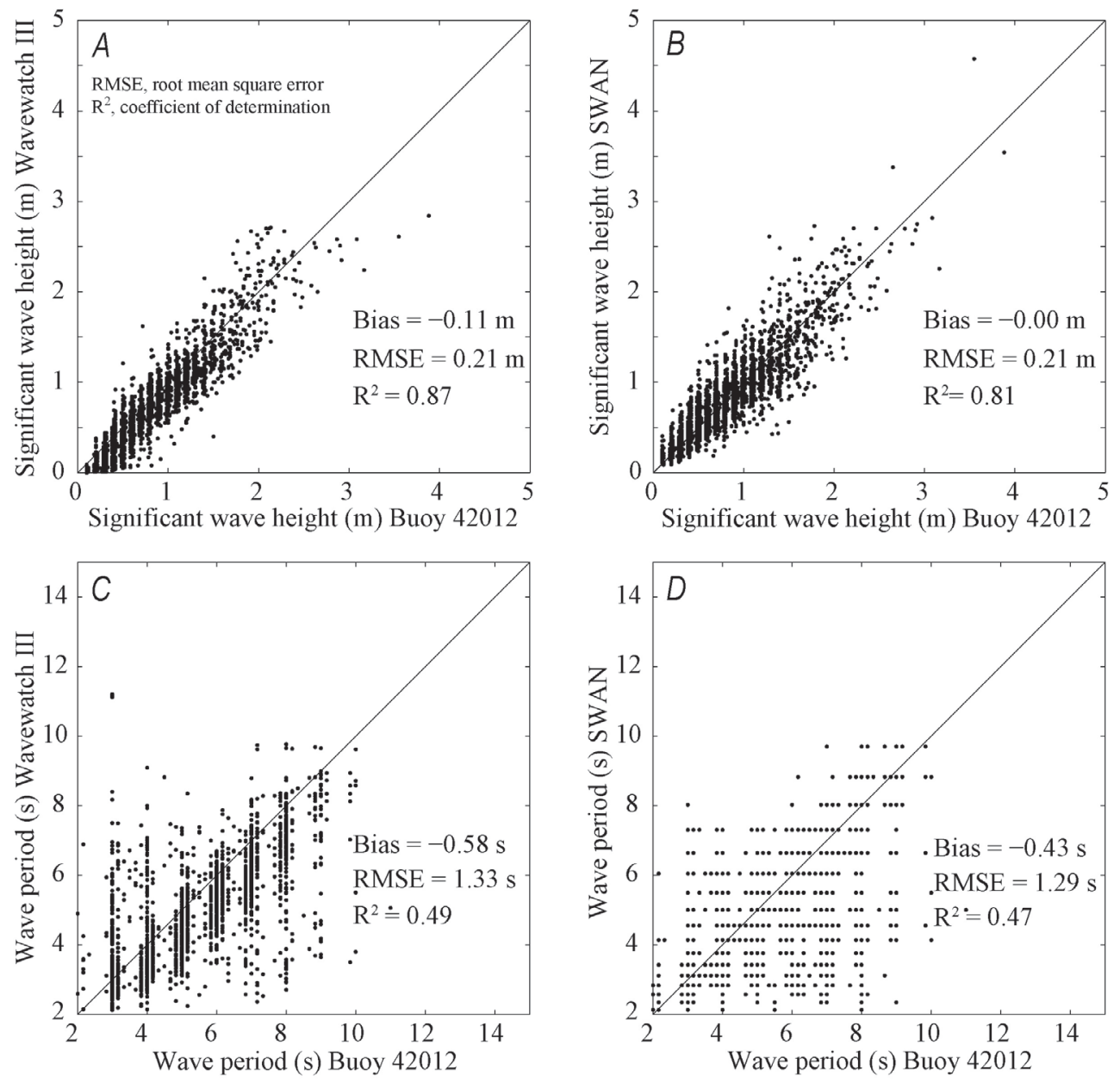

Table 3. Comparison of high resolution SWAN model output to Wavewatch III model output, evaluated against observed buoy data from May 1, 2010, to May 1, 2011.

[m, meters; $\mathrm{R}^{2}$, coefficient of determination; RMSE, root mean square error; s, seconds]

\begin{tabular}{|c|c|c|c|c|c|c|c|}
\hline \multirow{2}{*}{ Buoy } & \multirow{2}{*}{ Depth (m) } & \multicolumn{3}{|c|}{ Significant wave height (m) } & \multicolumn{3}{|c|}{ Peak wave period (s) } \\
\hline & & Bias & RMSE & $\mathbf{R}^{2}$ & Bias & RMSE & $\mathbf{R}^{2}$ \\
\hline \multicolumn{8}{|c|}{ Wavewatch III } \\
\hline 42012 & 27.7 & -0.11 & 0.21 & 0.87 & -0.58 & 1.33 & 0.49 \\
\hline 42040 & 164.6 & -0.02 & 0.22 & 0.88 & -0.68 & 1.32 & 0.46 \\
\hline 42039 & 307 & -0.13 & 0.23 & 0.90 & -0.68 & 1.24 & 0.48 \\
\hline \multicolumn{8}{|c|}{ SWAN } \\
\hline 42012 & 27.7 & 0.00 & 0.21 & 0.81 & -0.43 & 1.29 & 0.47 \\
\hline 42040 & 164.6 & 0.00 & 0.21 & 0.88 & -0.48 & 1.25 & 0.45 \\
\hline 42039 & 307 & -0.07 & 0.20 & 0.90 & -0.53 & 1.21 & 0.47 \\
\hline
\end{tabular}


Table 4. Comparison of Wavewatch III model output to data from three northern Gulf of Mexico offshore NDBC buoys for the 2-year time period of from May 1, 2010, to May 1, 2012.

[m, meters; $\mathrm{R}^{2}$, coefficient of determination; RMSE, root mean square error; s, seconds]

\begin{tabular}{|c|c|c|c|c|c|c|c|}
\hline \multirow{2}{*}{ Buoy } & \multirow{2}{*}{ Depth (m) } & \multicolumn{3}{|c|}{ Significant wave height (m) } & \multicolumn{3}{|c|}{ Peak wave period (s) } \\
\hline & & Bias & RMSE & $\mathbf{R}^{2}$ & Bias & RMSE & $\mathbf{R}^{2}$ \\
\hline 42012 & 27.7 & -0.10 & 0.20 & 0.86 & -0.56 & 1.28 & 0.49 \\
\hline 42040 & 164.6 & -0.02 & 0.21 & 0.90 & -0.61 & 1.25 & 0.50 \\
\hline 42039 & 307 & -0.13 & 0.23 & 0.91 & -0.72 & 1.29 & 0.46 \\
\hline
\end{tabular}

$A$

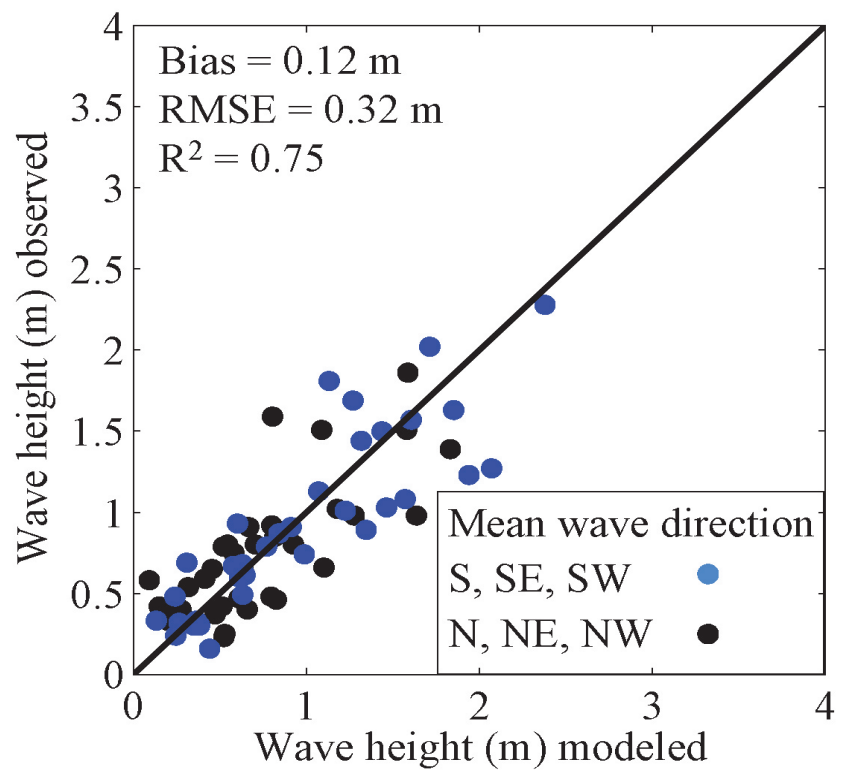

$B$

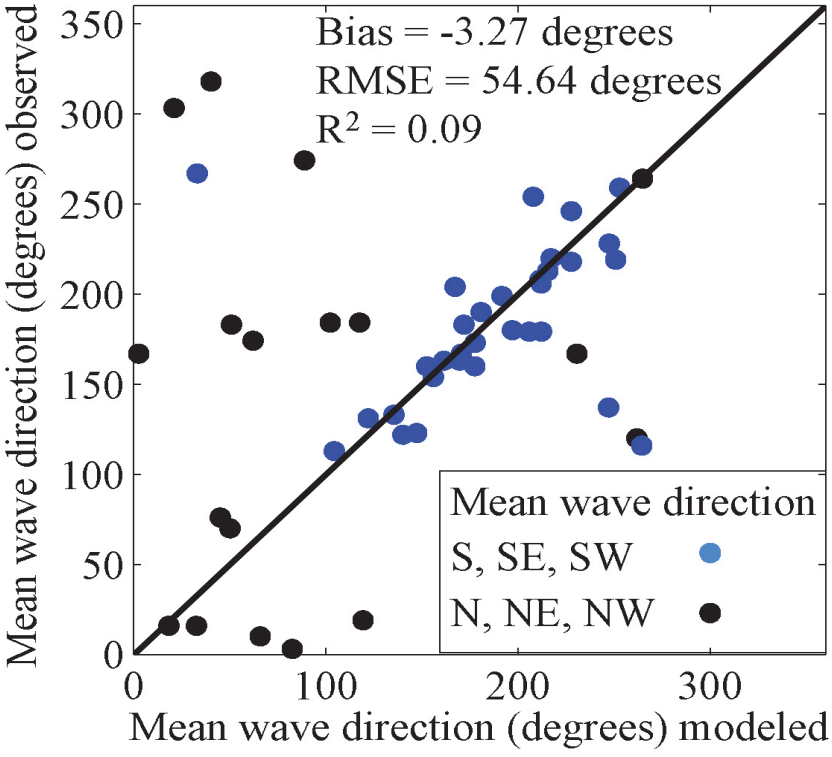

Figure 13. Model predictions of $A$, wave height and $B$, wave direction from the 80 scenarios compared with observations at NDBC buoy 42012 in the northern Gulf of Mexico alongshore Alabama and Florida. Shown are scenarios when mean offshore wave direction (buoy 42040) was from the southeast, south, and southwest (wave direction bins D5-D12; fig. 2) and from northwest, north, and northeast (wave direction bins D1-D4 and D13-D16; fig. 2). The error statistics correspond to modeled waves for D5-D12 scenarios.

but poorly for waves from the north. We note that northern waves observed at the offshore buoy (42040) and buoy 42012 in about 30-m water depth usually correspond to small wave events along the coast of the northern Gulf of Mexico, which result in weak alongshore currents and therefore weak mobility or transport. These events also have a low probability of occurrence.

Finally, wave model predictions at Santa Rosa Island, Fla., for the winter time series (January 15-25, 2007) were compared with data collected by researchers at the Naval Research Laboratory (K.T. Holland, Naval Research Laboratory, unpub. data, 2012) for the same time period by an ADCP in approximately $12-\mathrm{m}$ water depth. The comparison (fig. 14) shows that wave height was predicted within acceptable tolerance (0.24-m bias error and 0.31-m RMS error).
Models of wave direction and periods produced a $27^{\circ}$ and -1 -s, respectively, bias error and $14^{\circ}$ and 1 -s RMS error, respectively. Largest errors in wave period and direction corresponded to the lowest wave heights (less than $0.5 \mathrm{~m}$ ); these errors would have little impact on alongshore current or mobility calculation errors. The modeled peak period compares well with the observed mean period (fig. 14A-C).

\section{Tide and Storm Simulations}

NOAA operates tide stations at Dauphin Island, Pensacola Bay, and Panama City (National Oceanic and Atmospheric Administration, 2012). Observations from the permanent tide stations were used to evaluate the accuracy of water level predictions along the coast and into the bays 

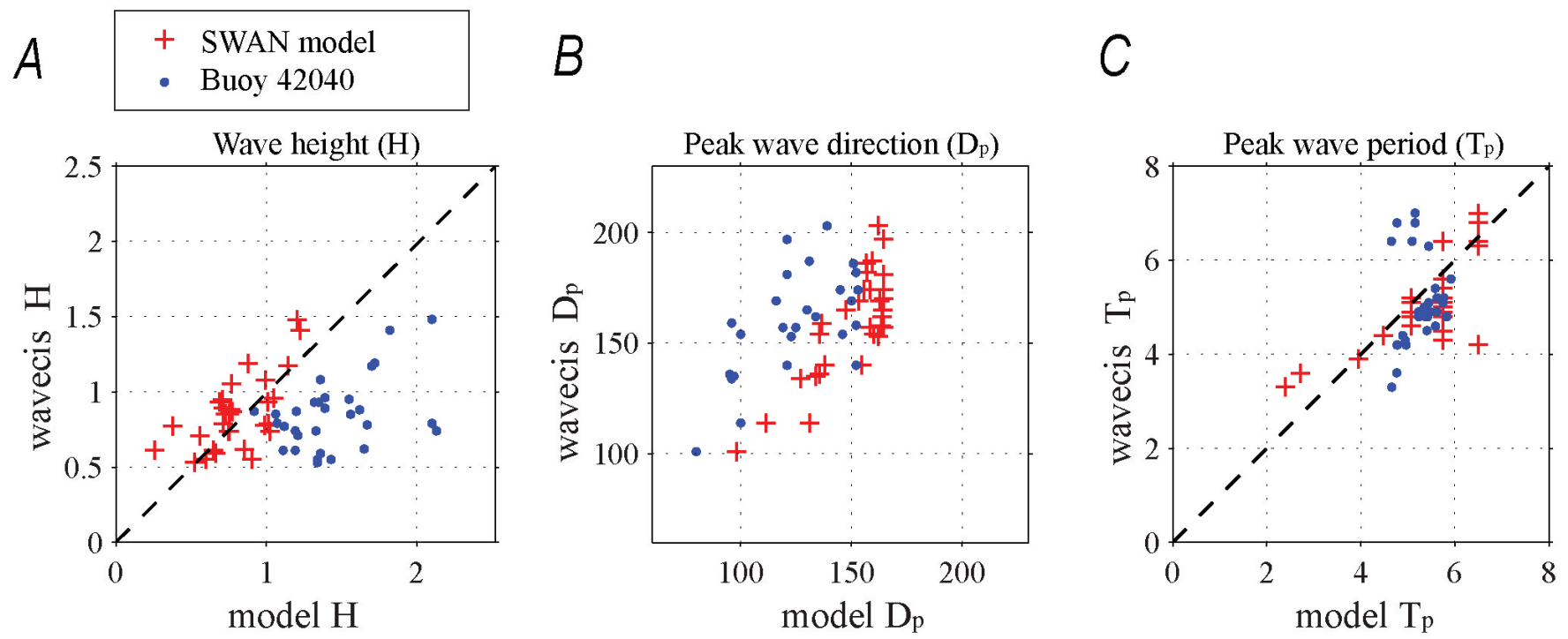

Figure 14. Model predictions of $A$, wave height $(\mathrm{H}), B$, peak wave direction (Dp), and $C$, peak wave period (Tp) in the northern Gulf of Mexico alongshore Alabama and Florida for January 15-25, 2007, compared with observations (wavecis) from a Naval Research Laboratory acoustic doppler current profiler at Santa Rosa Island, Florida. To demonstrate the accuracy of the model, we show the values from NDBC buoy 42040 offshore in the northern Gulf of Mexico as an alternative model for predicting nearshore values. Only cases where the measured nearshore wave height exceeded 0.5 meter are shown.

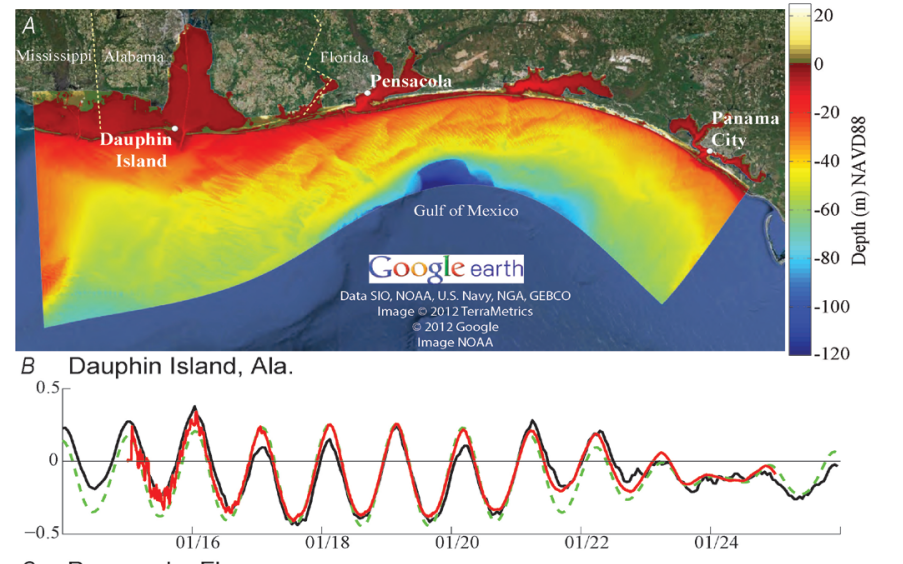

C Pensacola, Fla.
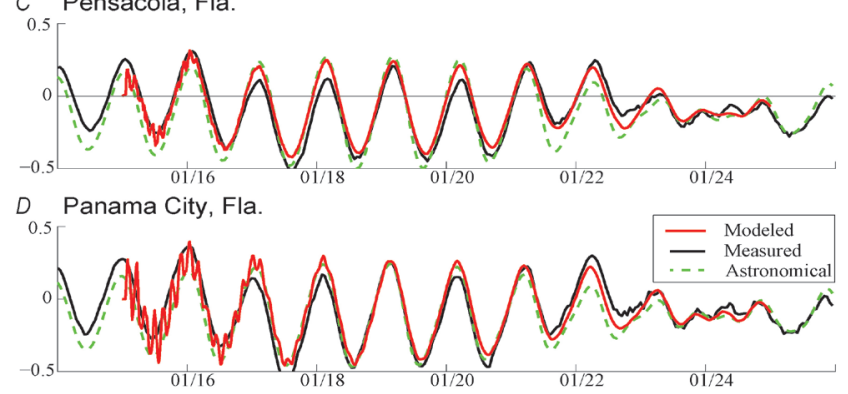

Figure 15. Evaluation of accuracy of simulated (modeled) water levels (in meters) against NOAA tidal measurements at $A$, three coastal inlet tide stations at $B$, Dauphin Island, Ala., $C$, Pensacola Pass, Fla., and $D$, Panama City Inlet, Fla. Astronomical water level predictions are also shown. The model predictions include some noise in the initial spinup of the flow simulations, which disappears after a few tidal cycles. within the project site for time-series simulations. We evaluated the accuracy of the tidal model using data from the tide stations for the January 15-25, 2007, time-series simulation. The comparison indicates minimal errors in both phase and amplitude at all locations (fig. 15).

The approach and landfall of Hurricane Isaac in late August 2012 was used to evaluate simulation accuracy under more extreme weather conditions. Wave characteristics and water level predictions were compared with waves measured at buoy 42012 (National Data Bouy Center, 2012) and to water level at the three NOAA tidal stations (National Oceanic and Atmospheric Administration, 2012; fig. 15). Wave height during the peak of the storm was slightly underpredicted, but predictions for mean wave direction and period showed reasonable approximations (fig. 16). It is not unusual for wind models to incorrectly predict the intensity of tropical storms (Rogers and others, 2006) and therefore lead to errors in modeled wave heights. The water level predictions underestimated water level observations at all locations (fig. 17). Our simulations relied on the large-scale models for adequate boundary conditions. We experimented with several different large-scale models to supply water level boundary conditions for the OSAT3 domain and determined that none of the alternate models offered improved accuracy compared with the others. The results here use HYCOM for large-scale water level boundary conditions at the OSAT3 model boundaries. Errors between the model and observations may reflect errors in the large-scale model predictions that provided boundary conditions to our simulations or shortcomings in the model implementation. The predictions were substantially improved compared with a simple astronomical prediction and captured 
A Significant wave height in meters (m)

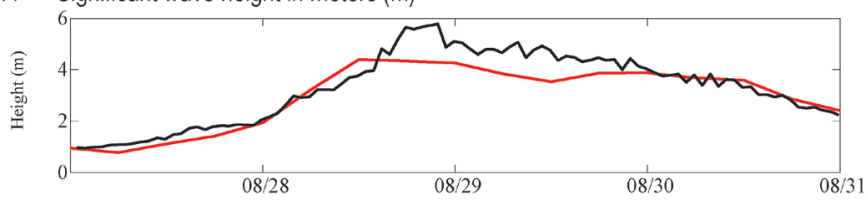

B Mean wave direction in degrees (deg)

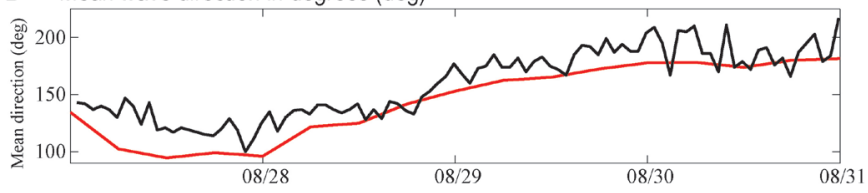

C Mean wave period in seconds (s)

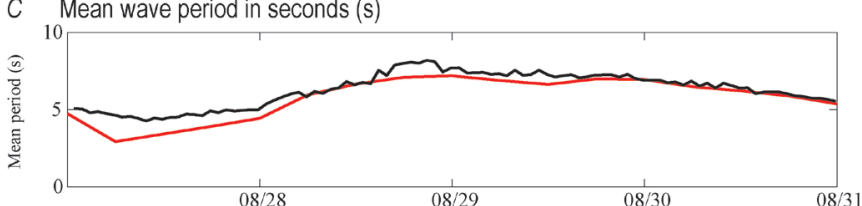

Figure 16. Simulated and measured wave characteristics at buoy 42012 (fig. 11) in the northern Gulf of Mexico alongshore Alabama and Florida during Hurricane Isaac in August 2012. Characteristics include $A$, significant wave height, $B$, mean wave direction, and $C$, mean wave period.

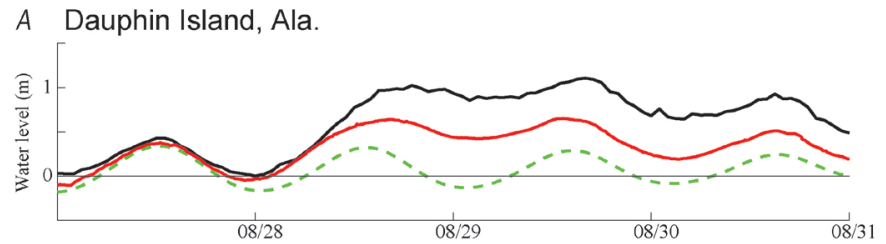

B Penscacola, Fla.
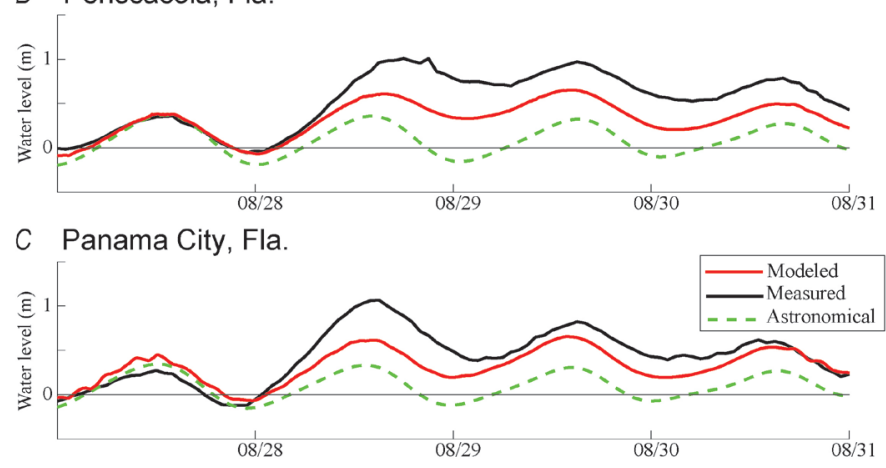

Figure 17. Simulation of water levels (in meters) in the northern Gulf of Mexico alongshore Alabama and Florida during Hurricane Isaac in August 2012 compared with measured water level at the NOAA tide stations at $A$, Dauphin Island, Ala., $B$, Pensacola, Fla., and $C$, Panama City, Fla. tide stations (fig. 15A) and to astronomical tide predictions. the relevant dynamics associated with Hurricane Isaac's approach and landfall to the west of the area of interest.

\section{Scenario Simulation Results}

Results of the modeling simulations were exported from the irregular model grid as point and polygon shapefiles and are available in the digital release of this report. Alongshore patterns in currents, mobility, and potential flux varied significantly among the 80 scenarios, depending on the wave height and angle of approach and the amount of alongshore variability in the incoming wave field; variability in mobility around the inlets was noted over a tidal cycle.

\section{Scenario Analysis}

Figures 18 through 21 illustrate hydrodynamic analyses (table 2, metrics 1 to 4) from two scenarios, H3_D6 and H3_D8 (fig. 2). The selected scenarios present an offshore wave height of 1 to $1.5 \mathrm{~m}$ but from slightly different wind directions, southeast and south-southeast, respectively. Significant wave height (metric 1) barely reaches $0.75 \mathrm{~m}$ near the coast with the southeast winds (scenario H3_D6; fig. 18A), but significant wave height exceeds $1 \mathrm{~m}$ with the south-southeast winds (H3 D8; fig. 18B). Maximum alongshore velocity (metric 2) is westward under scenario H3_D6 (fig. 19A) and mixed east and west under scenario H3_D8 (fig. 19B). Flow convergence (metric 3; meters per second, $\mathrm{m} / \mathrm{s}$ ) is absent under scenario H3_D6 (fig. 20A) but occurs at several different locations in scenario H3_D8 with the southsoutheast wind (fig. 20B). Flow deceleration (metric 4; meters per second squared, $\mathrm{m} / \mathrm{s}^{2}$ ) of varying magnitude and direction occurred under both scenarios (fig. 21). For scenario H3 D8 (figs. $20 B$ and $21 B$ ), a combination of south-southeast waves, offshore features, and orientation of the coast produced numerous flow decelerations and reversals. Under scenario H3_D6 (figs. 20 $A$ and 21 $A$ ), numerous alongshore convergences and spatial decelerations can affect the potential accumulation, burial, and removal of SRBs. The scenarios, while similar in originating wave energy and only $40^{\circ}$ different in offshore wave angle, indicate that the movement of SRBs caused by alongshore flows is dependent on the specific wave conditions (for example, a specific time period of interest) and, potentially, the sequence of wave conditions over time that may allow SRBs to be transported from one area of accumulation to another.

The potential for movement of SRBs was assessed by calculating the mobility as represented by the ratio (table 2 , metric 5) of the $\tau_{\mathrm{wC}}$ for each scenario to the critical stress of incipient motion for each representative SRB class, with a mobility greater than 1 indicating that the threshold for mobility was exceeded (SRB and sand mobility section). For the H3_D6 scenario shown in figure $22 \mathrm{~A}$, with offshore waves between 1 and $1.5 \mathrm{~m}$, the mobility threshold of $2.5-\mathrm{cm} \mathrm{SRBs} \mathrm{is} \mathrm{only}$ exceeded at isolated patches in the surf zone. In contrast, when 
Figure 18. Significant wave height (table 2, metric 1) for scenarios $A, \mathrm{H} 3$ _D6 and $B, \mathrm{H} 3$ _ D8 (fig. 2) in the northern Gulf of Mexico alongshore Alabama and Florida. Nearshore wave height in each scenario originated with 1- to 1.5-meter (m)-high waves at National Oceanic and Atmospheric Administration buoy 42040 , but with southeasterly and southsoutheasterly wind directions, respectively.

Figure 19. Maximum alongshore velocity (table 2, metric 2) smoothed over a 2-kilometer length scale for scenarios $A, \mathrm{H} 3$ _D6 and $B, \mathrm{H} 3$ _ D8 (fig. 2) in the northern Gulf of Mexico alongshore Alabama and Florida. Green and red arrows indicate eastward- and westward-directed flows, respectively. Flow is to the west throughout the domain in $A$, whereas there are mixed flow directions in $B$.
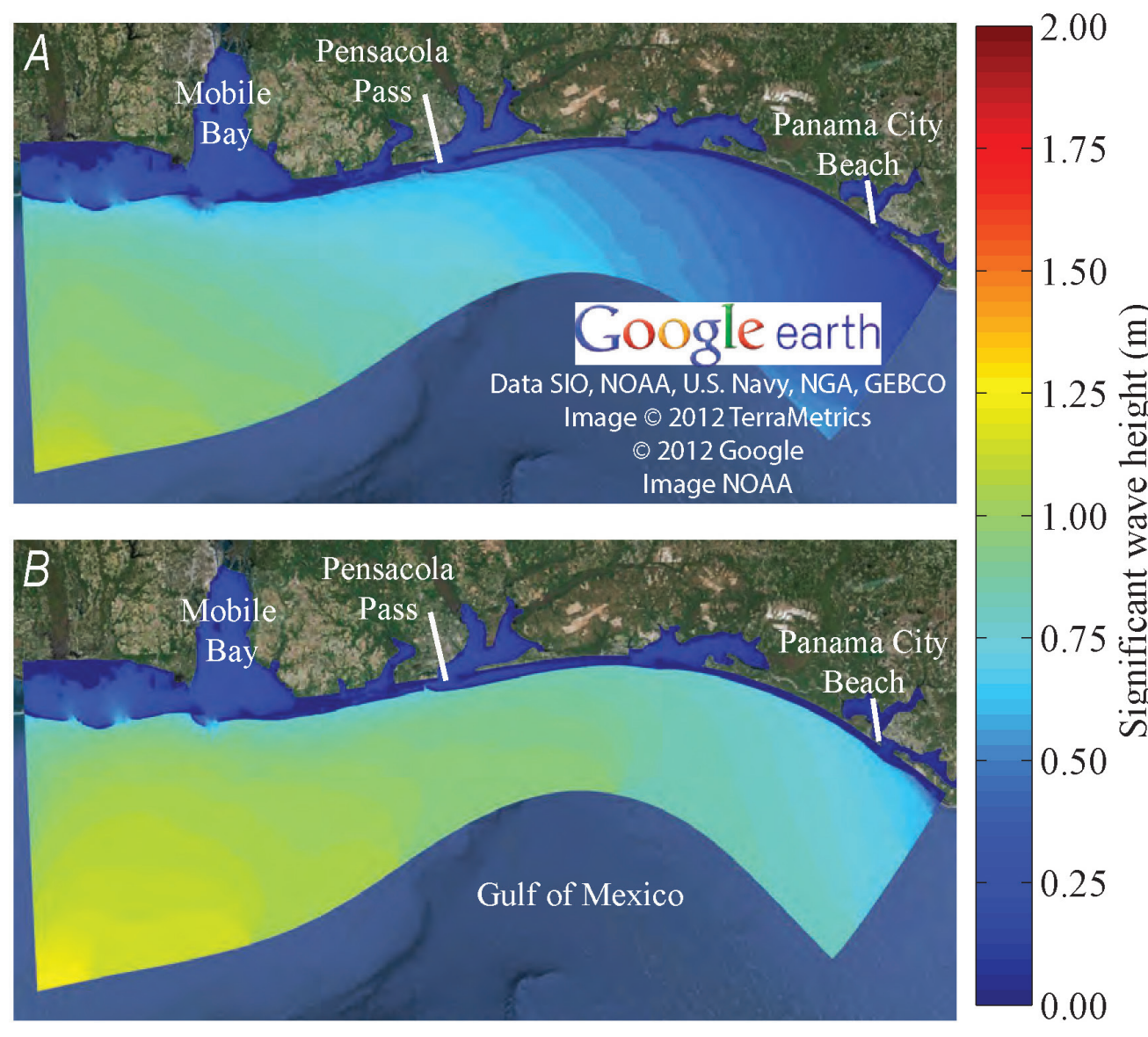

East
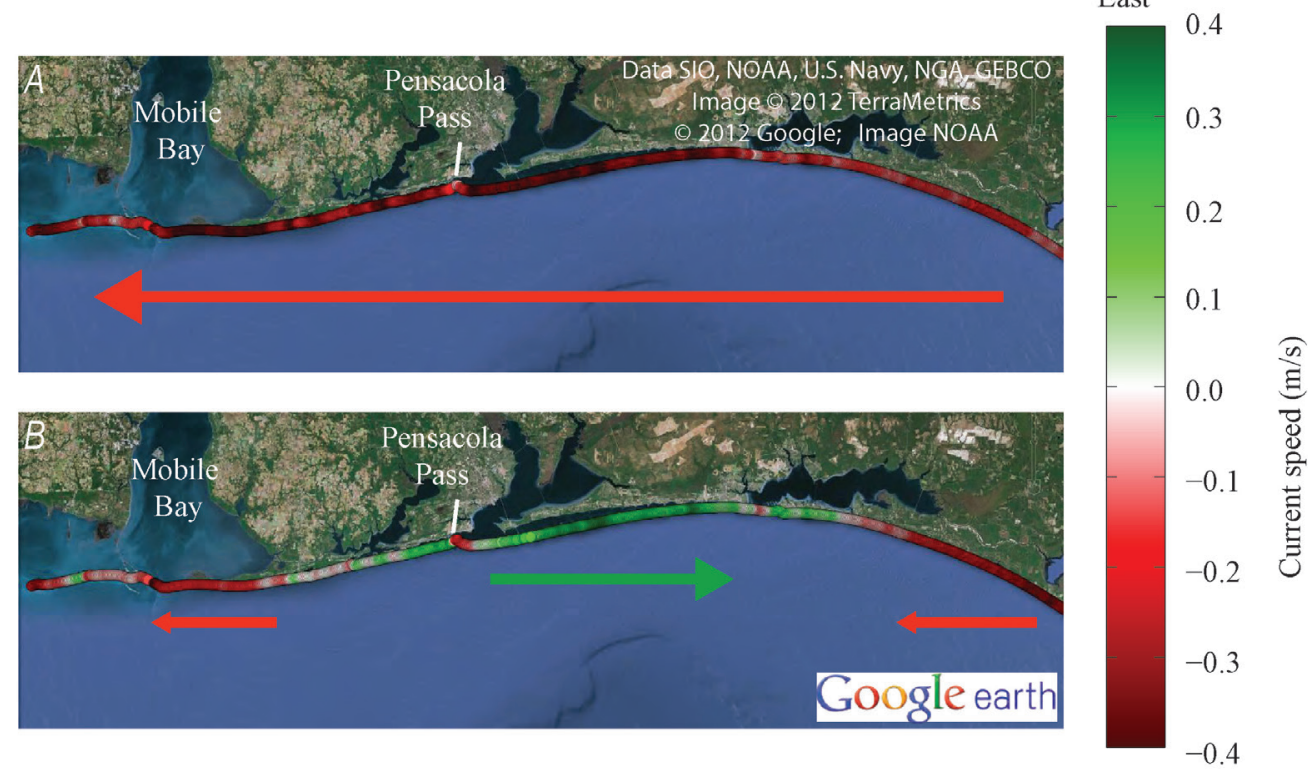

West 

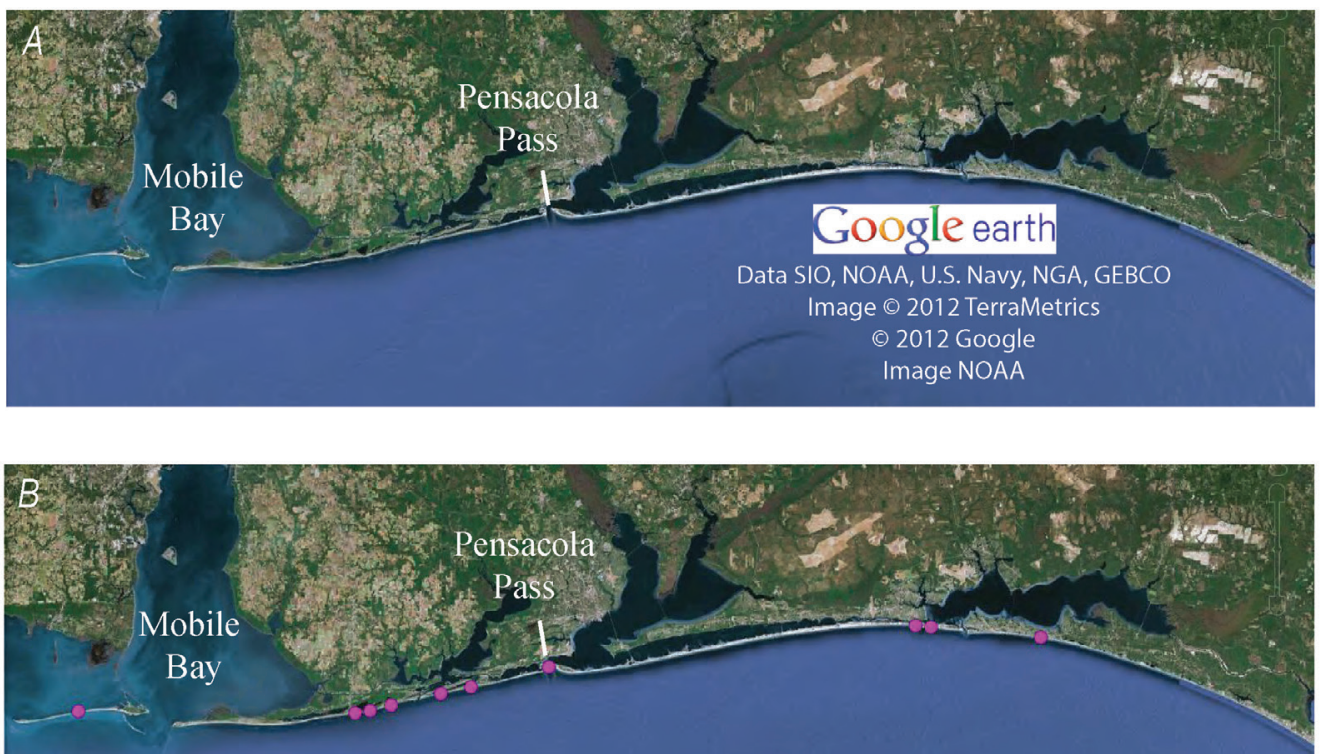

Convergence location
Figure 20. Flow convergence (table 2, metric 3 ) for scenarios $A, \mathrm{H} 3 \_\mathrm{D} 6$ and $B, \mathrm{H} 3 \_\mathrm{D} 8$ (fig. 2) in the northern Gulf of Mexico alongshore Alabama and Florida. Flow reversals are absent in $A$, whereas several flow reversals were identified in $B$ and correspond to color changes in fig. 19B.

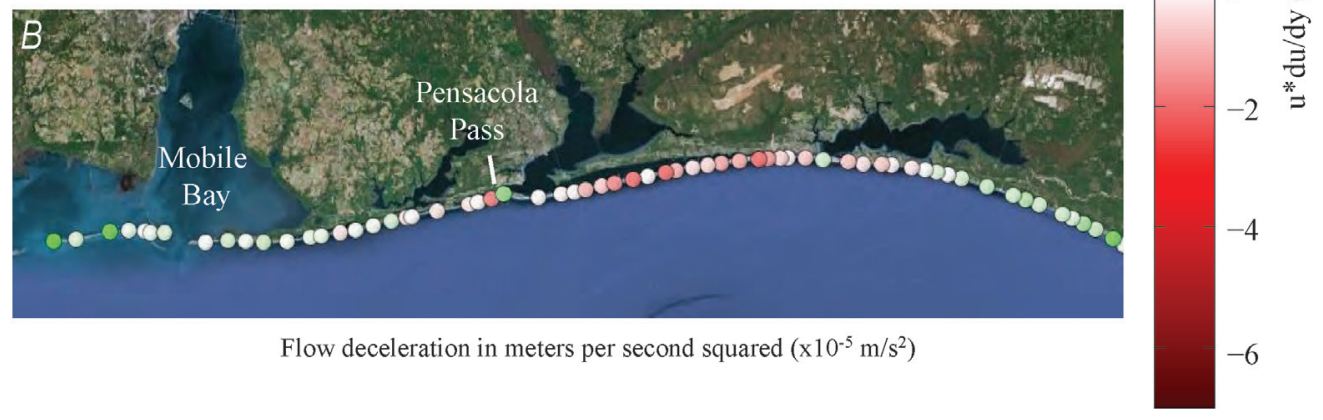

Figure 21. Flow deceleration (table 2, metric 4; as change, delta, $d$, meters per second squared, $\left.\mathrm{m} / \mathrm{s}^{2}\right)$ for scenarios $A, \mathrm{H} 3 \mathrm{D} 6$ and $B, \mathrm{H} 3$ D8 (fig. 2) in the northern Gulf of Mexico alongshore Alabama and Florida. Spatial decelerations of varying magnitudes are found in both scenarios. 
Fiugre 22. Mobility ratio (table 2, metric 5) in the northern Gulf of Mexico alongshore Alabama and Florida for a midlevel threshold of 2.5-centimeter surface residual balls (SRBs; table 1) for scenarios $A, \mathrm{H} 3$ D6 6 and $B, \mathrm{H} 4$ _D6 (fig. 2). Areas with a mobility ratio of 1 (in pink) indicate where the mobility threshold was exceeded. Whereas the mobility threshold is exceeded only in small sections in very shallow water in $A$, the large wave heights result in mobility along the coast as well as over shallow bar and ebb tidal delta features in $B$.

Figure 23. Mobility ratio (table 2, metric 5) in the northern Gulf of Mexico alongshore Alabama and Florida for sand for scenarios $A, \mathrm{H} 3 \_\mathrm{D} 6$ and $B, \mathrm{H} 4$ _D6 (fig. 2). Areas with a mobility ratio of 1 (in pink) indicate where the mobility threshold was exceeded. Compared with 2.5-centimeter surface residual balls (SRBs; fig. 22), sand is mobile over a large portion of the domain in both scenarios, yielding the potential for exhumation and burial of SRBs in regions where the SRBs themselves are immobile.
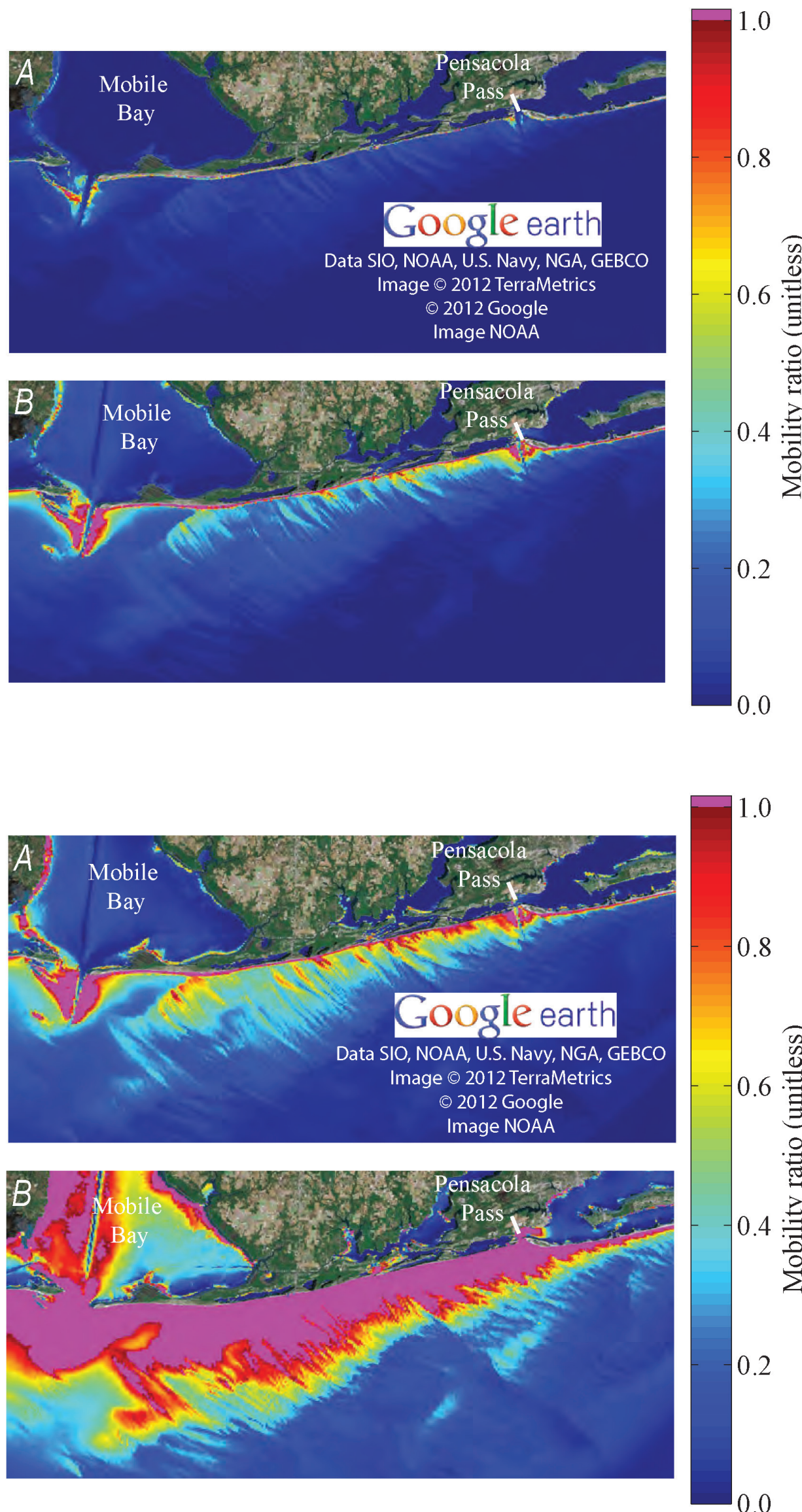
the waves come from the same direction but the wave height increases to between 1.5 and $2 \mathrm{~m}$, the mobility threshold of $2.5-\mathrm{cm}$ SRBs is exceeded in a narrow band along the coastline and over shallow bar features (fig. 22B). In comparison, sand is mobilized under a significantly larger portion of the domain for both scenarios (fig. 23), with an associated potential for SRB exhumation or burial. In the case of northerly wind and wave scenarios (H5_D1), significant mobility may be found in some locations along the bay side of barrier islands (fig. 24).

The surf-zone integrated potential alongshore SRB flux (smoothed over $2 \mathrm{~km}$ ) for each scenario and SRB class was calculated as described in the Methods section (table 2, metric 6; kilograms per second, $\mathrm{kg} / \mathrm{s}$ ). High, medium, and low critical stress estimates were analyzed to quantify the uncertainty in the potential flux estimates due to SRB exposure above the sea floor. Values less than 0 indicate transport to the west, values greater than 0 indicate transport to the east, values equal to 0 indicate no potential transport. Because of the limited mobility in scenario H3_D6 (fig. 25A), the potential flux is virtually 0 , whereas for H4_D6 (fig. 25B), there are areas of potential flux (table 2, metric 6) throughout the domain for the model. The potential flux may be used to estimate likely spatial patterns in SRB redistribution; for example, in the illustrated scenario, $2.5-\mathrm{cm}$ SRBs are more likely to be deposited where the magnitude of the westward potential flux decreases (fig. $25 B$ detail).

\section{SRB and Sand Weighted Mobility Probability and Potential Flux}

The weighted mobility probability for SRB class 4 (fig. 26), calculated as described in Methods (table 2, metric 7), varied from 0 to 1 , with values approaching 1 indicating that the mobility threshold was likely to be exceeded under most wave conditions, and values approaching 0 indicating mobility was unlikely under most conditions. Weighted mobility, which is the probability of mobility threshold exceedance, is analogous to the fraction of time an SRB of this size class is mobile. The variability between high, medium, and low mobility estimates provide a measure of the uncertainty in SRB mobility due to uncertainty in the estimation of critical stress thresholds. Alongshore Alabama and Florida on the northern Gulf of Mexico, 2.5-cm SRBs that are flush to the bed (highest estimate of critical stress among samples analysed; fig. 26A) are rarely mobilized, whereas SRBs more exposed to the flow field (lowest estimate of critical stress; fig. 26B) have a probability of mobilization of 0.6 , corresponding to mobility approximately 60 percent of the time.

The weighted surf-zone integrated potential flux (table 2, metric $8 ; \mathrm{kg} / \mathrm{s}$ ) is a measure of the long-term patterns in probable SRB movement. There is a convergence in the weighted potential flux of $2.5-\mathrm{cm}$ SRBs around Pensacola Pass, indicating SRBs of this size are likely to accumulate at this location (fig. 27).

\section{Tidal-Inlet Time-Series Results}

The analysis of SRB and sediment mobility over a 24-hour period illustrates variability as a result of the tidal cycle. The variation in SRB mobility that can occur between ebb and flood near a coastal inlet can potentially lead to increased probability of SRB deposition within the lagoon over the tidal cycle (table 2, metric 9; fig. 28). The variation over the tidal cycle in mobility of sand and $2.5-\mathrm{cm}$ SRBs can also be observed in animations, which are included in the digital release of this report, for the inlets at Pensacola Pass, Little Lagoon, and Panama City.

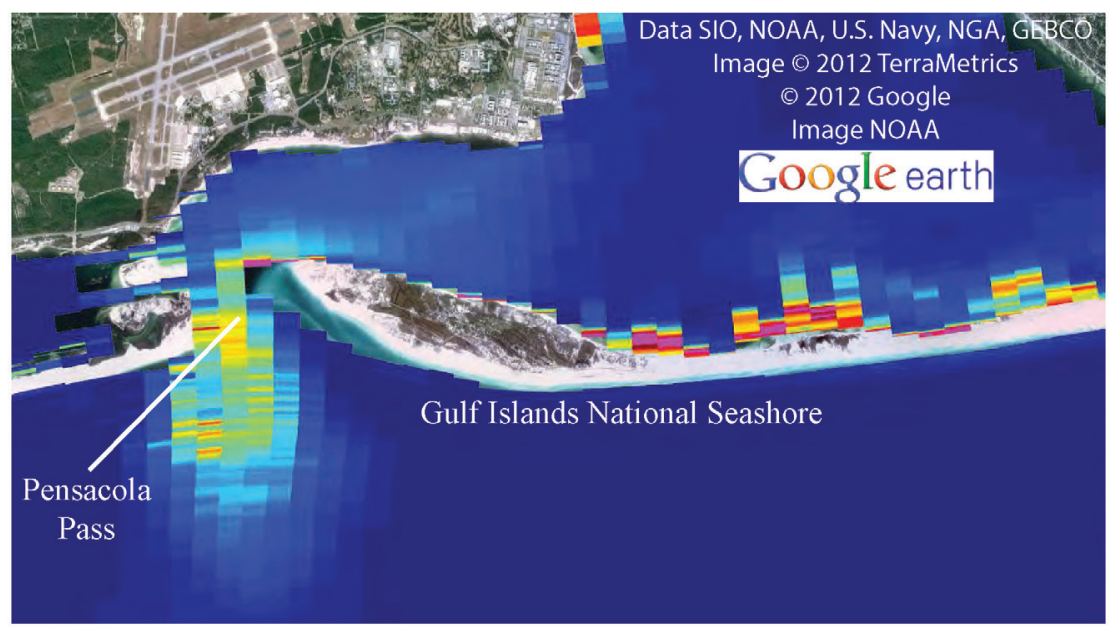

Figure 24. Mobility ratio (table 2 , metric 5) in the northern Gulf of Mexico alongshore Alabama and Florida for a midlevel threshold of C 2.5-centimeter $(\mathrm{cm})$ surface residual balls (SRBs; table 1) along the Gulf Islands National Seashore (east of Pensacola Pass, Florida) for wave scenario H5_D1, corresponding to waves observed at NDBC buoy 42040 of height greater than 2 meters and coming from a north-northeasterly direction (fig. 2). Where the mobility ratio exceeded 1 (in pink) mobility of $2.5-\mathrm{cm}$ SRBs was indicated at locations along the back-barrier from northerly wind-waves locally generated behind the barrier. 
Figure 25. Surf-zone integrated alongshore potential flux smoothed over 2 kilometers (table 2, metric 6) for 2.5-centimeter surface residual balls (SRBs; table 1) in the northern Gulf of Mexico alongshore Alabama and Florida for scenarios $A, \mathrm{H} 3$ _D6 and $B, \mathrm{H} 4 \_\mathrm{D} 6$. Because of the limited mobility in $A$ (fig. 23), there is virtually no potential flux, whereas there is westward potential flux throughout the domain in $B$. Areas where the magnitude of the flow decreases ( $B$, inset) are more likely areas of SRB deposition.

Figurre 26. Weighted mobility probability (table 2, metric 7) from April 2010 to May 2012 along the Gulf Islands National Seashore (east of Pensacola Pass, Fla.) for 2.5-centimeter surface residual balls (SRBs). Shown is an estimate using $A$, the highest estimate of critical stress, appropriate for SRBs flush with the seabed, and $B$, the lowest estimate of critical stress, appropriate for SRBs sitting atop the seabed.
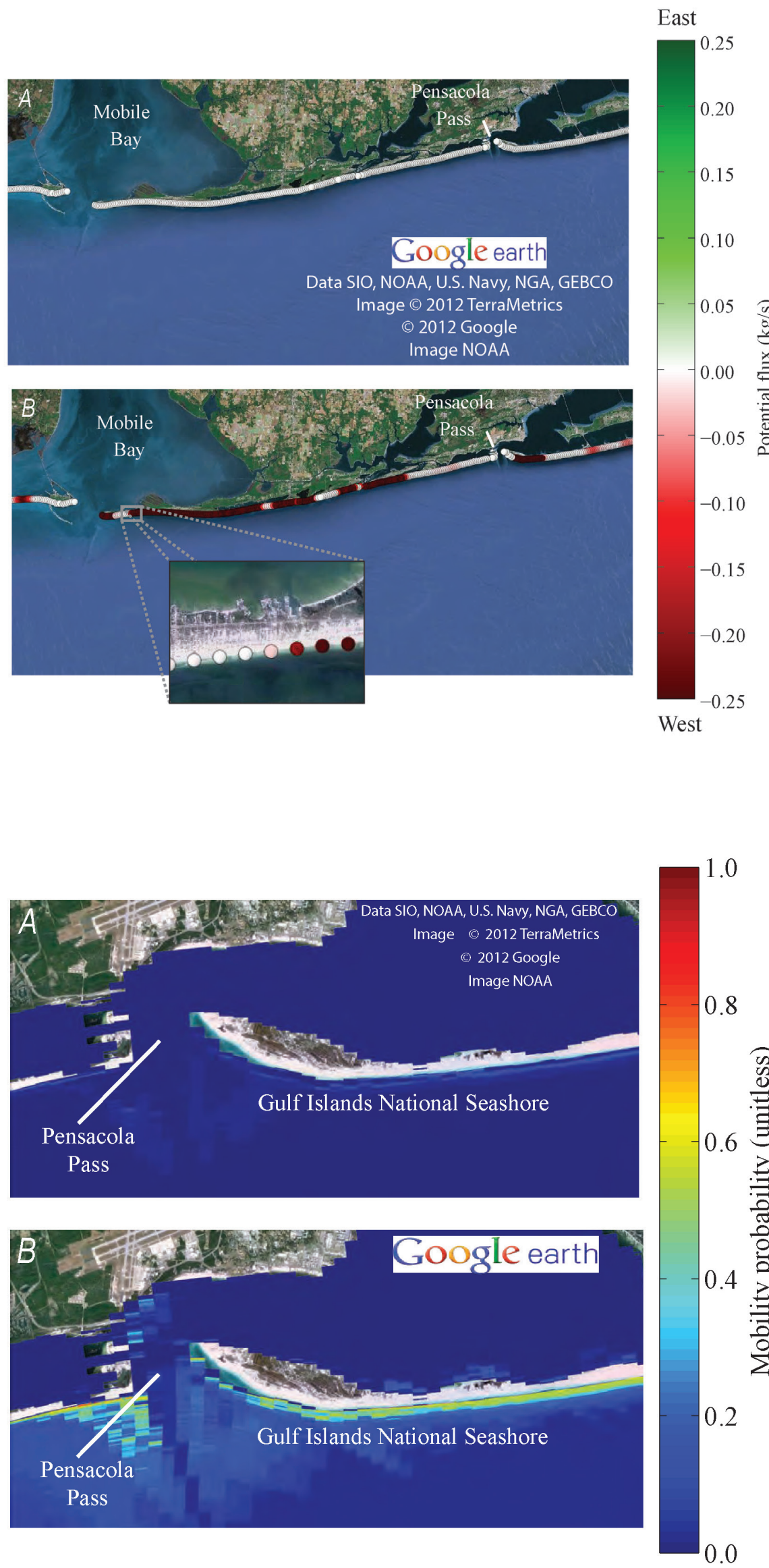

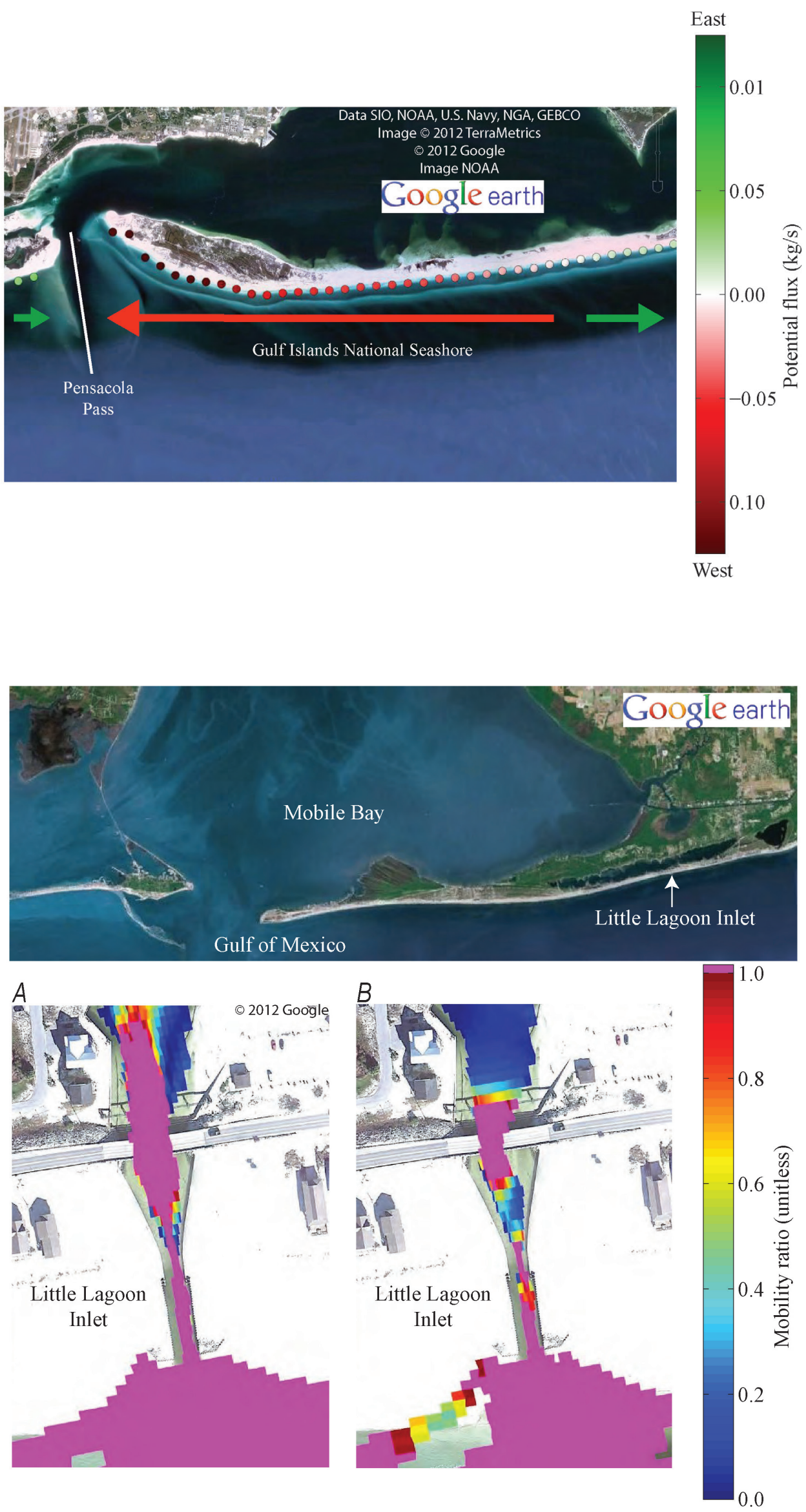

Figure 27. Weighted surf-zone integrated alongshore potential flux (table 2, metric 8), indicating the average potential flux in the northern Gulf of Mexico alongshore Alabama and Florida from April 2010 to May 2012 for 2.5-centimeter surface residual balls (SRBs; table 1) using a midrange estimate of critical stress. There is a convergence in the probable flux at Pensacola Pass, Fla., and divergence toward the east of Pensacola Pass.
Figure 28. Tidal inlet surface residual ball (SRB) mobility (table 2, metric 9) at $A$, maximum flood and $B$, maximum ebb for 2.5-centimeter SRBs (table 1) using a low critical threshold at Little Lagoon Inlet, Ala. (fig. 1). Areas where the mobility ratio is 1 (in pink) indicate that the critical threshold for SRB mobility is exceeded. The greater extent of tidal inlet SRB mobility during flood increases the probability that SRBs brought in by the tide will remain trapped. Local surficial sediment is mobilized throughout the illustrated domain during both flood and ebb tide, leading to potential for burial and exposure of SRBs. 


\section{Discussion}

\section{Implications of Results for Understanding SRB Formation, Burial, Exhumation, and Transport}

The results of the numerical modeling allow specific conclusions to be drawn for a given time period of interest based on the scenario or on scenario-averaged results that indicate patterns in alongshore currents and their gradients, sediment and SRB mobility and potential transport, gradients, and complexities associated with tidal inlets under specific conditions. The results can be used to address many detailed questions; in this section, we identify and discuss some general findings that directly address the objectives of the OSAT3 subgroup.

\section{Alongshore-Currents and Gradients in Transport}

A primary objective of the OSAT3 subgroup effort was to identify regions of varying alongshore current speeds and directions, resulting in areas of persistent convergence and divergence of alongshore currents and, by inference, the deposition of SRBs. A striking example of convergence was detected in the model at Pensacola Pass where, because of the bend in the shoreline, alongshore flows and therefore potential SRB flux were directed toward the inlet (fig. 29). In this situation, SRBs occurring nearshore would be transported toward the inlet. This situation could lead to an increase in the complexity of SRB transport because waves, alongshore flows, and tidal currents would all interact with the sediment and SRBs.

\section{Inlet Dynamics}

Inlet dynamics are complicated because they respond strongly to tidal- and storm surge-driven currents that affect both the inlet interior and open coast. These flows interact with a variety of morphological features including the sand spits at the inlet, ebb and flood delta shoals, sandbars and sand flats inside the inlet, and surf zone bars extending along the inlet spits (fig. 30). The interaction of morphology and tidal flow typically produces asymmetries in flow patterns that consist of strong flood tides in the channel, strong currents along the shoreline entering the inlet, and ebb flow jets that are
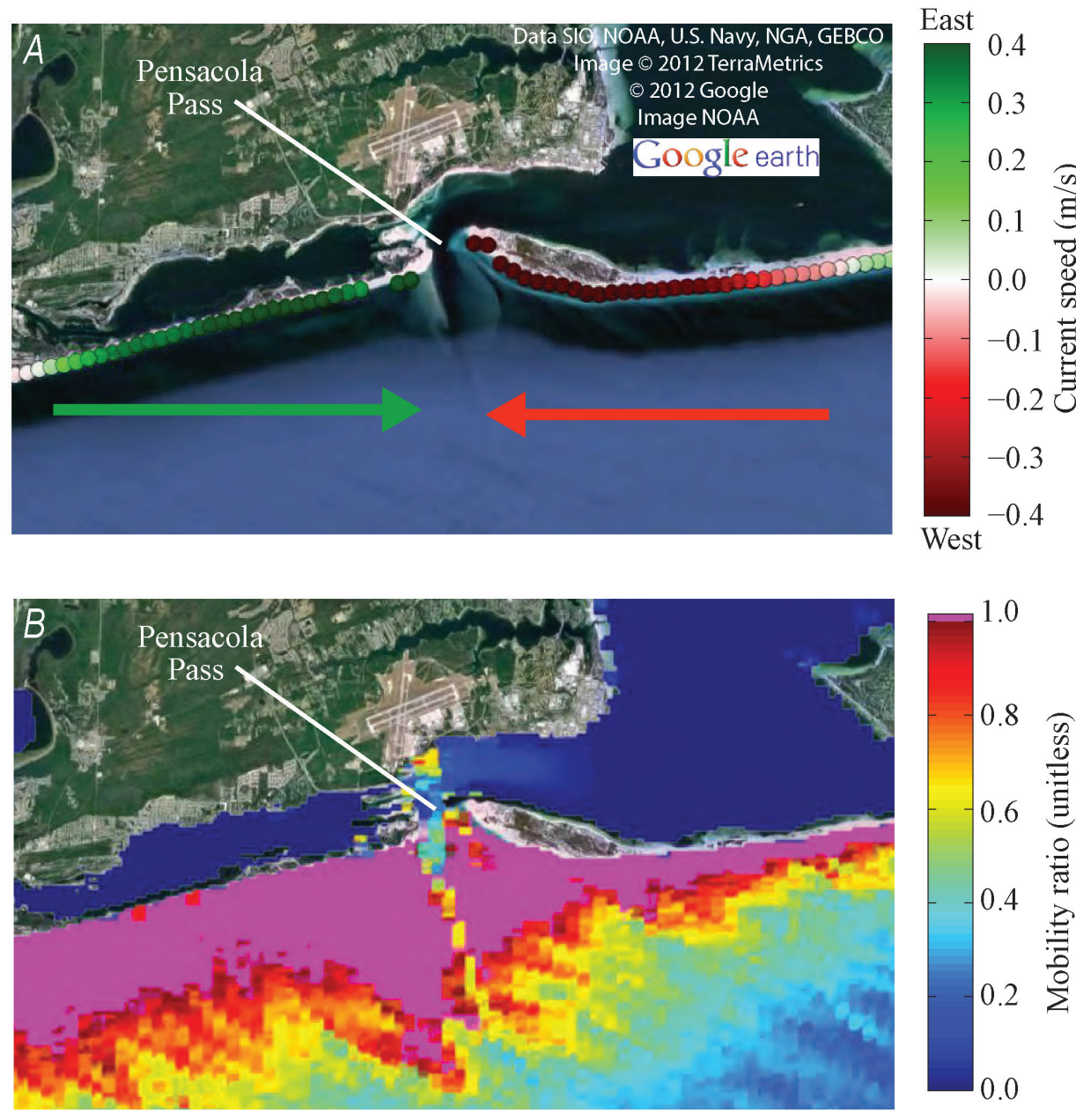

Figure 29. $A$, Maximum alongshore flow speed (green and red arrows) smoothed over a 2-kilometer length scale (table 2, metric 2) and $B$, mobility ratio (table 2 , metric 5) using the lowest critical stress threshold, appropriate for surface residual balls (SRBs) sitting on top of the seabed, for 10-centimeter SRBs (table 1) near Pensacola Pass, Fla., for scenario H5_D8 (fig. 2). All small-size classes of SRBs are also mobilized, leading to convergence and a high probability of deposition in Pensacola Pass during the wave conditions represented by this scenario. 

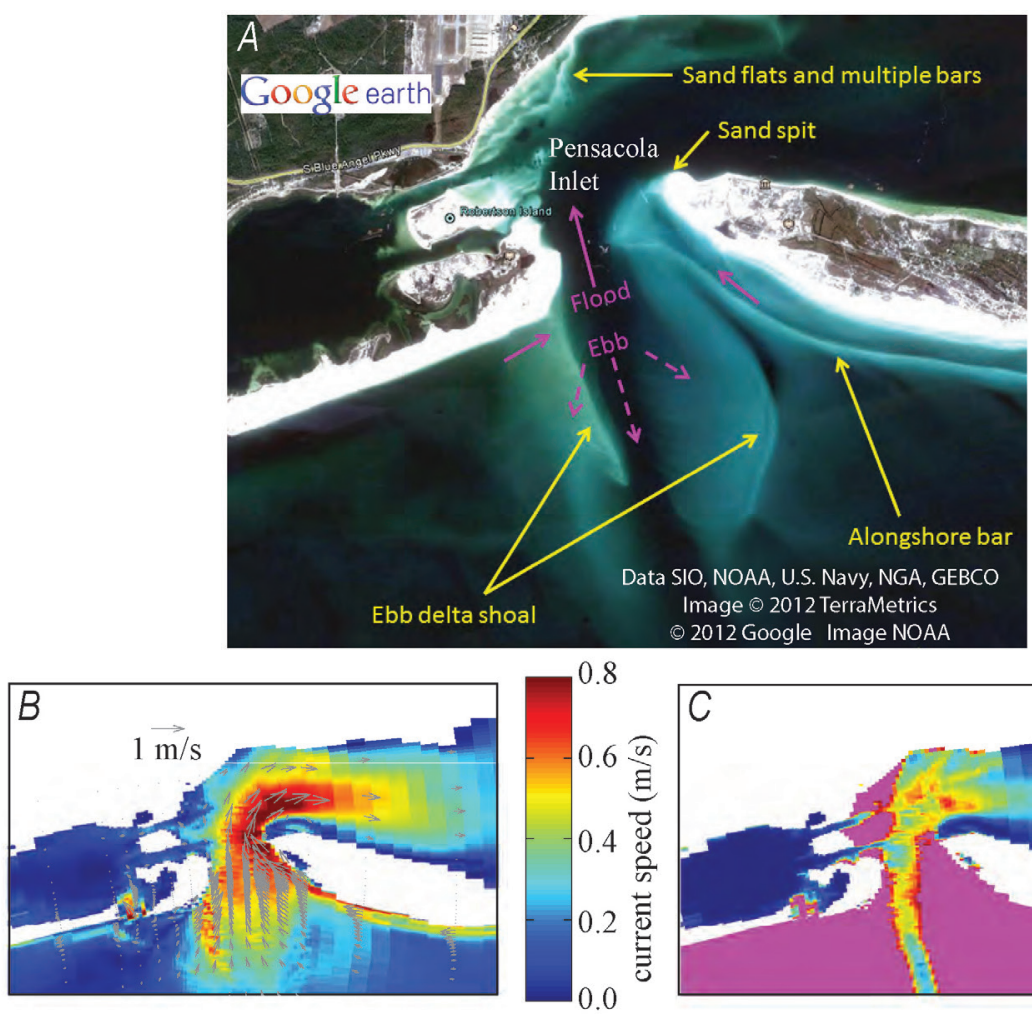

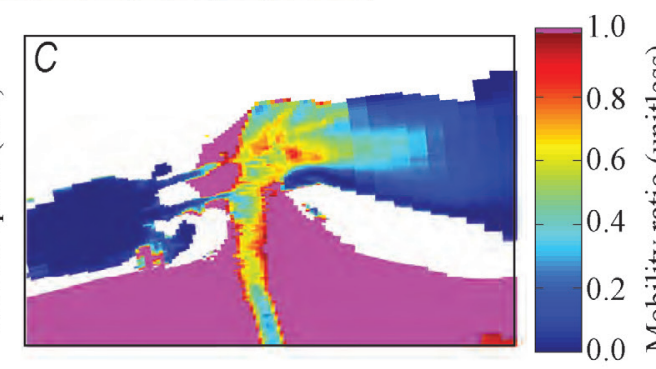

Figure 30. A, Morphologic features (yellow arrows) at the Pensacola Inlet, Fla., that interact with the tidal flow (pink arrows - solid arrows indicate flood tide flows and dashed arrows indicate ebb tide flows). $B$, Modeled inlet flow speeds and $C, 2.5$-centimeter surface residual ball (SRB) mobility for low threshold calculations during flood tide with moderately large waves (scenario H4_D7; fig. 2). Areas where the mobility ratio is 1 (in pink) indicate that SRB mobility threshold is exceeded. focused by the channel. Hence, there can be a net tidal inflow along the shoreline. If SRBs exist along that shoreline, they can, therefore, be directed toward and concentrate in the inlet. Additionally, inlets may be wide enough to allow waves to enter the estuary and support mat and SRB deposition on sand flats, multiple sandbars, and shorelines in the presence of oil.

\section{Complexity of Coupled SRB and Sand Dynamics}

The complexity of the SRB source, burial, exhumation, and transport of SRBs relevant to the OSAT3 objective to define or determine reoiling mechanisms is explained in the predicted variation in the timing and spatial extent of SRB and sediment mobility. The simulations demonstrate that, compared with sand, SRBs are less likely to be mobilized by any specific set of conditions (figs. 9 and 31) and therefore are often at the mercy of sediment deposition or erosion. Because larger SRBs are less likely to move than smaller SRBs, it is possible that transport processes will segregate the different sizes of SRBs. For instance, lag deposits of large SRBs may be created and subsequently buried or exhumed by the movement of local sediment.

\section{Effect of Assumptions}

\section{Scenario Selection}

We assume that a broad range of actual conditions was well represented by the subset of conditions defined by our wave height-direction scenarios. To test this assumption, we used the results from the 80 scenarios to reconstruct a simulated wave time series to compare to observations collected from the Naval Research Laboratory ADCP off the coast at Santa Rosa Island in 12-m water depth. The reconstruction is calculated using the observed time series at the offshore NDBC buoy 42040 and, for each hour, assigning each scenario with the likelihood that it best represents this time period based on observed wave height, direction, period, and wind speed and direction. The modeled wave parameters at the nearshore location for each scenario are multiplied by the respective likelihood values and summed across all scenarios. If our set of scenarios represents the range of conditions that exists over this region, then the waves reconstructed from the scenarios should compare well with the nearshore observations. The bias and RMS error in wave height for this reconstruction were $0 \mathrm{~m}$ and $0.26 \mathrm{~m}$, respectively (fig. 32), which is as accurate as the time series comparison (compare with fig. 14).

\section{SRB Size, Shape, and Exposure}

The calculations forming the basis of shear stress estimation, mobility, and potential flux parameters used in this analysis have been most extensively validated in the nearshore environment for sand-sized particles by Soulsby (1997) and Soulsby and Whitehouse (1997). Application and validation of formulations for these processes for cobble or mixed sand and cobble beaches in a similar size range to SRBs have been limited (Van Wellen and others, 2000; Boyer and others, 2002; 
Figure 31. Mobility ratios (table 2, metric 5) of $A, 0.03$-centimeter $(\mathrm{cm})$ quartz sand (sediment); and $B, 2.5$ $\mathrm{cm}$ and $C, 10-\mathrm{cm}$ surface residual balls (SRBs) under large wave (more than 2-meter) conditions in the northern Gulf of Mexico alongshore Alabama and Florida corresponding to scenario H5_D8 (fig. 2). Where the mobility ratio is 1 (pink areas), the SRB mobility threshold is exceeded. Sediment is more mobile than centimeter-sized SRBs, with mobility decreasing with increasing SRB size.

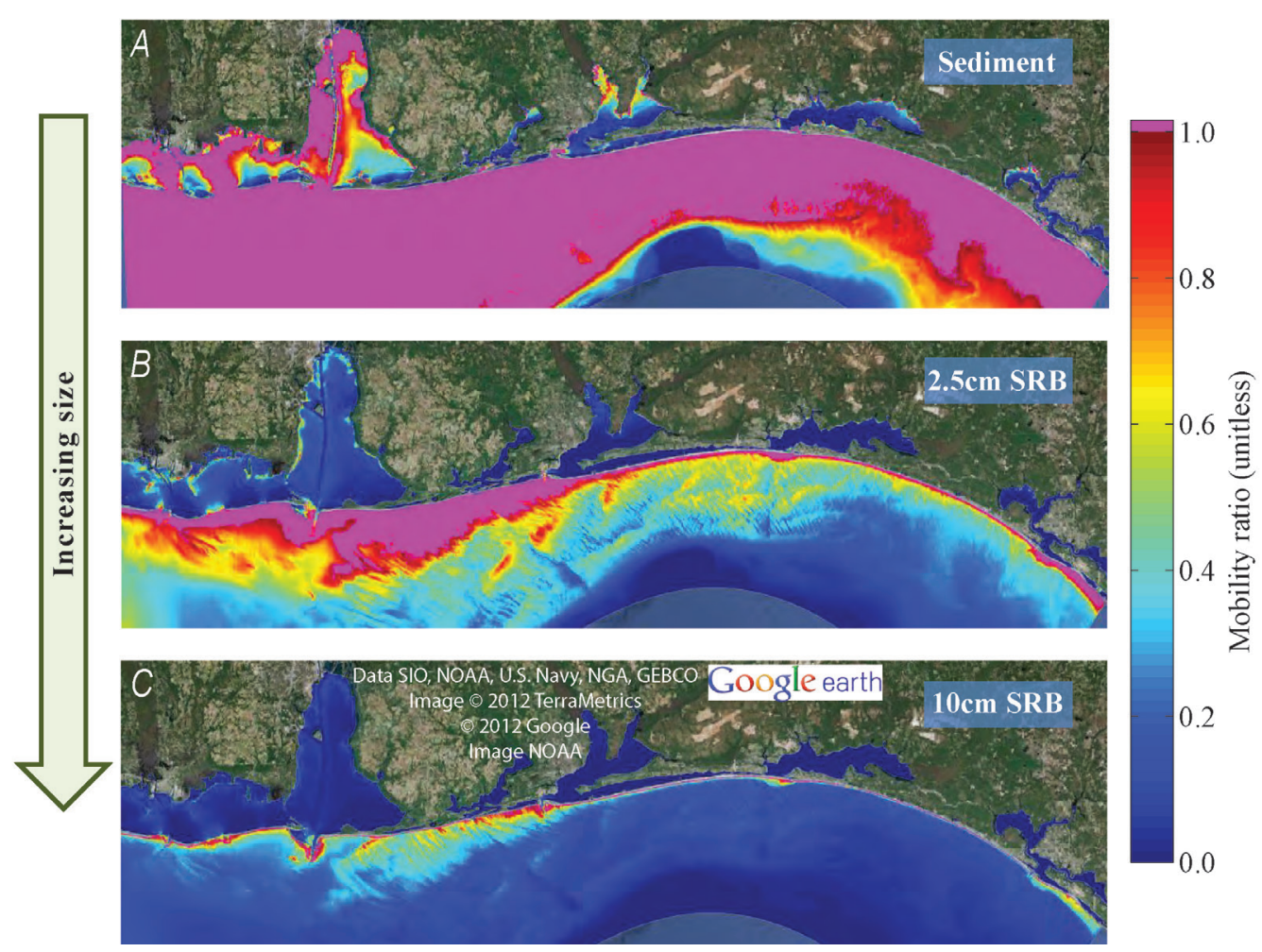

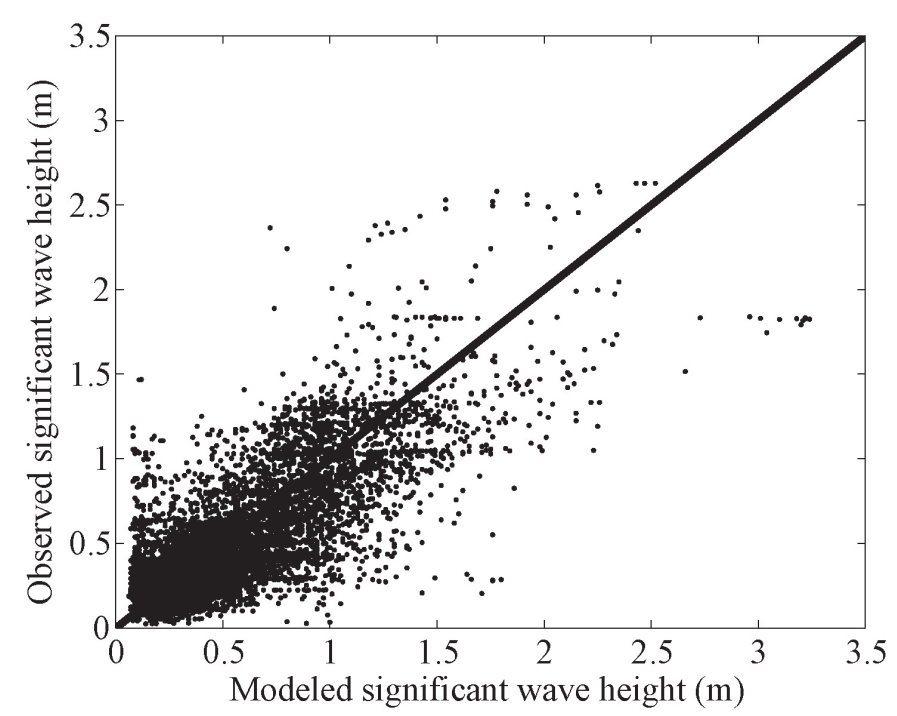

Figure 32. Observed wave height at the Naval Research Labortory acoustic dopler current profiler (ADCP) in the northern Gulf of Mexico alongshore Alabama and Florida for September 15, 2006, through December 23, 2007, against the reconstructed wave height using corresponding subset of modeled scenarios.
Soulsby and Damgaard, 2005), and there has been no known previous application specifically to SRBs. The extension to very large particles, such as SRBs, that may not be spherical and are sparsely distributed on the sand matrix of the seabed requires consideration of the influence of shape and exposure of the SRBs. The findings from the existing literature on mixed grain sizes and shapes were used to constrain the range of critical shear stresses required to mobilize SRBs (fig. 8). Exposed SRBs would be more likely to move than SRBs that are hidden through burial. Shape was considered less important since flat objects would have reduced exposure compared with round objects, even though their transport might be enhanced once they were tipped up on edge and mobilized. It is not known how an aggregate of sand and oil, such as an SRB, would behave differently than a solid object, such as a cobble, as a result of deformation, disintegration, or interaction with the surrounding sediment.

\section{Focus on Alongshore Processes}

The analysis in this report did not explicitly account for cross-shore transport processes but rather focused on predicting the potential for alongshore movement of SRBs. Although the influence of oscillating currents beneath waves and tidally driven flows at inlets is included in mobility estimates, the cross-shore transport caused by these processes was not considered, and cross-shore currents such as rip currents were not considered in either mobility or potential flux calculations. The numerical model also did not account for hydrodynamic processes in the extremely shallow swash zone, which may result 
in cross-shore or alongshore transport of SRB-sized objects (Osborne, 2005). Based on the observational data, SRBs must be transported in the cross-shore direction, particularly near the shoreline where SRBs are often recovered. Based on their large size, it is likely that SRBs are dominated by bed load transport mechanisms, which is driven onshore under asymmetric flows beneath breaking or almost breaking waves (Bowen, 1980). In simplified terms, the onshore-directed flow beneath wave crests is higher in magnitude but occurs for a shorter time than the offshore-directed flow beneath wave troughs. Because bed load transport responds to the flow speed raised to some power (typically assumed to be cubed) of the velocity, the net average transport is in the onshore direction. However, these simple formulations have not produced accurate predictions of cross-shore sediment movement and it is not clear at present how to solve the coupled sand-SRB transport problem.

Hence, our focus on the alongshore transport aimed at answering the questions "Are SRBs of a given size mobilized under a specific set of conditions?" and "If SRBs move, then what is the probable distribution pattern caused by alongshore processes?". Implicit in this approach was an assumption that cross-shore processes would not actually contribute to modulating the alongshore transport, such as by concentrating SRBs in a cross-shore location of relatively high or relatively low alongshore current speeds or by preferentially transporting SRBs either landward onto shore or seaward onto the shelf and out of the surf zone domain.

\section{Static Bathymetry}

For the most part, the bathymetry used to support the numerical modeling did not vary in time. The NGDC dataset resolved features that were $30 \mathrm{~m}$ or larger and included nearshore sandbars and shoreline with substantial spatial variability. However, this variability was aliased by our relatively coarse alongshore resolution of about $250 \mathrm{~m}$. This resulted in some apparent short-scale variations in alongshore currents and mobility that likely did not accurately reflect true variations at the $250-\mathrm{m}$ scale. This short-scale variability was addressed though alongshore smoothing over a 2-km-length scale of the alongshore currents and potential flux, although mobility estimates were not smoothed. At Little Lagoon Inlet, Ala., high resolution data were required to resolve the inlet, and the model domain's alongshore resolution was increased to about $1 \mathrm{~m}$. This increase in resolution improved the detail and fidelity of the inlet dynamics at this location. However, compared with the uncertainty introduced by the critical threshold (for example, the dependency of mobility on SRB exposure, quantified by the difference between the high, medium, and low mobility estimates), small bathymetric changes are expected to have a relatively minor impact on mobility calculations. The details of the inlet and its surrounding shoal and channel features, however, can change substantially with time through natural processes as well as dredging. We note that comparing simulations that incorporated updated bathmetric elevations around Little Lagoon Inlet with those that did not incorporate updated bathymetric elevations, showed a change in maximum alongshore currently velocity of only about 10 centimeters per second. While the exact shape of the alongshore profile can be drastically affected by small changes in the bathymetry, the statistics we use to compute quantities, such as potential flux, do not appear to be impacted. Changes in mobility will depend on the magnitude of the change in bathymetry. A large change in depth can significantly affect mobility. Change in mobility will also depend on how close the original stress was to the threshold value. If the original stress was well over the threshold, it will likely continue to exceed the threshold and vice versa. A variety of indirect effects potentially exist that may be important to mobility and flux and are too numerous to evaluate here, such as changes in bathymetry offshore leading to changes in wave dissipation, wave height, and currents.

\section{Accuracy of Boundary Conditions}

For the boundary conditions for our model, we identified specific times when the Wavewatch III hindcast data matched the conditions of each scenario and thus assumed that the hindcast data on the high-resolution boundary accurately reflected conditions for the scenario. No attempt was made to correct these boundary conditions with buoy data. Instead, the buoy data on the interior of the high-resolution domain were used to evaluate the accuracy of our approach. In the case of the two time series (data from Santa Rosa Island, Fla., in 2007 and during Hurricane Isaac in August 2012), we also assumed that the model inputs of tides and storm surge were accurate. Errors in water levels, particularly during Hurricane Isaac (for example, fig. 15) may be due to boundary conditions errors, bathymetric errors, or other errors associated with model implementation and simplification. Based on the model-data comparisons that we have analyzed, we concluded that the predictions are skillful and, in spite of some errors, provide estimates of oceanographic variables that are significant improvements compared with climatologic or astronomic predictions.

\section{Research Gaps}

The numerical modeling of SRB behavior and the application of the model results to the OSAT3 objectives have identified several fundamental knowledge gaps relevant to our understanding of the formation, movement, evolution, burial, and exhumation of SRBs. Some of these knowledge gaps require additional, focused research, and other gaps require enhanced observations to support research and operational OSAT3 objectives. For example, at the outset of the numerical modeling planning effort, we recognized the lack of the ability to predict the details of cross-shore sediment and SRB transport responsible for changing the position of the shoreline, offshore sandbars, and SRBs. The shoreline reoiling problem 
required better understanding and prediction of these processes to better understand if and when SRBs in the surf zone will be transported and deposited on the shoreline or beach. To achieve the OSAT3 objectives, the cross-shore distribution of alongshore transport was addressed and resolved by the numerical model. Utilizing this knowledge for further practical applications of the results requires specifying the cross-shore distribution of SRBs. This gap was filled through nonmodeling techniques developed by other researchers in OSAT3, which included observations from cleanup and SRB recovery efforts, measurements of cross-shore profiles, and vertical and stereoimage analysis.

The broader OSAT3 analysis and discussion (which included observations of morphologic change and collections of SRBs on the beach and in the surf zone that was not described in this report) considered the spatially variant probability of mat formation, but did not include hydrodynamic variability such as variations in waves and water levels that were the subject of the current modeling effort. In addition, the details of the formation of SRBs from mats were not considered. Thus, SRB behavior assessments relied on extrapolation from studies not necessarily focused on agglomerates of sand and tar. Specific, detailed studies of SRBs on which to demonstrate good understanding and predictive skill were lacking during the course of this analysis.

\section{Future Research Opportunities}

Gaps in prediction capability and fundamental understanding of SRB behavior could be filled by additional effort on the following topics.

Research on modeling of cross-shore sediment transport processes to accurately predict shoreline and sandbar changes.-Currently [2012], only parameterized modeling approaches (for example, Plant and others, 1999; Yates and others, 2009, 2011) appear to have skill in applications to accurately simulate shoreline and sandbar changes, but these simplified approaches require persistent time-series of observations for calibration. Fundamental understanding of cross-shore sediment transport would likely provide better simulations of waves, water levels, and currents. This research pursuit has been ongoing for more than 30 years (Stive, 1987).

Research on mat and SRB formation.-The environmental conditions that were conducive to mat and SRB formation were identified by the overall OSAT3 effort, whose scope included collection of field observations of SRB occurrence. These included open-coast shorelines and, typically, shallow sandbars that were likely exposed or nearly exposed at low tide. Additionally, mat and SRBs were observed near and inside inlets where tidal and wave action likely contributed to their distribution. However, observations demonstrate substantial variability in the location of mats and resulting SRBs. Studies that investigate the details of mat formation, variability with changing hydrodynamic conditions such as tidal or surf water level or wave conditions, and response to burial and exhumation and creation of SRBs would further improve understanding of SRB behavior.

Research on observed SRB movement, burial, exhumation, and alteration.-The simulations of SRB mobility include many uncertainties associated with SRB shape and interaction with sand-sized sediments that affect SRB exposure to the mobilizing and transporting flows. No direct observations of particle movement of comparably sized and dense SRBs were available to test the model predictions, nor do fundamental data, such as friction coefficients between SRBs and the sea floor, exist to allow development of singleparticle tracking analysis to estimate distance traveled and velocity. Very little is known about the breakup of mats into SRB particles and of large, angular SRBs into smaller, rounded SRBs. Observations of SRB surrogates in laboratory and field settings could provide improved predictions for future applications to responses for reoiling or similar contaminants.

\section{Operational Applications of Results and Methods}

The modeling effort and the interaction of the subteam with the overall OSAT3 yielded a number of potential capabilities that could support the ongoing response to beach reoiling and provide guidance for future response activities associated with oil spills or other beach contamination situations. Here, we list several operational activities that could be implemented with or without further effort on the research gaps listed above.

Operational hindcast, nowcast, and forecast of SRB movement.-The methods employed under OSAT3 to simulate SRB movement are capable of providing substantially more detail into past, ongoing, and future reoiling. The operational challenges that can be overcome include developing a methodology to reconstruct detailed time series from a small number of scenarios, formal integration of oiling and SRB observation histories with simulated time series, and providing forecasts and uncertainties to be used in prioritization of cleanup response efforts.

Operational observations of shoreline and sandbar changes.-Observations of actual bathymetry and topography to resolve shoreline and sandbars and the nearshore seabed were valuable to understanding the likely locations of mats and SRBs and to simulation of waves and currents that drive SRB movement. The value of aerial imagery for shoreline and sandbar position and elevation estimates demonstrated that a range of ground-truth and remote sensing methods could be applied to this or similar responses. There is an opportunity to couple observation tasking with oceanographic models to optimize data acquisition. Formal evaluation of what data should be collected at what frequency and at what locations could be conducted with the present approach.

Operational assessment of the time-varying water-level intersection with intertidal bars and beach.-The OSAT3 identified that SRB source mats formed near the shoreline. However, the shoreline varies with tide and wave conditions, 
both of which vary in time. An alongshore variant time series of water excursion probability during oiling could be developed from existing extensions to the present modeling approach and be used to identify a two-dimensional probability distribution of mat formation locations. This analysis could include wave runup and swash elevations. In addition, variability in bathymetry around inlets and ebb or flood tidal deltas or over very shallow sandbar features could be assessed to further quantify the uncertainty in potential buried mats at these locations.

\section{Summary And Conclusions}

U.S. Geological Survey scientists have developed a model-based assessment of transport and deposition of residual oil that is causing shoreline reoiling within the northern Gulf of Mexico in the form of mixtures of sand and weathered oil, known as surface residual balls (SRBs). The results of the assessment can be used to provide guidance for ongoing response activities and data collection needs as well as to guide response for future oil spills or related events.

Results from these modeling efforts have identified spatial and temporal variations in alongshore currents, including locations where there are gradients resulting in convergences and decelerations in the flow. Likewise, the results identify spatial and temporal variations in the mobility of sand and SRBs. A striking example of convergence identified by the model was shown at Pensacola Pass, Fla., where trends in the orientation of the adjacent shoreline cause flow and potential SRB flux to be driven toward the inlet. This situation forces SRBs to interact with tidal currents, and the complexity of the situation is exacerbated by SRBs interacting with sandbars and channels which are themselves undergoing constant reconfiguration as wave and tide conditions change.

Modeling results suggest that, under the most commonly observed low-energy wave conditions, larger SRBs are not likely to move very far alongshore. This finding suggests that, under nonstorm condtions, large SRBs from one source location may not be redistributed to other alongshore locations. Under storm conditions, however, it is possible for larger SRBs to be mobilized. SRBs are likely to become buried and unburied under normal sand transport processes because they are less mobile than sand, thereby lengthening the time SRBs take to move onshore and adding a layer of complexity to the model.

\section{References Cited}

Andrews, E.D., 1983, Entrainment of gravel from naturally sorted riverbed material: Geological Society of America Bulletin, v. 94, no. 10, p. 1225-1231.
Balsam, W.L., and Beeson, J.P., 2003, Sea-floor sediment distribution in the Gulf of Mexico: Deep Sea Research Part I: Ocean Research Papers, v. 50, no. 12, p. 1421-1444.

Battjes, J.A., and Janssen, J.P.F.M., 1978, Energy loss and setup due to breaking of random waves, chap. 32 of Coastal engineering - 1978: Conference on Coastal Engineering, 16th, Hamburg, Germany, 1978, Proceedings, p. 569-587.

Bendat, J.S., and Piersol, A.G., 1971, Random data: Analysis and measurement procedures: Wiley-Interscience, $407 \mathrm{p}$.

Booij, N., Ris, R.C., and Holthuijsen, L.H., 1999, A third-generation wave model for coastal regions-1. Model description and validation: Journal of Geophysical Research, v. 104 , no. C4, p. 7649-7666.

Bottacin-Busolin, Andrea, Tait, Simon, Marion, Andrea, Chegini, Amir, and Tregnaghi, Matteo, 2008, Probabilistic description of grain resistance from simultaneous flow field and grain motion measurements: Water Resources Research, v. 44, no. 9, WO9419, 12 p.

Bowen, A.J., 1980, Simple models of nearshore sedimentation-Beach profiles and longshore bars, in Mccann, S.B., ed., The coastline of Canada-Littoral processes and shore morphology: Geological Survey of Canada Paper 80-10, p. 1-11.

Boyer, D.L., Fernando, H.J.S., and Voropayev, S.I., 2002, The dynamics of cobbles in and near the surf zone: Arizona State University, 37 p., accessed September 5, 2012, at http://www.dtic.mil/dtic/tr/fulltext/u2/a412197.pdf.

COMET® Website [2011] University Corporation for Atmospheric Research (UCAR), sponsored in part through cooperative agreement(s) with NOAA, U.S. Department of Commerce (DOC). C1997-2011 University Corporation for Atmospheric Research. All Rights Reserved. Used with permission. Accessed September 5, 2012, at http://www.meted.ucar.edu/marine/ripcurrents/NSF .

Davies, A.G., Soulsby, R.L., and King, H.L., 1988, A numerical model of the combined wave and current bottom boundary layer: Journal of Geophysical Research-Oceans, v. 93, no. C1, January 15, p. 491-508.

Deigaard, Rolf, Fredsøe, Jørgen, and Mikkelsen, M.B., 1991, Measurements of the bed shear stress in a surf zone: Lungby, Denmark, Technical University of Denmark, Institute of Hydrodynamics and Hydraulic Engineering Progress Report 73, p. 21-30.

Deltares, 2007, Delft3D-Flow-Simulation of multidimensional hydrodynamic flows and transport phenomena, including sediments-User manual: Delft, Netherlands, Deltares, 614 p. 
Egbert, Gary, and Erofeeva, Svetlana, 2010, TPXO global tide model, version 7.2: Oregon State University, accessed September 5, 2012, at http://volkov.oce.orst.edu/tides/ global.html.

Environmental Modeling Center [2012], NOAA Wavewatch III-MMAB operational wave models: National Weather Service National Centers for Environmental Prediction, recently renamed Weather Prediction Center (WPC), Date accessed 5 September 2012, at http://www.emc.ncep.noaa.gov/.

Fenton, J.D., and Abbott, J.E., 1977, Initial movement of grains on a stream bed-The effect of relative protrusion: Proceedings of the Royal Society of London Series A, Mathematical and Physical Sciences, v. 352, no. 1671, February 4, p. 523-537.

Fredsoe, Jørgen, 1984, Sediment transport in current and waves: Technical University of Denmark, Institute of Hydrodynamics and Water Resources Series Paper 35, $293 \mathrm{p}$.

Grant, W.D., and Madsen, O.S., 1979, Combined wave and current interaction with a rough bottom: Journal of Geophysical Research-Oceans, v. 84, no. C4, April 20, p. 1797-1808.

Hasselmann, K., Barnett, T.P., Bouws, E., Carlson, H., Cartwright, D.E., Enke, K., Ewing, J.A., Gienapp, H., Hassellman, D.E., Kruseman, P., Meerburg, A., Müller, P., Olbers, D.J., Richter, K., Sell, W., and Walden, H., 1973, Measurements of wind-wave growth and swell decay during the joint North Sea wave project (JONSWAP): Hamburg, Germany, Deutsches Hydrographisches Institut Ergänzungsheft zur Deutschen Hydrogrphischen Zeitscrift Reihe A, v. 8, no. 12, 95 p., Date accessed September 5, 2012, at http://repository.tudelft.nl/view/hydro/ uuid:f204e188-13b9-49d8-a6dc-4fb7c20562fcl

Huynh-Thanh, Son, and Temperville, Andre, 1991, A numerical model of the rough turbulent boundary layer in combined wave and current interaction, in Edge, B.L., ed., Proceedings of the International Coastal Engineering Conference, 22, Delft, Netherlands, July 2-6, 1990: American Society of Civil Engineers, v. 1, p. 853-866.

Hybrid Coordinate Ocean Model, [2012a], HYCOM + NCODA Gulf of Mexico 1/25 Analysis (GOM10.04): National Ocean Partnership Program HYCOM Consortium for Data Assimilative Modeling, Date accessed September 5, 2012, at http://hycom.org/dataserver/ goml0pt04
Hybrid Coordinate Ocean Model, [2012b], HYCOM + NCODA Global 1/12 Analysis (GLBa0.08/expt_90.8): National Ocean Partnership Program HYCOM Consortium for Data Assimilative Modeling, Date accessed September 5, 2012, at http:/hycom.org/dataserver/glb-analysis/ expt-90pt8

Integration and Application Network, [2012], IAN symbol libraries: University of Maryland, Date accessed September 5, 2012, at http://ian.umces.edu/symbols/.

Komen, G.J., Hasselmann, S., and Hasselmann, K., 1984, On the existence of a fully developed wind-sea spectrum: Journal of Physical Oceanography, v. 14, no. 8, p. 1271-1285.

Lesser, G.R., Roelvink, J.A., van Kester, J.A.T.M., and Stelling, G.S., 2004, Development and validation of a three-dimensional morphological model: Journal of Coastal Engineering, v. 51, nos. 8-9, October, p. 883-915.

Love, M.R., Amante, C.J., Eakins, B.W., and Taylor, L.A., 2012, Digital elevation models of the northern Gulf coastProcedures, data sources and analysis: National Oceanic and Atmospheric Administration Technical Memorandum NESDIS NGDC-59, 43 p., Date accessed September 5, 2012, at http://www.ngdc.noaa.gov/dem/squareCellGrid/ download/731.

National Data Buoy Center, [2012], NDBC Meteorologi$\mathrm{cal} /$ Ocean stations 42012, 42039, and 42040: National Oceanic and Atmospheric Administration's National Weather Service, Date accessed September 5, 2012, at http://www.ndbc.noaa.gov/.

National Oceanic and Atmospheric Administration, [2012], Center for Operational Oceanographic Products and Services-National Ocean Service tide stations, Dauphin Island, AL (8735180), Pensacola Bay, FL (8729840), and Panama City (8729108): National Oceanic and Atmospheric Administration, accessed September 5, 2012, at http://tidesandcurrents.noaa.gov/index.shtml.

Osborne, P.D., 2005, Transport of gravel and cobble on a mixed-sediment inner bank shoreline of a large inlet, Grays Harbor, Washington: Marine Geology, v. 224, no. 1, p. 145-156.

Plant, N.G., Holman, R.A., Freilich, M.H., and Birkemeier, W.A., 1999, A simple model for interannual sandbar behavior: Journal of Geophysical Research-Oceans, v. 104 , no. C7, p. $15755-15776$.

Reniers, A.J.H.M., Thornton, E.B., Stanton, T.P., and Roelvink, J.A., 2004, Vertical flow structure during Sandy Duck - Observations and modeling: Coastal Engineering, v. 51 , no. 3 , p. $237-260$. 
Ris, R.C., Holthuijsen, L.H., and Booij, N., 1999, A thirdgeneration wave model for coastal regions-2. Verification: Journal of Geophysical Research, v. 104, no. C4, p. 7667-7681.

Rogers, Robert, Aberson, Sim, Black, Michael, Black, Peter, Cione, Joe, Dodge, Peter, Gamache, John, Kaplan, John, Powell, Mark, Dunion, Jason, Uhlhorn, Eric, Shay, Nick, and Surgi, Naomi, 2006, The intensity forecasting experiment-A NOAA multiyear field program for improving tropical cyclone intensity forecasts: Bulletin of the American Meteorological Society, v. 87, no. 11, p. 1523-1537.

Shields, Albert, 1936, Anwendung der Ähnlichkeits-Mechanik und der Turbulenzforschung auf die Geschiebebewegung: Berlin, Preussishe Versuchsanstalt für Wasserbrau und Schiffbau, v. 26, p. 524-526.

Soulsby, R.L., 1997, Dynamics of marine sands-A manual for practical applications: London, Thomas Telford Publications, $249 \mathrm{p}$.

Soulsby, R.L., and Damgaard, J.S., 2005, Bedload sediment transport in coastal waters: Coastal Engineering, v. 52, no. 8, August, p. 673-689.

Soulsby, R.L., and Whitehouse, R.J.S., 1997, Threshold of sediment motion in coastal environments, in Pacific Coasts and Ports '97, Christchurch, New Zealand, September 7-11, 1997: Proceedings of the 13th Australasian Coastal and Ocean Engineering Conference and the 6th Australasian Port and Harbour Conference, v. 1, p. 145-154.

Soulsby, R.L., Hamm, L., Klopman, G., Myrhaug, D., Simons, R.R., and Thomas, G.P., 1993, Wave-current interaction within and outside the bottom boundary layer: Coastal Engineering, v. 21, nos. 1-3, December, p. 41-69.

Stive, M.J.F., 1987, A model for cross-shore sediment transport, in Edge, B.L., ed., Proceedings of the Conference of Coastal Engineering, 20, Taipei, Taiwan, November 9-14, 1986: American Society of Civil Engineers, v. 1, p. $1550-1564$.
Tolman, H.L., 2008, A mosaic approach to wind wave modeling: Ocean Modeling, v. 25, nos. 1-2, p. 35-47.

U.S. Army Corps of Engineers National Coastal Mapping Program, 2010, USACE topo/bathy lidar -Alabama and Florida: Digital Coast NOAA Coastal Services Center, Date accessed September 5, 2012, at http://www.csc.noaa.gov/ dataviewer/\#.

Van Wellen, E., Chadwick, A.J., and Mason, T., 2000, A review and assessment of longshore sediment transport equations for coarse-grained beaches: Coastal Engineering, v. 40 , no. 3 , June, p. 243-275.

Wiberg, P.L., and Smith, J.D., 1987, Calculations of the critical shear stress for motion of uniform and heterogeneous sediments: Water Resources Research, v. 23, no. 8, August, p. 1471-1480.

Wilcock, P.R., 1998, Two-fraction model of initial sediment motion in gravel-bed rivers: Science, v. 280 , no. 5362 , April 17, p. 410-412.

Yates, M.L., Guza, R.T., and O'Reilly, W.C., 2009, Equilibrium shoreline response-Observations and modeling: Journal of Geophysical Research, v. 114, no. C9, C09014, 16 p., doi:10.1029/2009JC005359, Date accessed September 5, 2012, at http://cdip.ucsd.edu/SCBPS/DOCS/ Publications/Article/A133_yates_equilibrium_jgr.pdf.

Yates, M.L., Guza, R.T., O’Reilly, W.C., Hansen, J.E., and Barnard, P.L., 2011, Equilibrium shoreline response of a high wave energy beach: Journal of Geophysical Research, v. 116, no. C4, C04014, p., doi:10.1029/2010JC006681, Date accessed September 5, 2012, at http://cdip.ucsd.edu/ SCBPS/DOCS/Publications/Article/2010JC006681.pdf. 



\section{Appendix 1. Scenarios}

In this appendix, we define scenarios for reducing the full-time series to representative conditions and identify time periods that represent these scenarios for running simulations with spatially varying boundary conditions. As described in the Methods section of this report, scenarios were defined by drawing observations from 5 wave height ranges (i.e., bins) and 16 wave direction ranges, yielding 80 unique scenarios. The specifications for each scenario are defined in table 1-1. In addition to being defined by wave height and direction, the scenarios are further described by the conditional mean values of wave period, wind speed, and wind direction based on the observed data (from NDBC buoy 42040) for each scenario (fig. 1-1).

Table 1-1. Wave height and direction scenarios.

$\left[\mathrm{m}\right.$, meters; ${ }^{\circ}$, degrees; >, greater than $]$

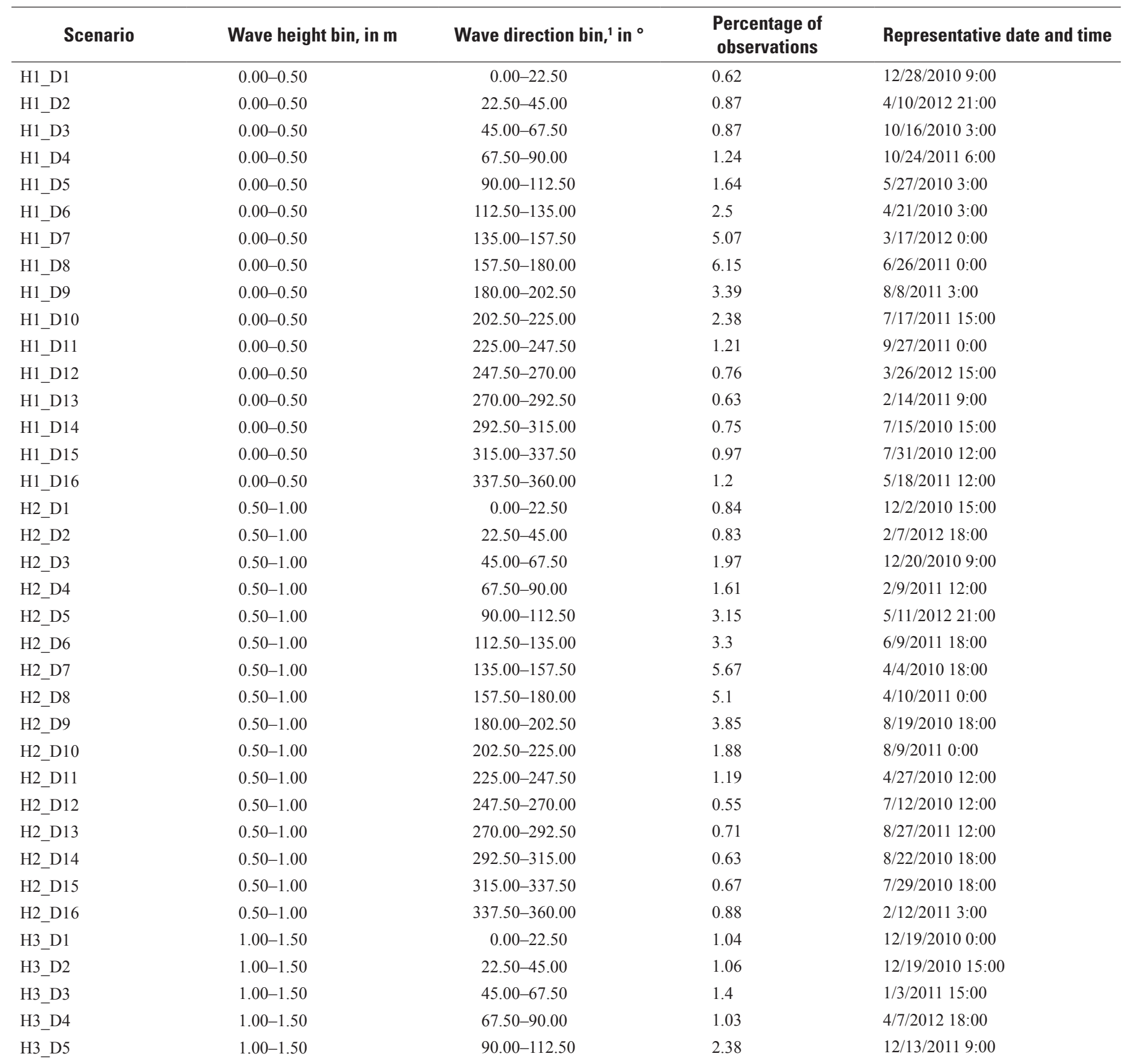




\section{Application of Hydrodynamic and Sediment Transport Model for Deepwater Horizon Oil Spill Response}

Table 1-1. Wave height and direction scenarios.-Continued

$\left[\mathrm{m}\right.$, meters; ${ }^{\circ}$, degrees; >, greater than]

\begin{tabular}{|c|c|c|c|c|}
\hline Scenario & Wave height bin, in m & Wave direction bin, ${ }^{1}$ in ${ }^{\circ}$ & $\begin{array}{l}\text { Percentage of } \\
\text { observations }\end{array}$ & Representative date and time \\
\hline H3_D6 & $1.00-1.50$ & $112.50-135.00$ & 2.61 & 10/6/2011 6:00 \\
\hline H3_D7 & $1.00-1.50$ & $135.00-157.50$ & 3.65 & 4/18/2012 9:00 \\
\hline H3_D8 & $1.00-1.50$ & $157.50-180.00$ & 2.47 & 4/20/2011 18:00 \\
\hline H3_D9 & $1.00-1.50$ & $180.00-202.50$ & 1.33 & 6/22/2011 9:00 \\
\hline H3_D10 & $1.00-1.50$ & $202.50-225.00$ & 0.61 & 11/17/2010 12:00 \\
\hline H3_D12 & $1.00-1.50$ & $247.50-270.00$ & 0.11 & $1 / 29 / 20113: 00$ \\
\hline H3_D13 & $1.00-1.50$ & $270.00-292.50$ & 0.15 & 5/29/2012 15:00 \\
\hline H3_D14 & $1.00-1.50$ & $292.50-315.00$ & 0.24 & 1/7/2011 6:00 \\
\hline H3_D15 & $1.00-1.50$ & $315.00-337.50$ & 0.56 & 3/11/2011 0:00 \\
\hline H3_D16 & $1.00-1.50$ & $337.50-360.00$ & 0.99 & 9/30/2010 6:00 \\
\hline H4_D5 & $1.50-2.00$ & $90.00-112.50$ & 1.27 & 11/6/2011 9:00 \\
\hline H4_D6 & $1.50-2.00$ & $112.50-135.00$ & 1.38 & 4/15/2012 9:00 \\
\hline H4_D7 & $1.50-2.00$ & $135.00-157.50$ & 1.62 & 12/22/2011 12:00 \\
\hline H4_D8 & $1.50-2.00$ & $157.50-180.00$ & 1.05 & 6/29/2010 15:00 \\
\hline H4_D9 & $1.50-2.00$ & $180.00-202.50$ & 0.44 & $3 / 3 / 2012$ 15:00 \\
\hline H4_D10 & $1.50-2.00$ & $202.50-225.00$ & 0.17 & $12 / 17 / 201015: 00$ \\
\hline H4_D11 & $1.50-2.00$ & $225.00-247.50$ & 0.19 & 11/29/2011 9:00 \\
\hline H4_D12 & $1.50-2.00$ & $247.50-270.00$ & 0.05 & 1/8/2011 6:00 \\
\hline H4_D13 & $1.50-2.00$ & $270.00-292.50$ & 0.25 & 11/28/2011 21:00 \\
\hline H4_D14 & $1.50-2.00$ & $292.50-315.00$ & 0.21 & 12/27/2011 21:00 \\
\hline H5_D5 & $>2.00$ & $90.00-112.50$ & 0.66 & 10/8/2011 18:00 \\
\hline H5_D6 & $>2.00$ & $112.50-135.00$ & 0.98 & 3/4/2011 0:00 \\
\hline H5_D7 & $>2.00$ & $135.00-157.50$ & 1.27 & 11/27/2011 12:00 \\
\hline H5_D8 & $>2.00$ & $157.50-180.00$ & 1.13 & $5 / 3 / 201012: 00$ \\
\hline H5_D9 & $>2.00$ & $180.00-202.50$ & 0.48 & 9/5/2011 9:00 \\
\hline H5_D10 & $>2.00$ & $202.50-225.00$ & 0.16 & $12 / 16 / 201021: 00$ \\
\hline H5_D11 & $>2.00$ & $225.00-247.50$ & 0.07 & $1 / 11 / 2012$ 15:00 \\
\hline H5_D12 & $>2.00$ & $247.50-270.00$ & 0.02 & 1/8/2011 6:00 \\
\hline H5_D13 & $>2.00$ & $270.00-292.50$ & 0.15 & 12/27/2011 12:00 \\
\hline H5_D14 & $>2.00$ & $292.50-315.00$ & 0.27 & $12 / 12 / 201015: 00$ \\
\hline H5_D15 & $>2.00$ & $315.00-337.50$ & 0.31 & 12/13/2010 6:00 \\
\hline H5_D16 & $>2.00$ & $337.50-360.00$ & 0.47 & 4/22/2012 9:00 \\
\hline
\end{tabular}

${ }^{1}$ Indicates the direction of the waves, in degrees from north. 
The period chosen to represent each scenario was identified by matching the multivariate wave height and direction of that scenario to the values defining each bin. The match was made by evaluating the likelihood of each observation given the bin-defining values. Observations were given an uncertainty equal to 0.1 times the width of the bin to allow matching observations that fall on bin boundaries. It is expected that the best-match scenario would come from a short time period (6 hours) where the conditions consistently met the scenario conditions in order to avoid choosing transitional conditions that may produce unrepresentative conditions. The comparison of the best match to the H3_D8 scenario shows that this approach effectively selected time periods with representative wave period and offshore wind conditions (fig. 1-2).
$A$

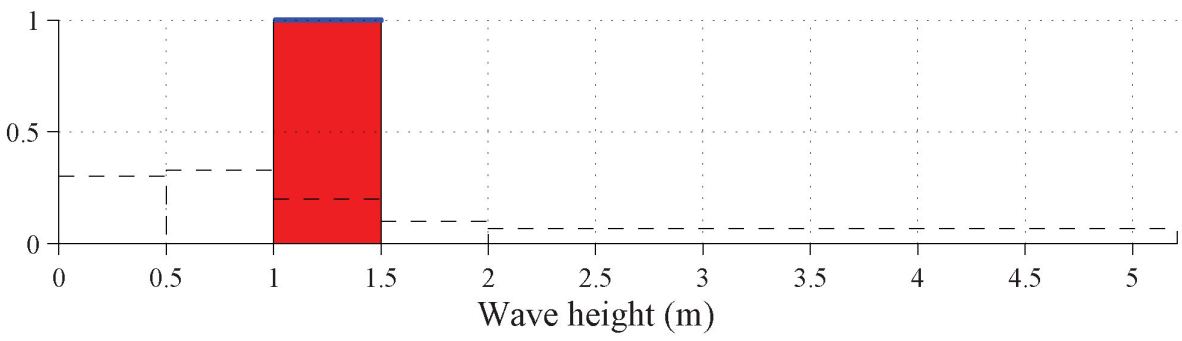

$B$
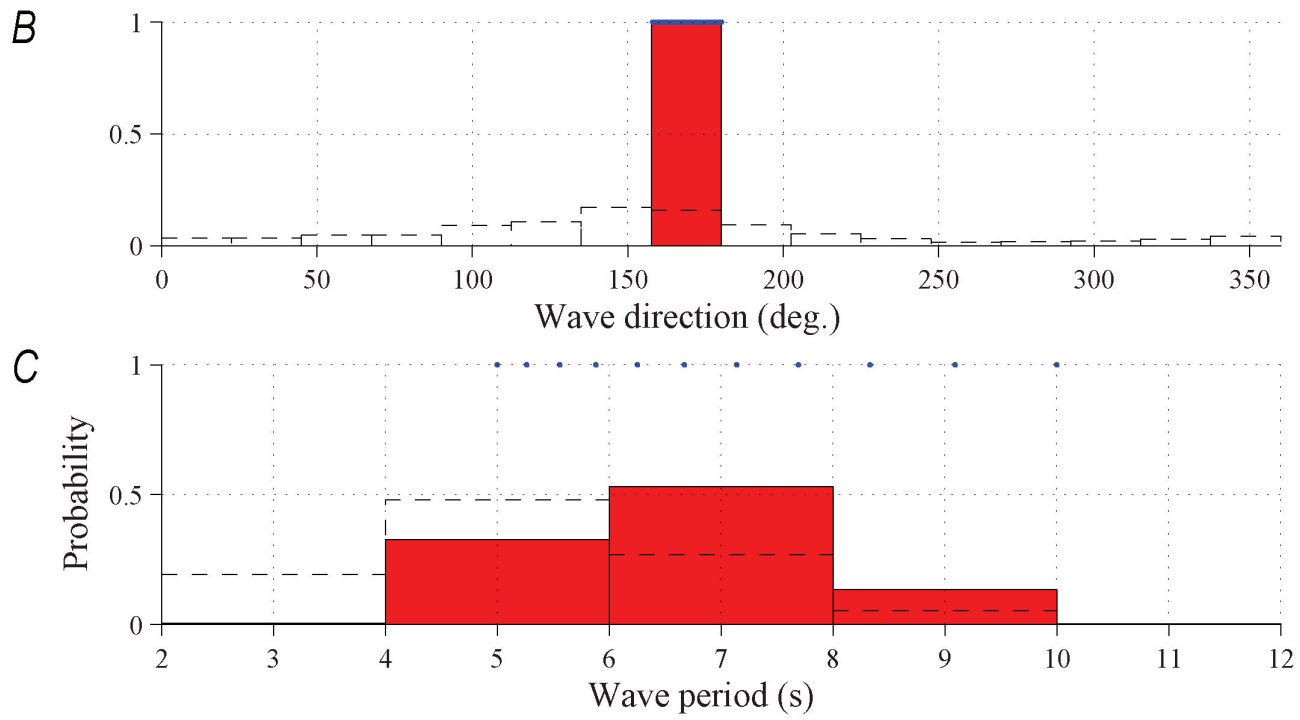

$D$

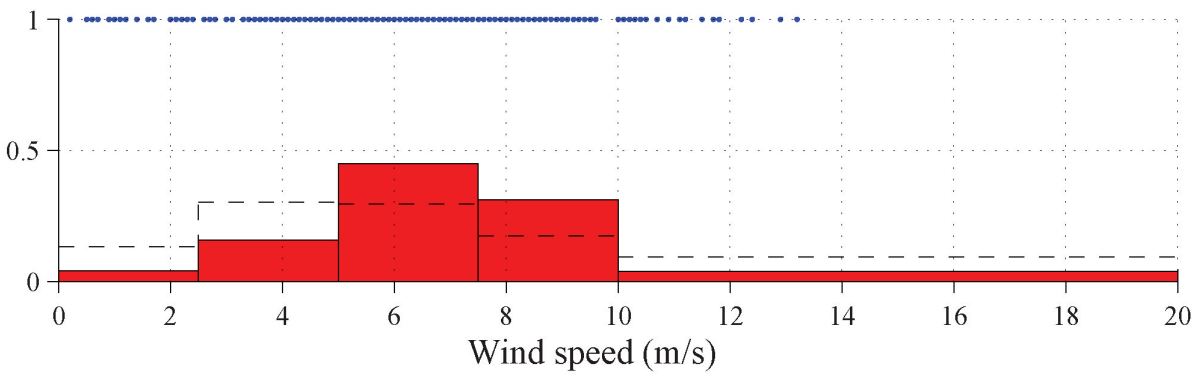

$E$

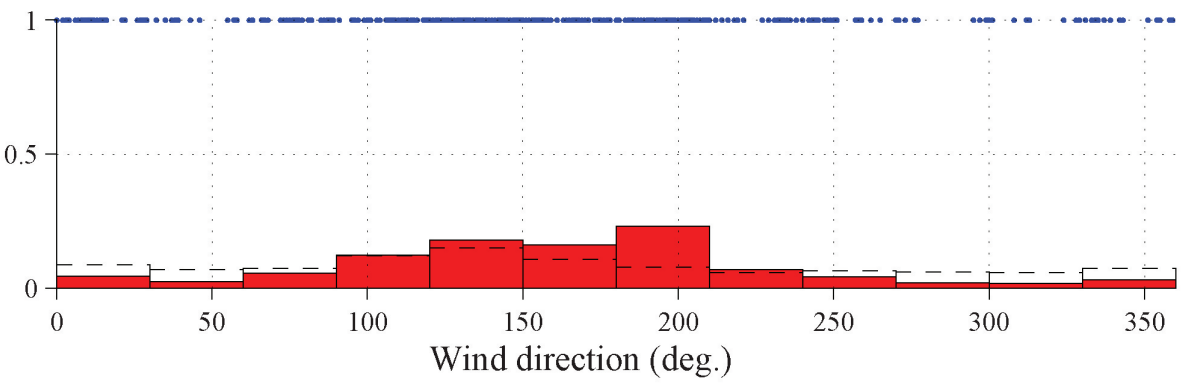

Figure 1-1. Example of a scenario H3_D8 with wave height of 1.25 meters and wave direction of 169 degrees. Red bars show the normalized distribution of other relevant variables, constrained by height and direction: $A$, Wave height; $B$, Wave direction; $C$, Wave period; D, Wind speed; and, E, Wind direction. Blue dots show the data for the observation times that fall within this scenario. 

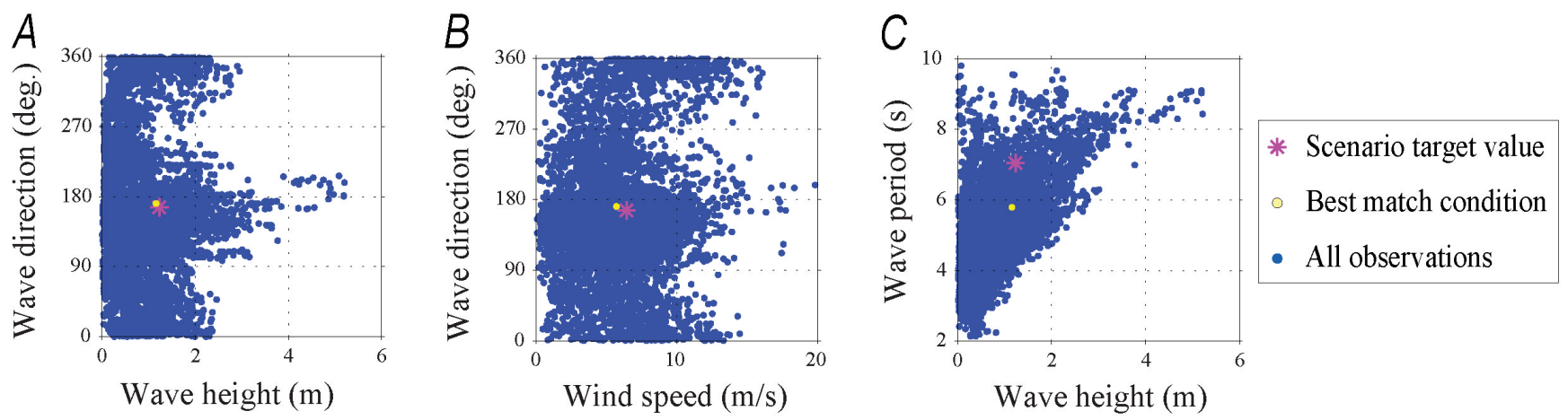

Figure 1-2. Comparison of the best-match condition (yellow dot) to the target values for the scenario (magenta asterisk) against all observations (blue dots) for scenario H3_D8. $A$, wave height and direction, $B$, wind speed and wave direction, and $C$, wave height and period. 


\section{Appendix 2. Examples of Input Files for the Model}

Files for FLOW (flow.mdf) and WAVE (wave.mdw) modules can be found with the digital version of this report.

\section{Flow Input File}

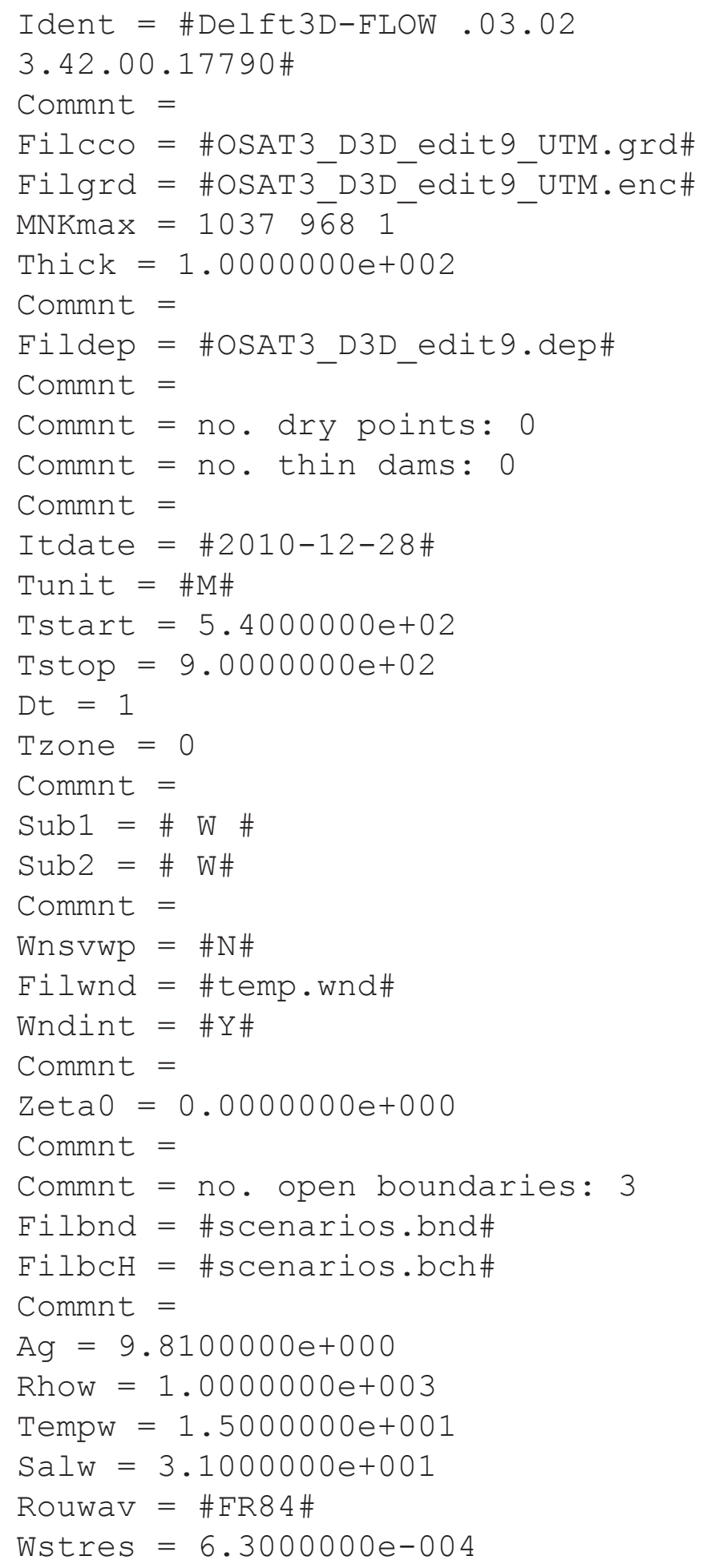

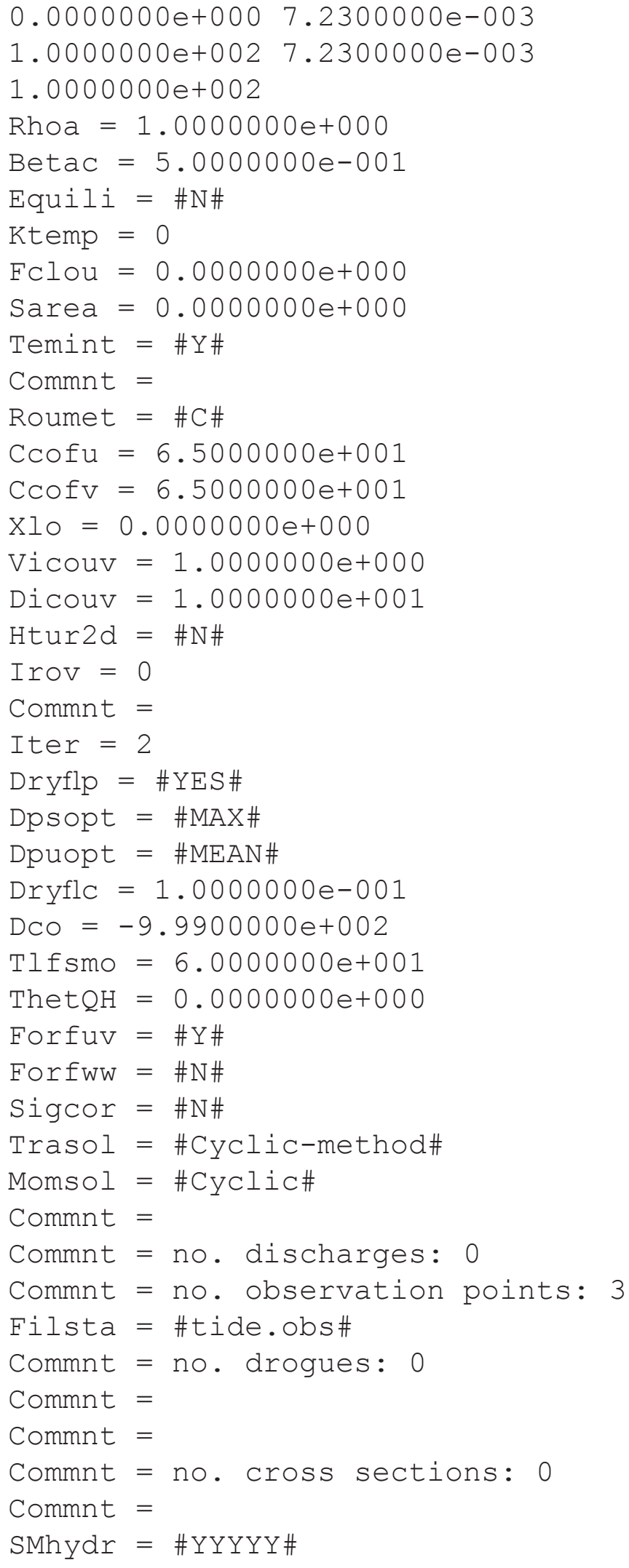




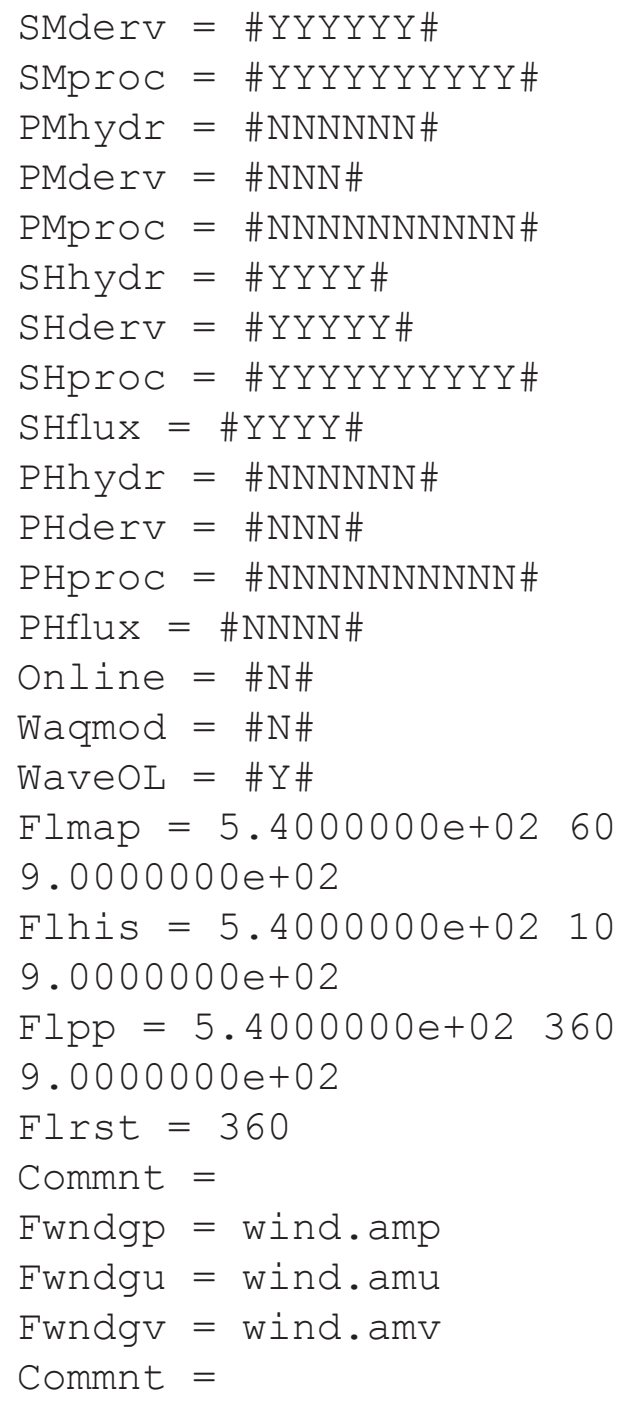

\section{Wave Input File}

[WaveFileInformation]

FileVersion $=02.00$

[General]

FlowFile = flow.mdf OnlyInputVerify = false SimMode = stationary

DirConvention = nautical

ReferenceDate = 2010-12-28 WindSpeed $=0.0000000 e+000$ WindDir $=0.0000000 e+000$ [Constants]

WaterLevelCorrection = $0.0000000 e+000$

Gravity $=9.8100004 \mathrm{e}+000$

WaterDensity $=1.0250000 e+003$ NorthDir $=9.0000000 e+001$

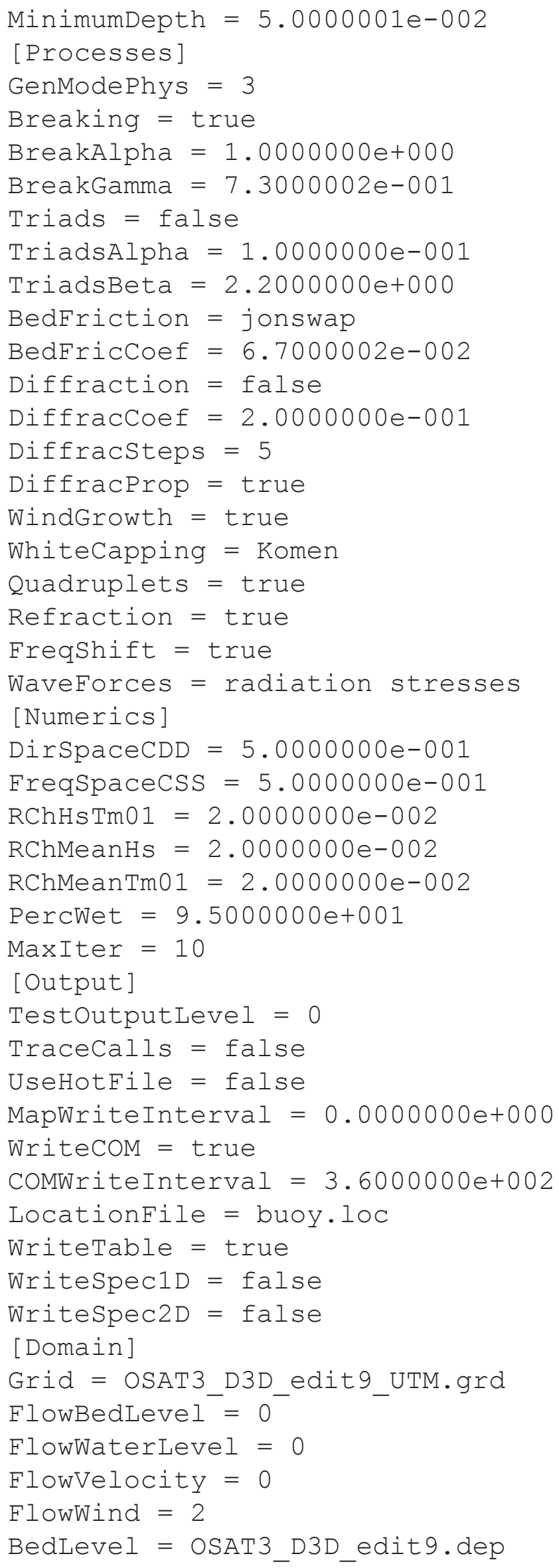




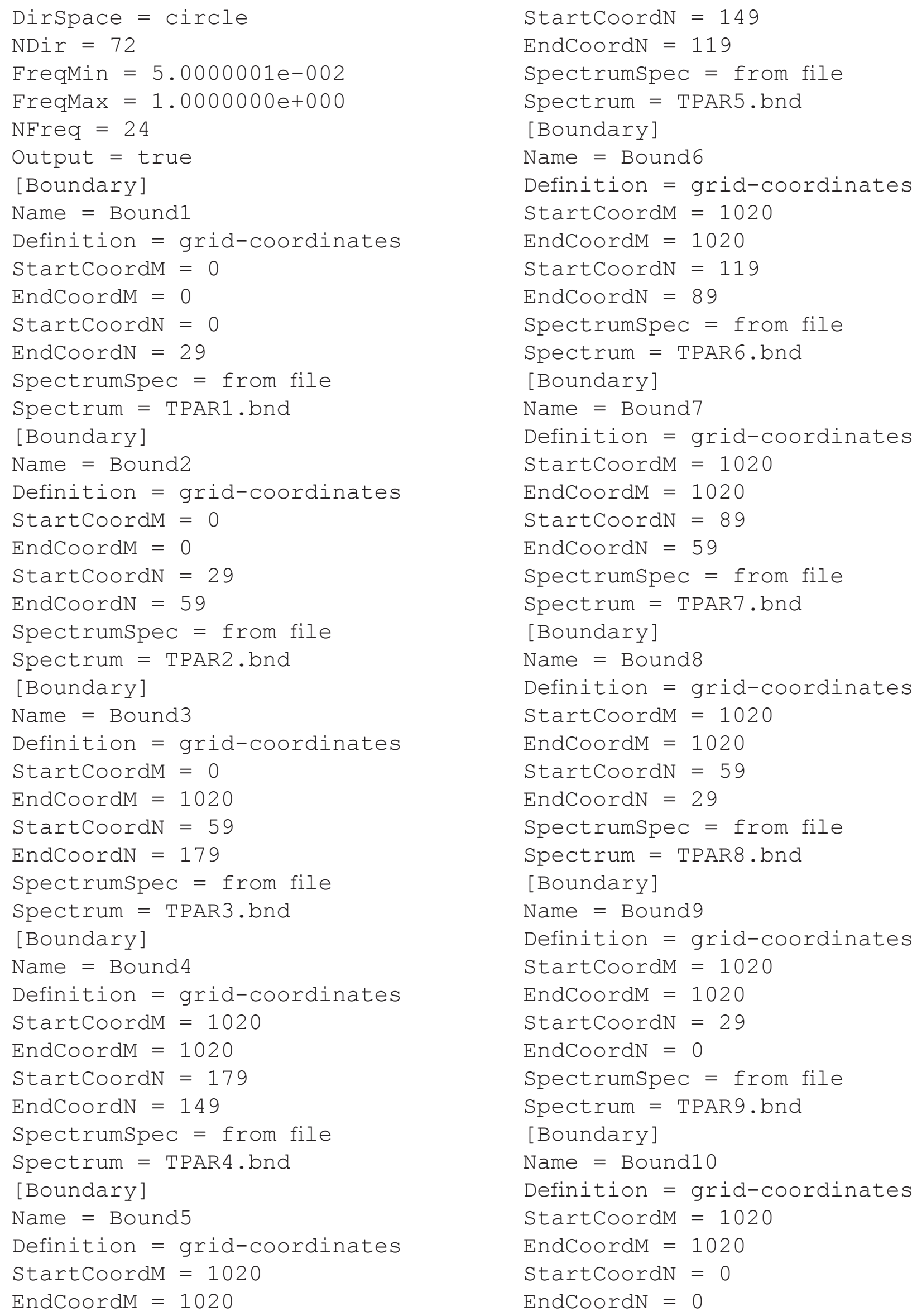


SpectrumSpec $=$ from file

Spectrum $=$ TPAR10.bnd

[Boundary]

Name = Bound11

Definition $=$ grid-coordinates

StartCoordM $=1020$

EndCoordM $=989$

StartCoordN $=0$

EndCoordN $=0$

Spectrumspec = from file

Spectrum $=$ TPAR11. bnd

[Boundary]

Name = Bound12

Definition $=$ grid-coordinates

StartCoordM $=989$

EndCoordM $=959$

StartCoordN $=0$

EndCoordN $=0$

Spectrumspec = from file

Spectrum $=$ TPAR12. bnd

[Boundary]

Name $=$ Bound13

Definition $=$ grid-coordinates

StartCoordM $=959$

EndCoordM $=929$

StartCoordN $=0$

EndCoordN $=0$

Spectrumspec = from file

Spectrum $=$ TPAR13.bnd

[Boundary]

Name $=$ Bound14

Definition $=$ grid-coordinates

StartCoordM $=929$

EndCoordM $=899$

StartCoordN $=0$

EndCoordN $=0$

Spectrumspec = from file

Spectrum $=$ TPAR14.bnd

[Boundary]

Name = Bound15

Definition $=$ grid-coordinates

StartCoordM $=899$

EndCoordM $=869$

StartCoordN $=0$

EndCoordN $=0$

Spectrumspec $=$ from file

Spectrum $=$ TPAR15. bnd
[Boundary]

Name $=$ Bound16

Definition $=$ grid-coordinates

StartCoordM $=869$

EndCoordM $=839$

StartCoordN $=0$

EndCoordN $=0$

Spectrumspec = from file

Spectrum $=$ TPAR16.bnd

[Boundary]

Name = Bound17

Definition = grid-coordinates

StartCoordM $=839$

EndCoordM $=809$

StartCoordN $=0$

EndCoordN $=0$

Spectrumspec = from file

Spectrum $=$ TPAR17.bnd

[Boundary]

Name $=$ Bound18

Definition = grid-coordinates

StartCoordM $=809$

EndCoordM $=779$

StartCoordN $=0$

EndCoordN $=0$

Spectrumspec = from file

Spectrum $=$ TPAR18.bnd

[Boundary]

Name = Bound19

Definition = grid-coordinates

StartCoordM $=779$

EndCoordM $=749$

StartCoordN $=0$

EndCoordN $=0$

Spectrumspec = from file

Spectrum $=$ TPAR19.bnd

[Boundary]

Name = Bound20

Definition = grid-coordinates

StartCoordM $=749$

EndCoordM $=719$

StartCoordN $=0$

EndCoordN $=0$

Spectrumspec = from file

Spectrum $=$ TPAR20.bnd

[Boundary]

Name $=$ Bound21 
Definition $=$ grid-coordinates

StartCoordM $=719$

EndCoordM $=689$

StartCoordN $=0$

EndCoordN $=0$

SpectrumSpec = from file

Spectrum $=$ TPAR21. bnd

[Boundary]

Name $=$ Bound22

Definition $=$ grid-coordinates

StartCoordM $=689$

EndCoordM $=659$

StartCoordN $=0$

EndCoordN $=0$

SpectrumSpec = from file

Spectrum $=$ TPAR22. bnd

[Boundary]

Name $=$ Bound23

Definition $=$ grid-coordinates

StartCoordM $=659$

EndCoordM $=629$

StartCoordN $=0$

EndCoordN $=0$

Spectrumspec = from file

Spectrum $=$ TPAR23. bnd

[Boundary]

Name $=$ Bound24

Definition $=$ grid-coordinates

StartCoordM $=629$

EndCoordM $=599$

StartCoordN $=0$

EndCoordN $=0$

SpectrumSpec = from file

Spectrum $=\operatorname{TPAR} 24 . \mathrm{bnd}$

[Boundary]

Name = Bound25

Definition $=$ grid-coordinates

StartCoordM $=599$

EndCoordM $=539$

StartCoordN $=0$

EndCoordN $=0$

Spectrumspec = from file

Spectrum $=$ TPAR25. bnd

[Boundary]

Name $=$ Bound26

Definition = grid-coordinates

StartCoordM $=539$

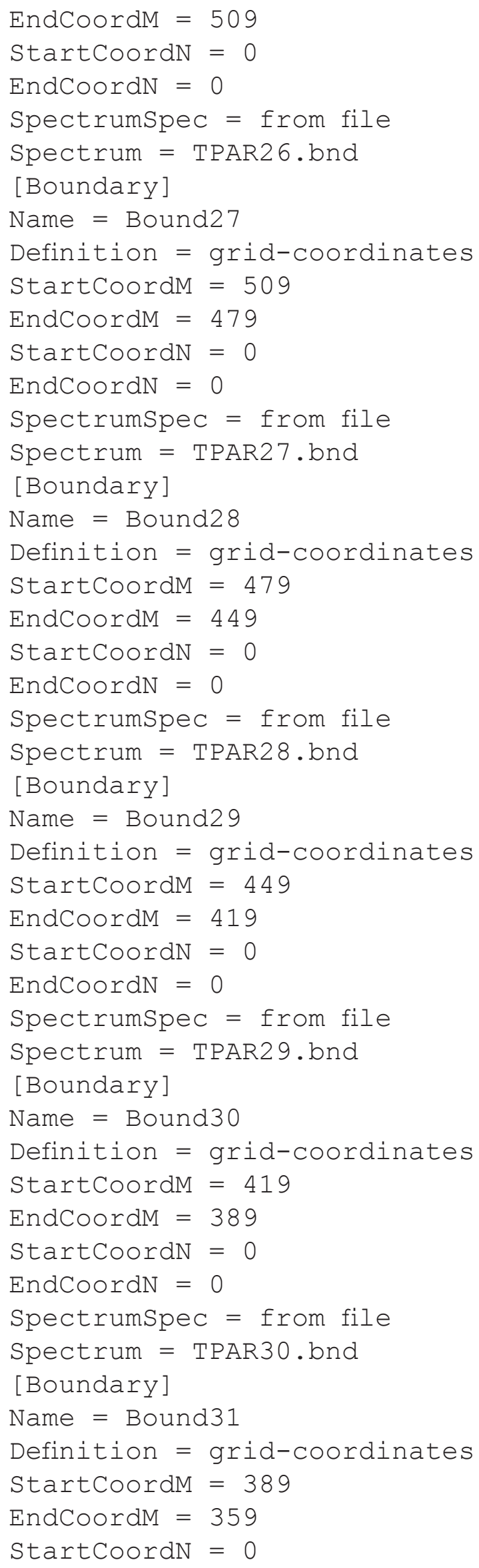




\section{Application of Hydrodynamic and Sediment Transport Model for Deepwater Horizon Oil Spill Response}

EndCoordN $=0$

Spectrumspec = from file

Spectrum $=$ TPAR31.bnd

[Boundary]

Name $=$ Bound32

Definition $=$ grid-coordinates

StartCoordM $=359$

EndCoordM $=329$

StartCoordN $=0$

EndCoordN $=0$

Spectrumspec $=$ from file

Spectrum $=$ TPAR32. bnd

[Boundary]

Name $=$ Bound33

Definition $=$ grid-coordinates

StartCoordM $=329$

EndCoordM $=299$

StartCoordN $=0$

EndCoordN $=0$

Spectrumspec $=$ from file

Spectrum $=$ TPAR33. bnd

[Boundary]

Name = Bound34

Definition $=$ grid-coordinates

StartCoordM $=299$

EndCoordM $=269$

StartCoordN $=0$

EndCoordN $=0$

Spectrumspec = from file

Spectrum $=$ TPAR34. bnd

[Boundary]

Name $=$ Bound35

Definition $=$ grid-coordinates

StartCoordM $=269$

EndCoordM $=239$

StartCoordN $=0$

EndCoordN $=0$

Spectrumspec $=$ from file

Spectrum $=$ TPAR35. bnd

[Boundary]

Name $=$ Bound36

Definition $=$ grid-coordinates

StartCoordM $=239$

EndCoordM $=209$

StartCoordN $=0$

EndCoordN $=0$

Spectrumspec $=$ from file

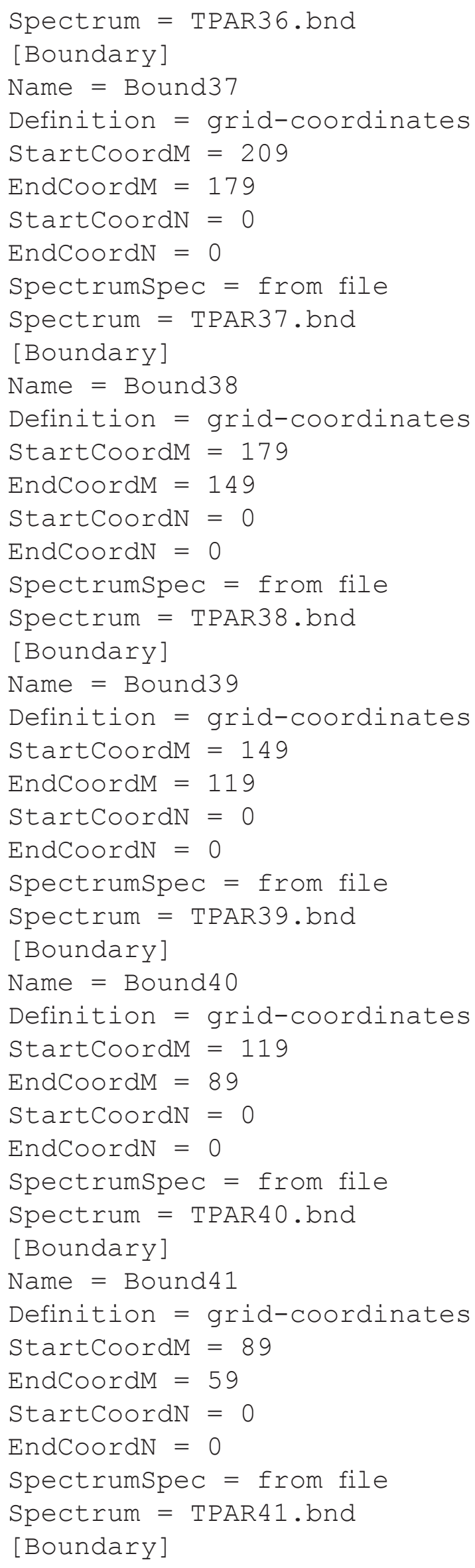




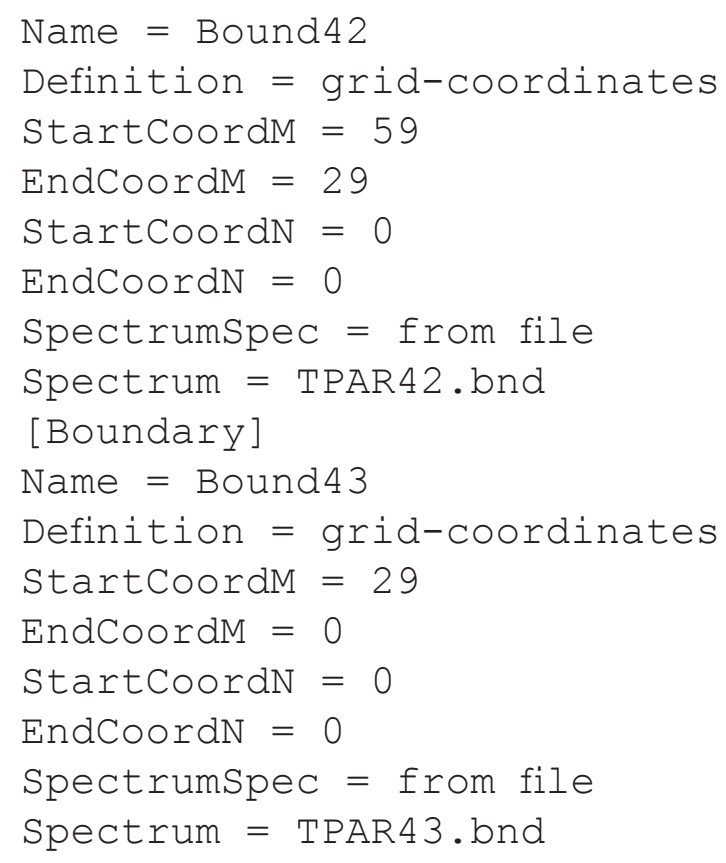




\section{Appendix 3. Calculations of Mobility and Potential Flux}

\section{Shear Stress Calculated From Hydrodynamic Model Output}

In order to estimate mobility, the combined wave-current shear stress must be calculated for the modeled hydrodynamic conditions. A formulation was developed by Soulsby (1997) to parameterize four methods, which provide good overall performance for estimating wave-current stress, based on original formulations by Grant and Madsen (1979), Fredsøe (1984), Davies and others (1988), and Huynh-Thanh and Temperville (1991). The combined wave-current stress $\left(\tau_{\mathrm{wc}}\right)$ for the individual components of wave and current stress was calculated for hydrodynamic model output (depth-averaged velocity magnitude and direction, wave bottom orbital velocity, wave period, wave direction, and water depth) following the method prescribed in Soulsby (1997) for each of the four formulations. The density of water used in the calculations was as assumed to be 1,027 kilograms per cubic meter $\left(\mathrm{kg} / \mathrm{m}^{3}\right)$, and the grainsize roughness contribution $\left(\mathrm{z}_{0}\right)$ was calculated to be (Soulsby, 1997) the diameter of the particle (either surface residual ball (SRB) or surficial sediment) divided by 12 . The mean value of the four formulations was used to estimate the combined wave-current shear stress for each hydrodynamic scenario and for all time-steps of the time varying simulations. Evaluation of the standard deviation of the four methods indicated the uncertainty introduced by calculation method is low compared with the magnitude of the calculated stress (less than 1 percent).

\section{Critical Stress for Incipient Motion}

Most research into critical thresholds for incipient motion of noncohesive sediment (including large grains such as gravel and cobbles, in a similar size range to SRBs) has at least partial basis in the work of Shields (1936) who created a dimensionless parameter $\left(\theta_{\mathrm{cr}}\right)$ based on the shear stress $\left(\tau_{\mathrm{cr}}\right)$. The shear stress balances the gravitational weight of the particle (described in Soulsby, 1997):

$$
\theta_{c r}=\frac{\tau_{c r}}{g\left(\rho_{s}-\rho\right) d}
$$

where

$g \quad$ is the acceleration due to gravity ( 9.81 meters per second squared $\left.\left(\mathrm{m} / \mathrm{s}^{2}\right)\right)$,

$\rho s \quad$ is the density of the sediment,

$\rho \quad$ is the density of water, and

$d \quad$ is the diameter of the grain of the sediment.

Soulsby empirically determined the relation between this critical value and the grain diameter and density; the equation was subsequently updated by Soulsby and Whitehouse (1997) to cover a wider range of conditions.

$$
\theta_{c r}=\frac{0.30}{1+1.2 D_{*}}+0.055\left[1-\exp \left(-0.020 D_{*}\right)\right] \text {, }
$$

where $D^{*}$ is the dimensionless grain size, calculated as follows:

$$
D_{*}=\left[\frac{g\left(\frac{\rho_{s}}{\rho}-1\right)}{v^{2}}\right]^{\frac{1}{3}} d
$$

where $v$ is the kinematic viscosity of water, $1.36 \times 10^{-6} \mathrm{~m}^{2} / \mathrm{s}$.

The high critical stress estimate for each SRB class (and the only critical stress value used for sand) was attained by replacing $\theta_{\mathrm{cr}}$ in equation 3-1 with the value of $\theta_{\mathrm{cr}}$ from equation 3-2 and solving for $\tau_{\mathrm{cr}}$; the estimate is appropriate for the conditions for which the formulation was calibrated, for example, particles not protruding above the bed into the flow.

Experiments have demonstrated that the extent to which any individual particle protrudes from the bed (such as could be expected for a single SRB on a seabed of sand) can lower that particle's critical shear stress $\left(\tau_{\mathrm{cr}}\right)$ value (Fenton and Abbott, 1977; Andrews, 1983; Wiberg and Smith, 1987; Wilcock, 1998; Bottacin-Busolin and others, 2008). Empirical studies of cobbles have indicated that the dimensionless critical shear stress $\left(\theta_{\text {cr }}\right)$ approaches a minimum value of 0.01 to 0.02 (Fenton and Abbott, 1977; Andrews, 1983; Wiberg and Smith, 1987; Wilcock, 1998; Bottacin-Busolin and others, 2008). Note that, although the dimensionless Shields parameter $\theta_{\text {cr }}$ is constant for the exposed particle stress case, the conversion to the physically meaningful force (in pascals) includes a dependence on grain size; thus, the critical stress compared with modeled stress forcing increases for large particles. For the analysis of SRB mobility, when particle extrusion is important, the critical stress value is calculated from a $\theta_{\text {cr }}$ of 0.02 (medium threshold) and 0.01 (low threshold) to provide a limit on the uncertainty in mobility for the range of conditions from an SRB in a relatively uniform bed of SRBs such as a mat (for example, little particle extrusion) to an isolated SRB sitting relatively high in the flow.

\section{SRB Density}

For sediment mixed with oil, Operational Science Advisory Team (OSAT3) data were used to constrain the den- 
sity of observed SRBs (L. Bruce, British Petroleum Corporation, GCRO, Science NRDA Team, unpub. data, 2012). Composition data provide the percentage of moisture $\left(\mathrm{f}_{\mathrm{H} 2 \mathrm{O}}\right)$ and the percentage of oil by dry weight ( $f_{\text {oild,dry }}$ ) of the sampled SRBs; the total percentage of oil of the original (wet weight) sample is taken as $\mathrm{f}_{\text {oil }}=\left(1-\mathrm{f}_{\mathrm{H} 2 \mathrm{O}}\right) \times \mathrm{f}_{\text {oil,dry }}$. To estimate the density of the samples, an assumed density of $1,027 \mathrm{~kg} / \mathrm{m}^{3}$ was assigned to the moisture fraction, an assumed density of $900 \mathrm{~kg} / \mathrm{m}^{3}$ was assigned to the oil fraction, and the remaining fraction of 1 $\mathrm{f}_{\mathrm{H} 2 \mathrm{O}}-\left(1-\mathrm{f}_{\mathrm{H} 20}\right) \times \mathrm{f}_{\text {oildry }}$ was assumed to consist of quartz sand with a density of $2,650 \mathrm{~kg} / \mathrm{m}^{3}$. The approximate density $\left(\rho_{\mathrm{SRB}}\right)$ of each sample in the dataset was therefore estimated to be:

$\rho_{S R B}=\left(\frac{f_{H 2 O}}{1,027}+\frac{\left(1-f_{H 2 O}\right) \times f_{\text {oil }, d r y}}{900}+\frac{1-f_{H 2 O}-\left(1-f_{H 2 O}\right) \times f_{\text {oil }, d r y}}{2,650}\right)^{-1}$

The densities calculated in this manner for all the observed SRB data were used in assessing the variability of SRB critical stress. 


\section{Appendix 4. File Naming Conventions}

The analyses described in the Methods section of this report have been applied for each wave scenario to determine patterns in alongshore currents, movement probability for surface residual balls (SRBs) and sediment, and probable alongshore redistribution patterns for SRBs of mobilized size classes. These results are available in geographic information systems (GIS) polygon or point shapefile format, with all files for a given scenario having a prefix of $\mathrm{Hh}$ _Dd, where $\mathrm{h}$ and $\mathrm{d}$ denote the scenario wave height $(\mathrm{H})$ and direction (D) bin number, respectively. So, for example, a prefix of "H1_D1" corresponds to a wave height in the lowest bin $(0.0$ to $0.5 \mathrm{~m})$ and wave direction in the first bin ( 0 to 22.5 degrees). A table of scenario characteristics is provided in appendix 1 and is also included in a text file (.txt) zipped with each GIS shapefile. For SRB and sediment analyses, each shapefile includes results for each of the six SRB size classes and critical stress values described in table 1 of this report (also included zipped with each GIS shapefile). The final portion of the filename denotes the analysis type as described in table 2 in the Methods section of this report. For example, H1_D1_mobility. xxx would contain mobility analysis for scenario H1_D1 for sediment and each size and critical stress level for SRBs, with various file extensions (.xxx) associated with the GIS shapefile.

In addition to the GIS shapefiles, animations were created of the mobility of $2.5-\mathrm{cm}$ SRBs (size class 4 ) and sand over a tidal cycle for three inlets: Pensacola Pass, Fla.; Little Lagoon, Ala.; and Panama City, Fla. These files follow the naming convention [InletName]_SRB.avi and [InletName]_sediment.avi. 


\section{Appendix 5. Time Step of Maximum Ebb and Flood for Inlets in the Model Domain}

The time of maximum ebb and maximum flood varies for each inlet within the model domain. Table 5-1 provides the time step index and thus the corresponding GIS file of maximum flood and ebb for each inlet, defined as the time step corresponding to the maximum flow into and out of the inlet, respectively, in the center of the inlet for scenario H4_D7.

Table 5-1. Time step index corresponding to maximum flood and ebb for inlets within the model domain.

[The time step (TT) indicates the file naming convention for files in the geographic information system of this report, where files naming convention follows the pattern TT_mobility.xxx; $x x x$ indicates the file format]

\begin{tabular}{lcccc}
\hline \multicolumn{1}{c}{ Inlet } & Latitude & Longitude & Maximum flood TT & Maximum ebb TT \\
\hline $\begin{array}{l}\text { Mobile Bay, Ala- } \\
\quad \text { bama }\end{array}$ & 30.2253 & -88.0381 & 8 & 18 \\
Little Lagoon, Ala. & 30.2405 & -87.7377 & 11 & 23 \\
Perdido Pass, Ala. & 30.2724 & -87.5594 & 10 & 18 \\
$\begin{array}{l}\text { Pensacola Pass, } \\
\quad \text { Florida }\end{array}$ & 30.3210 & -87.3083 & 7 & 19 \\
Destin, Fla. & 30.3847 & -86.5080 & 10 & 22 \\
Panama City, Fla. & 30.1212 & -85.7327 & 7 & 18 \\
\hline
\end{tabular}






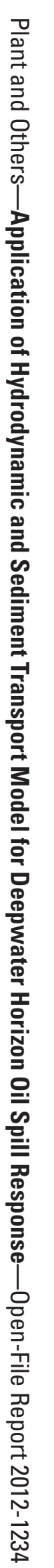

